\title{
Japanese Encephalitis Virus Interaction with Mosquitoes: A Review of Vector Competence, Vector Capacity and Mosquito Immunity
}

\author{
Claudia Van den Eynde ${ }^{1, * \mathbb{D}}$, Charlotte Sohier ${ }^{1}$, Severine Matthijs ${ }^{2}$ and Nick De Regge ${ }^{1}$ \\ 1 Exotic Viruses and Particular Diseases, Sciensano, Groeselenberg 99, 1180 Brussels, Belgium; \\ charlotte.sohier@sciensano.be (C.S.); nick.deregge@sciensano.be (N.D.R.) \\ 2 Enzootic, Vector-Borne and Bee Diseases, Sciensano, Groeselenberg 99, 1180 Brussels, Belgium; \\ severine.matthijs@sciensano.be \\ * Correspondence: claudia.vandeneynde@sciensano.be
}

check for updates

Citation: Van den Eynde, C.; Sohier, C.; Matthijs, S.; De Regge, N. Japanese Encephalitis Virus Interaction with Mosquitoes: A Review of Vector Competence, Vector Capacity and Mosquito Immunity. Pathogens 2022, 11, 317. https:// doi.org/10.3390/pathogens11030317 Academic Editor: Stephanie L. Richards

Received: 4 February 2022

Accepted: 1 March 2022

Published: 3 March 2022

Publisher's Note: MDPI stays neutral with regard to jurisdictional claims in published maps and institutional affiliations.

Copyright: (C) 2022 by the authors. Licensee MDPI, Basel, Switzerland. This article is an open access article distributed under the terms and conditions of the Creative Commons Attribution (CC BY) license (https:// creativecommons.org/licenses/by/ $4.0 /)$.

\begin{abstract}
Japanese encephalitis virus (JEV) is a mosquito-borne zoonotic flavivirus and a major cause of human viral encephalitis in Asia. We provide an overview of the knowledge on vector competence, vector capacity, and immunity of mosquitoes in relation to JEV. JEV has so far been detected in more than 30 mosquito species. This does not necessarily mean that these species contribute to JEV transmission under field conditions. Therefore, vector capacity, which considers vector competence, as well as environmental, behavioral, cellular, and biochemical variables, needs to be taken into account. Currently, 17 species can be considered as confirmed vectors for JEV and 10 other species as potential vectors. Culex tritaeniorhynchus and Culex annulirostris are considered primary JEV vectors in endemic regions. Culex pipiens and Aedes japonicus could be considered as potentially important vectors in the case of JEV introduction in new regions. Vector competence is determined by various factors, including vector immunity. The available knowledge on physical and physiological barriers, molecular pathways, antimicrobial peptides, and microbiome is discussed in detail. This review highlights that much remains to be studied about vector immunity against JEV in order to identify novel strategies to reduce JEV transmission by mosquitoes.
\end{abstract}

Keywords: Japanese encephalitis virus; vector competence; vector capacity; vector immunity; virusvector interactions; arboviruses

\section{Introduction}

Japanese encephalitis virus (JEV) is a zoonotic mosquito-borne flavivirus (family Flaviviridae) that is maintained in a transmission cycle between the mosquito vectors and vertebrate hosts, mainly Ardeid birds (herons and egrets are considered natural reservoirs), pigs (amplifying hosts), and possibly bats. These vertebrate hosts produce high viremias [1], allowing mosquitoes to become infected when taking a blood meal (Figure 1). While JEV is generally considered to be a mosquito-borne disease, Ricklin et al. [2] recently demonstrated that direct virus transmission can also occur between pigs, via oronasal secretions. The epidemiological relevance of this finding is, however, unclear.

Birds of the family Ardeidae do not demonstrate clinical disease [3]. This is in contrast to pigs, an amplifying host, in which JEV can cause abortion or lead to mummified, weak, or stillborn piglets after infection of pregnant sows. Infected boars can become infertile upon infection. Humans, cattle, and horses are considered to be dead-end hosts, since JEV infection results in an insufficient viremia to infect naïve mosquitoes when taking a blood meal. Nevertheless, infection of these hosts can result in encephalitis, in combination with fever, tremors, convulsions, coma, and death [4]. In humans, and mostly in children [5], 1\% of infected individuals will develop encephalitis, with a mortality rate in this group with 
disease symptoms of 20 to 30\% [6]. JEV was first isolated in 1935 [7] and is a leading cause of viral encephalitis in Asia, with 30,000-50,000 human cases reported annually [8].

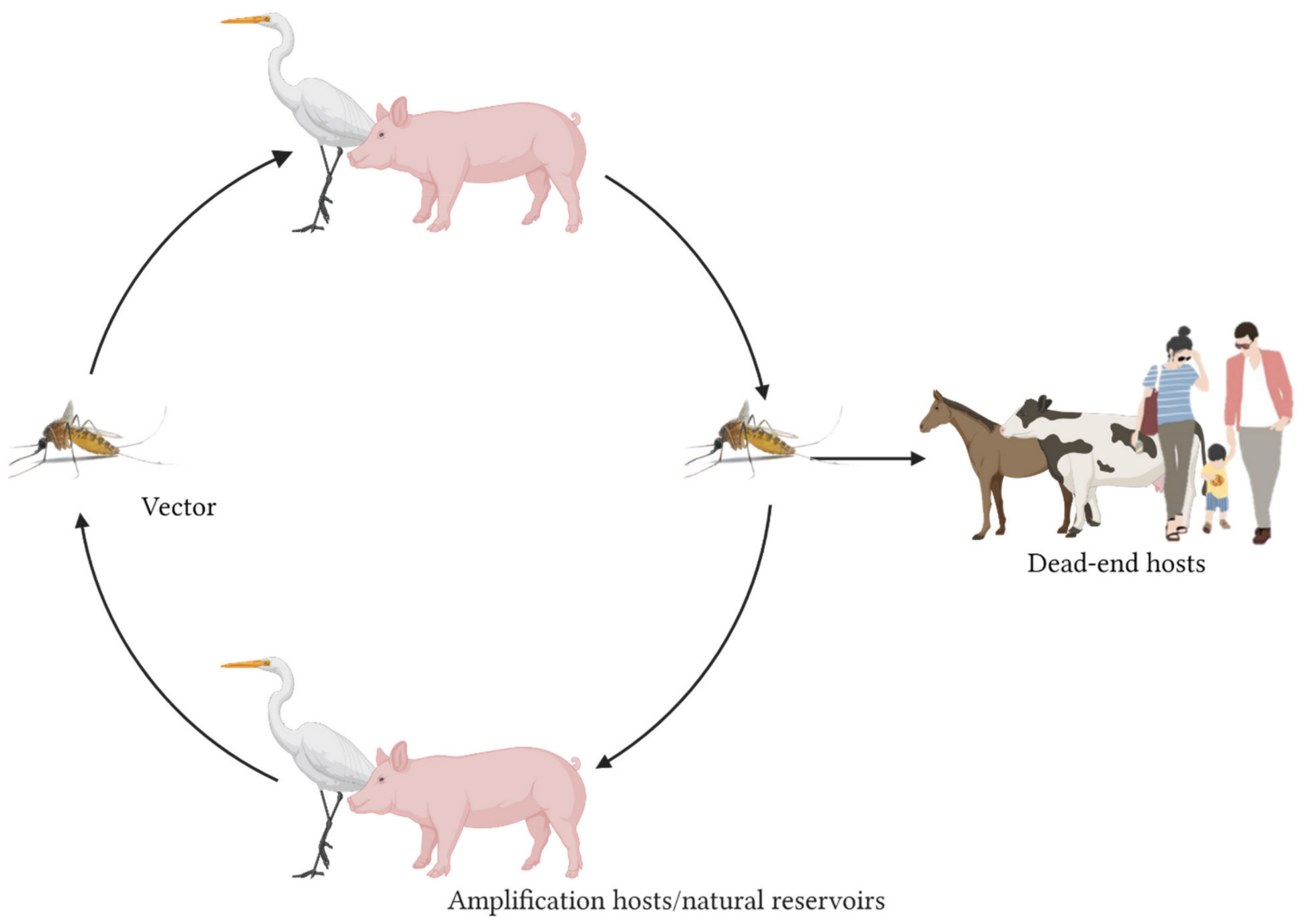

Figure 1. Transmission cycle of JEV. Competent mosquitoes transmit JEV between natural reservoirs, e.g., Ardeid birds and amplifying hosts, e.g., pigs. Horses, cattle, and humans are considered dead-end hosts. Created with BioRender.com.

JEV is currently endemic in Australia (Torres Strait islands) and southeast and east Asia, including the temperate zone of northeastern China, Japan, and Korea [6] (Figure 2) and exists in five different genotypes. Genotypes one (G-I), two (G-II), and three (G-III) are found throughout Asia, genotype four (G-IV) in Indonesia, and genotype five $(\mathrm{G}-\mathrm{V})$ in Malaysia, China, and Korea [9]. G-III was the predominant genotype in Japan and Korea up to the 1990s [10]. A shift towards the dominance of G-I strains has, however, been recorded since 1995 [11]. G-III strains have also been detected outside of their endemic areas, e.g., in Italy and Angola [12].

A study by Oliveira et al. [13] identified a number of potential entry routes for JEV in the US, e.g., (1) entry through infected vectors by means of aircraft, ships, wind, or on imported tires; (2) importation of viraemic animals, e.g., pigs; (3) entry of viraemic migratory birds; (4) importation of infected biological materials; (5) importation of infected animal products; (6) entry of infected humans by globalization; and (7) importation/production of contaminated biological material, e.g., vaccines. However, since humans are considered to be dead-end hosts for JEV (exhibit only low levels of viremia), it is unlikely that infected humans would contribute to the spread of JEV. According to Oliveira et al., the most probable method of introduction is through the entry of infected adult mosquitoes via aircraft and ships/containers. 
Japanese encephalitis, countries or areas at risk

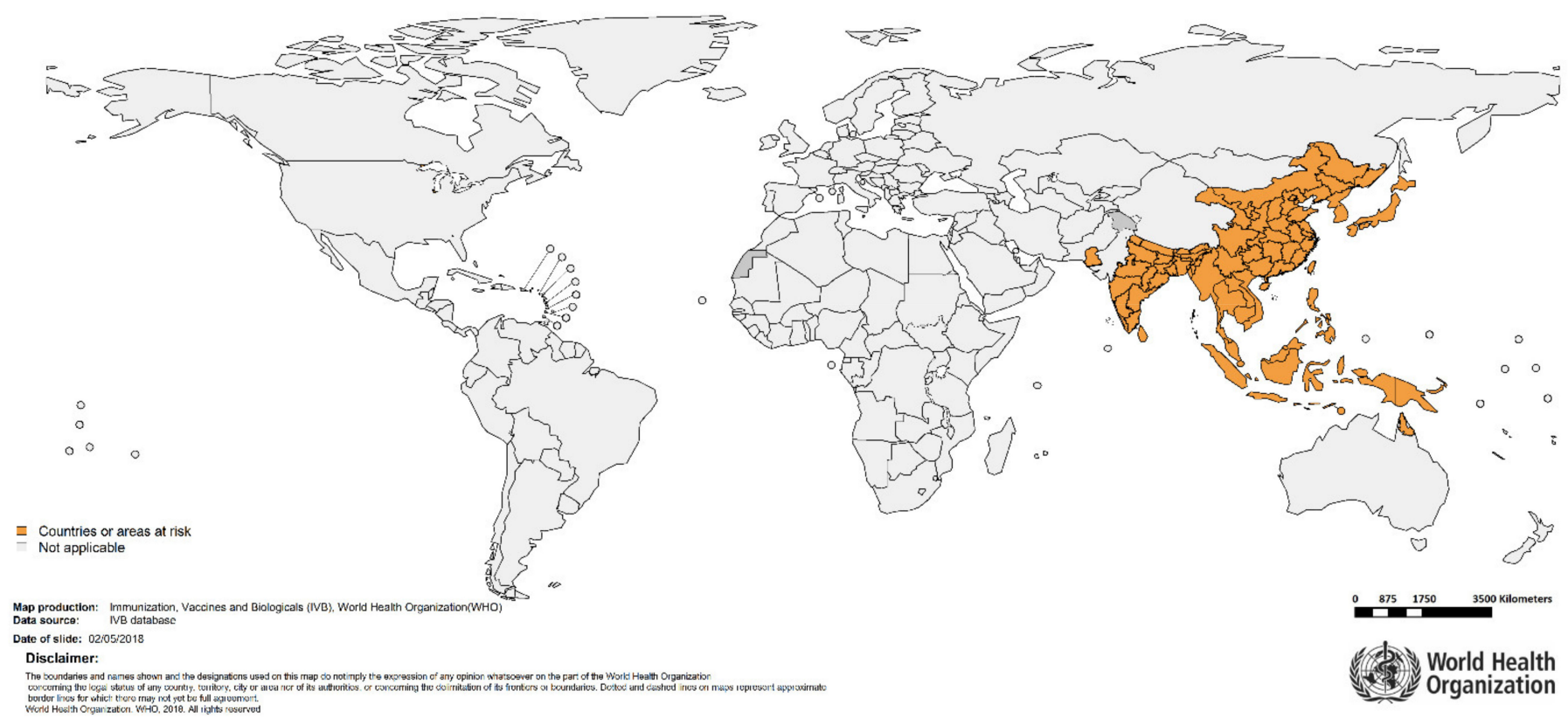

Figure 2. Map issued by the WHO showing the current countries or areas at risk for JEV [3]. Reprinted with permission from BioRender.com.

Upon introduction into non-endemic areas, JEV could then continue to be transmitted and possibly become established if competent vectors and suitable hosts are present. Competent vectors are mosquito species that have been shown to transmit JEV [14]. Competent vectors may be exotic or endemic mosquitoes. Invasive mosquitoes, e.g., Aedes albopictus and Aedes japonicus, are becoming more common and able to form permanent colonies in Europe, due to the current climate changes (warmer summers). On the other hand, indigenous mosquitoes may also be or may become (more) competent as a result of changing climatic factors, given that higher temperatures are known to increase the competence for flaviviruses [15] and shorten the extrinsic incubation periods (EIPs) [16]. Introduced infected mosquitoes could lead to infection of susceptible animals in these areas. Alternatively, infected viraemic animals could be imported. Subsequently, indigenous mosquitoes can become infected by taking a blood meal from these infected animals and transmit JEV if these species are competent. Vector competence studies should, thus, be carried out for mosquito species that are present in areas where JEV is not yet endemic, in order to evaluate which species could potentially transmit JEV in the event of an introduction.

Therefore, we reviewed the current knowledge on vector competence of mosquitoes for JEV and JEV detection in field-caught mosquitoes to get an idea of which species could have the highest vectorial capacity. Next, we also reviewed the available information on mosquito immunity against JEV in order to summarize the currently known underlying factors that influence the vector competence for this virus. Important factors of vector immunity are physical and physiological barriers, molecular pathways, antimicrobial peptides, and the vector microbiome.

\section{Results}

\subsection{Mosquito Vectors of JEV: Vector Competence and Capacity}

\subsubsection{JEV Detection in Field-Collected Mosquitoes}

An initial systematic review of the literature has revealed that JEV has so far been detected in more than 30 mosquito species, belonging to the genera Aedes, Anopheles, Armigeres, Coquillettidia, Culex, and Mansonia (Table 1). Detection studies are often conducted on a 
large scale, where pools of field-collected mosquitoes are tested per species. Once the mosquito pools have been tested, information about the number of mosquitoes collected, the number of pools that tested JEV-positive, and the number of mosquitoes in each individual pool are used to calculate the estimated infection rate. There are a variety of methods to estimate infection rate. The most reported is the minimum infection ratio (MIR), which is the ratio of the number of positive pools to the total number of mosquitoes in the sample [17]. The MIR is often an underestimation, as it assumes that only one individual of the pool is positive, whereas multiple individuals of the pool could be positive [18]. Therefore, small-sized pools are preferred in order to obtain a more accurate estimate of the MIR. Besides the pool size, also the number of mosquitoes collected, and the virus detection method may influence the MIR. Six methods have been used for virus detection (see Table 1), e.g., plaque or hemagglutination inhibition (HI) and complement fixation (CF) assays, reverse transcription polymerase chain reaction (RT-PCR), intracerebral inoculation of mice, virus isolation on continuous cell lines, ELISA, and inoculation of Toxorhynchites splendens mosquito larvae (Toxo-IFA). While RT-PCR is the most sensitive and specific, only intracerebral inoculation of mice, virus isolation, and Toxo-IFA can differentiate between the infectious and the non-infectious virus, although with lower sensitivity. Consequently, these different methods make it difficult to compare across studies.

Table 1. Overview of field-collected mosquitoes in which JEV was detected. Underlined species have been proven to be competent vectors through competence studies (see Table 3).

\begin{tabular}{|c|c|c|c|c|c|c|c|}
\hline $\begin{array}{l}\text { Mosquito } \\
\text { Species }\end{array}$ & $\begin{array}{l}\text { Country of } \\
\text { Sampling }\end{array}$ & $\begin{array}{l}\text { JEV } \\
\text { Genotype } \\
\text { and/or } \\
\text { Strain }\end{array}$ & $\begin{array}{l}\text { Detection } \\
\text { Method }\end{array}$ & $\begin{array}{l}\text { Total \# } \\
\text { Tested }\end{array}$ & $\begin{array}{c}\text { \# JEV } \\
\text { Positive } \\
\text { Pools/Total \# } \\
\text { of Pools }\end{array}$ & $\begin{array}{c}\text { MIR (\# } \\
\text { Positive } \\
\text { Pools/Total } \\
\text { Tested) } \times 100\end{array}$ & Reference \\
\hline \multirow{2}{*}{$\frac{\text { Aedes albopictus }}{\text { (Skuse, 1895) }}$} & Taiwan & G-I and III & RT-PCR & 177 & $1 / 25$ & $0.56 \%$ & [19] \\
\hline & Taiwan & ND & Isolation & ND & 20 & ND & [20] \\
\hline $\begin{array}{c}\text { Aedes butleri } \\
\text { (Theobald, 1901) }\end{array}$ & Malaysia & ND & $\begin{array}{l}\text { Isolation and } \\
\text { RT-PCR }\end{array}$ & 3950 & $4 / 79$ & $0.1 \%$ & {$[21,22]$} \\
\hline $\begin{array}{c}\text { Aedes curtipes } \\
\text { (Edwards, 1915) }\end{array}$ & Malaysia & ND & ND & ND & ND & ND & [23] \\
\hline $\begin{array}{c}\text { Aedes } \\
\text { lineatopennis } \\
\text { (Ludlow, 1905) }\end{array}$ & Malaysia & ND & $\begin{array}{l}\text { Isolation and } \\
\text { RT-PCR }\end{array}$ & 300 & $1 / 6$ & $0.33 \%$ & [22] \\
\hline \multirow{3}{*}{$\frac{\text { Aedes vexans }}{(\text { Meigen, } 1830)}$} & Taiwan & G-I and III & RT-PCR & 246 & $3 / 32$ & $1.22 \%$ & [19] \\
\hline & Taiwan & ND & Isolation & $\mathrm{ND}$ & 1 & $\mathrm{ND}$ & [20] \\
\hline & Taiwan & ND & RT-PCR & 61 & $1 / 9$ & $1.64 \%$ & [24] \\
\hline \multirow{2}{*}{$\frac{\text { Aedes vigilax }}{\text { (Skuse, 1889) }}$} & Australia & $\mathrm{ND}$ & Isolation & $\mathrm{ND}$ & 1 & ND & [25] \\
\hline & Australia & G-II & Isolation & 3073 & 1 & $0.03 \%$ & [26] \\
\hline $\begin{array}{c}\text { Anopheles } \\
\text { annularis (Wulp, } \\
1884)\end{array}$ & Indonesia & ND & Isolation & 250 & $1 / 28$ & $0.4 \%$ & [27] \\
\hline \multirow{2}{*}{$\begin{array}{c}\text { Anopheles } \\
\text { barbirostris } \\
\text { (Wulp, 1884) }\end{array}$} & India & ND & $\begin{array}{l}\text { ELISA and } \\
\text { Toxo-IFA }\end{array}$ & 22 & $1 / 8$ & $4.55 \%$ & [28] \\
\hline & India & ND & ND & ND & ND & ND & [29] \\
\hline $\begin{array}{c}\text { Anopheles } \\
\text { minimus } \\
\text { (Theobald, 1901) }\end{array}$ & Taiwan & G-I and III & RT-PCR & 18 & $1 / 7$ & $5.56 \%$ & [19] \\
\hline \multirow{2}{*}{$\begin{array}{c}\text { Anopheles } \\
\text { hyrcanus (Pallas, } \\
1771)\end{array}$} & India & ND & ND & ND & ND & ND & [30] \\
\hline & India & ND & ND & ND & ND & ND & [29] \\
\hline
\end{tabular}


Table 1. Cont.

\begin{tabular}{|c|c|c|c|c|c|c|c|}
\hline $\begin{array}{l}\text { Mosquito } \\
\text { Species }\end{array}$ & $\begin{array}{l}\text { Country of } \\
\text { Sampling }\end{array}$ & $\begin{array}{l}\text { JEV } \\
\text { Genotype } \\
\text { and/or } \\
\text { Strain }\end{array}$ & $\begin{array}{l}\text { Detection } \\
\text { Method }\end{array}$ & $\begin{array}{l}\text { Total \# } \\
\text { Tested }\end{array}$ & $\begin{array}{c}\text { \# JEV } \\
\text { Positive } \\
\text { Pools/Total \# } \\
\text { of Pools }\end{array}$ & $\begin{array}{c}\text { MIR (\# } \\
\text { Positive } \\
\text { Pools/Total } \\
\text { Tested) } \times \mathbf{1 0 0}\end{array}$ & Reference \\
\hline $\begin{array}{l}\text { Anopheles pallidus } \\
\text { (Theobald, 1901) }\end{array}$ & India & ND & $\begin{array}{l}\text { ELISA and } \\
\text { Toxo-IFA }\end{array}$ & 28 & $1 / 12$ & $3.57 \%$ & [28] \\
\hline $\begin{array}{c}\text { Anopheles } \\
\text { peditaeniatus } \\
\text { (Leicester, 1908) }\end{array}$ & India & ND & Isolation & 6306 & $1 / 133$ & $0.02 \%$ & [31] \\
\hline \multirow{4}{*}{$\begin{array}{c}\text { Anopheles sinensis } \\
\text { (Wiedemann, } \\
\text { 1828) }\end{array}$} & China & G-III & RT-PCR & ND & 12 & ND & [32] \\
\hline & China & ND & RT-PCR & 2802 & $5 / 55$ & $0.18 \%$ & [33] \\
\hline & China & G-I & Isolation & 14,170 & 3 & $0.02 \%$ & [34] \\
\hline & Taiwan & G-I and III & RT-PCR & 2638 & $6 / 119$ & $0.23 \%$ & [19] \\
\hline \multirow{4}{*}{$\begin{array}{c}\text { Anopheles } \\
\text { subpictus (Grassi, } \\
1899 \text { ) }\end{array}$} & India & ND & $\begin{array}{l}\text { ELISA and } \\
\text { Toxo-IFA }\end{array}$ & 1432 & $7 / 67$ & $0.49 \%$ & [28] \\
\hline & India & ND & $\begin{array}{l}\text { ELISA and } \\
\text { Toxo-IFA }\end{array}$ & ND & ND & ND & [35] \\
\hline & India & ND & $\begin{array}{l}\text { ELISA and } \\
\text { Toxo-IFA }\end{array}$ & 6550 & $4 / 131$ & $0.06 \%$ & [36] \\
\hline & India & ND & ND & ND & ND & ND & [37] \\
\hline$\frac{\text { Anopheles tessellatus }}{\text { (Theobald, 1901) }}$ & Taiwan & G-I and III & RT-PCR & 536 & $2 / 31$ & $0.37 \%$ & [19] \\
\hline $\begin{array}{l}\text { Anopheles vagus } \\
\text { (Dönitz, 1902) }\end{array}$ & Indonesia & ND & Isolation & 2700 & $1 / 42$ & $0.04 \%$ & [27] \\
\hline \multirow{5}{*}{$\frac{\text { Armigeres subalbatus }}{\text { (Coquillet, 1898) }}$} & China & G-I & Isolation & 394 & 2 & $0.51 \%$ & [34] \\
\hline & China & G-III & RT-PCR & ND & 3 & ND & [32] \\
\hline & India & ND & $\begin{array}{c}\text { ELISA and } \\
\text { Toxo-IFA }\end{array}$ & 110 & $1 / 21$ & $0.91 \%$ & [28] \\
\hline & Taiwan & G-I and III & RT-PCR & 225 & $3 / 30$ & $1.33 \%$ & [19] \\
\hline & Taiwan & ND & Isolation & ND & 8 & ND & [20] \\
\hline $\begin{array}{c}\text { Coquillettidia } \\
\text { ochracea } \\
\text { (Theobald, 1903) }\end{array}$ & China & ND & RT-PCR & 155 & $1 / 6$ & $0.65 \%$ & [38] \\
\hline \multirow{2}{*}{$\frac{\text { Culex annulirostris }}{\text { (Skuse, 1889) }}$} & Australia & G-III & RT-PCR & 2871 & $8 / 134$ & $0.28 \%$ & [39] \\
\hline & Australia & ND & Isolation & 23,890 & 42 & $0.18 \%$ & [25] \\
\hline \multirow{5}{*}{$\begin{array}{l}\text { Culex annulus } \\
\text { (Theobald, 1901) }\end{array}$} & Taiwan & G-I and III & RT-PCR & 991 & $9 / 79$ & $0.91 \%$ & [19] \\
\hline & Taiwan & ND & $\begin{array}{l}\text { Intracerebral } \\
\text { inoculation } \\
\text { of mice }\end{array}$ & 1338 & 3 & $0.23 \%$ & [40] \\
\hline & Taiwan & ND & Isolation & 54,910 & $31 / 703$ & $0.06 \%$ & [41] \\
\hline & Taiwan & ND & Isolation & ND & $7 / 31$ & ND & [42] \\
\hline & Taiwan & ND & Isolation & ND & 1 & ND & [20] \\
\hline
\end{tabular}


Table 1. Cont.

\begin{tabular}{|c|c|c|c|c|c|c|c|}
\hline $\begin{array}{l}\text { Mosquito } \\
\text { Species }\end{array}$ & $\begin{array}{l}\text { Country of } \\
\text { Sampling }\end{array}$ & $\begin{array}{c}\text { JEV } \\
\text { Genotype } \\
\text { and/or } \\
\text { Strain }\end{array}$ & $\begin{array}{l}\text { Detection } \\
\text { Method }\end{array}$ & $\begin{array}{l}\text { Total \# } \\
\text { Tested }\end{array}$ & $\begin{array}{c}\text { \# JEV } \\
\text { Positive } \\
\text { Pools/Total \# } \\
\text { of Pools }\end{array}$ & $\begin{array}{c}\text { MIR (\# } \\
\text { Positive } \\
\text { Pools/Total } \\
\text { Tested) } \times \mathbf{1 0 0}\end{array}$ & Reference \\
\hline \multirow{5}{*}{$\frac{\frac{\text { Culex }}{\text { bitaeniorhynchus }}}{\text { (Giles, 1901) }}$} & India & ND & $\begin{array}{l}\text { ELISA and } \\
\text { Toxo-IFA }\end{array}$ & 44 & $1 / 9$ & $2.28 \%$ & [28] \\
\hline & Korea & G-I & RT-PCR & 344 & $1 / 26$ & $0.29 \%$ & [43] \\
\hline & Korea & G-I and V & RT-PCR & 1960 & $2 / 175$ & $0.1 \%$ & [44] \\
\hline & Korea & ND & RT-PCR & 1140 & $1 / 45$ & $0.09 \%$ & [45] \\
\hline & Malaysia & ND & $\begin{array}{l}\text { Isolation and } \\
\text { RT-PCR }\end{array}$ & 550 & $3 / 11$ & $0.55 \%$ & [21] \\
\hline $\begin{array}{l}\text { Culex epidesmus } \\
\text { (Theobald, 1905) }\end{array}$ & India & ND & Isolation & ND & 1 & ND & [30] \\
\hline $\begin{array}{c}\text { Culex fuscanus } \\
\text { (Wiedemann, } \\
\text { 1820) }\end{array}$ & Taiwan & ND & Isolation & ND & 1 & ND & [20] \\
\hline \multirow{9}{*}{$\frac{\text { Culex fuscocephala }}{\text { (Theobald, 1907) }}$} & India & ND & Isolation & 14,664 & $1 / 257$ & $0.007 \%$ & [31] \\
\hline & India & ND & Isolation & 15,250 & $6 / 305$ & $0.04 \%$ & [46] \\
\hline & Indonesia & ND & Isolation & ND & 1 & ND & [47] \\
\hline & Malaysia & ND & $\begin{array}{l}\text { Isolation and } \\
\text { RT-PCR }\end{array}$ & 3800 & $2 / 76$ & $0.05 \%$ & [22] \\
\hline & Taiwan & G-I and III & RT-PCR & 394 & $3 / 19$ & $0.76 \%$ & [19] \\
\hline & Taiwan & ND & RT-PCR & 1150 & $1 / 23$ & $0.09 \%$ & [48] \\
\hline & Taiwan & ND & Isolation & 22,895 & $19 / 282$ & $0.08 \%$ & [49] \\
\hline & Thailand & ND & $\begin{array}{c}\text { Isolation or } \\
\text { HI and CF } \\
\text { assays }\end{array}$ & 142,375 & 2 & $0.001 \%$ & [50] \\
\hline & Thailand & ND & ND & ND & 2 & ND & [50] \\
\hline \multirow{14}{*}{$\begin{array}{l}\text { Culex gelidus } \\
\text { (Theobald, 1901) }\end{array}$} & Australia & ND & RT-PCR & 4872 & 3 & $0.06 \%$ & [51] \\
\hline & India & ND & Isolation & 6038 & $3 / 127$ & $0.05 \%$ & [31] \\
\hline & India & ND & ND & ND & ND & ND & [52] \\
\hline & India & ND & $\begin{array}{l}\text { ELISA and } \\
\text { Toxo-IFA }\end{array}$ & 7485 & $4 / 177$ & $0.05 \%$ & [53] \\
\hline & India & ND & Isolation & 9700 & $5 / 194$ & $0.05 \%$ & [46] \\
\hline & India & ND & $\begin{array}{l}\text { ELISA and } \\
\text { Toxo-IFA }\end{array}$ & 8750 & $17 / 175$ & $0.2 \%$ & [54] \\
\hline & India & ND & $\begin{array}{l}\text { ELISA and } \\
\text { Toxo-IFA }\end{array}$ & 17,678 & $12 / 403$ & $0.07 \%$ & [55] \\
\hline & India & ND & $\begin{array}{l}\text { ELISA and } \\
\text { Toxo-IFA }\end{array}$ & 16,658 & 10 & $0.06 \%$ & [56] \\
\hline & Indonesia & ND & ND & ND & 1 & ND & [57] \\
\hline & Indonesia & ND & Isolation & 7144 & $2 / 154$ & $0.03 \%$ & [47] \\
\hline & Malaysia & ND & $\begin{array}{l}\text { Isolation and } \\
\text { RT-PCR }\end{array}$ & 11,200 & $12 / 224$ & $0.11 \%$ & [22] \\
\hline & Malaysia & ND & ND & ND & 1 & ND & [58] \\
\hline & Malaysia & ND & ND & ND & ND & ND & [23] \\
\hline & Sri Lanka & ND & Isolation & 13,043 & 4 & $0.03 \%$ & [59] \\
\hline
\end{tabular}


Table 1. Cont.

\begin{tabular}{|c|c|c|c|c|c|c|c|}
\hline $\begin{array}{l}\text { Mosquito } \\
\text { Species }\end{array}$ & $\begin{array}{l}\text { Country of } \\
\text { Sampling }\end{array}$ & $\begin{array}{l}\text { JEV } \\
\text { Genotype } \\
\text { and/or } \\
\text { Strain }\end{array}$ & $\begin{array}{l}\text { Detection } \\
\text { Method }\end{array}$ & $\begin{array}{l}\text { Total \# } \\
\text { Tested }\end{array}$ & $\begin{array}{c}\text { \# JEV } \\
\text { Positive } \\
\text { Pools/Total \# } \\
\text { of Pools }\end{array}$ & $\begin{array}{c}\text { MIR (\# } \\
\text { Positive } \\
\text { Pools/Total } \\
\text { Tested) } \times 100\end{array}$ & Reference \\
\hline & Thailand & ND & $\begin{array}{l}\text { Isolation or } \\
\text { HI and CF } \\
\text { assays }\end{array}$ & 11,495 & 3 & $0.03 \%$ & [50] \\
\hline & Thailand & Not given & $\begin{array}{l}\text { Inoculation } \\
\text { in mice }\end{array}$ & 3097 & 18 & $0.6 \%$ & [60] \\
\hline & Vietnam & Not given & ND & ND & ND & ND & [61] \\
\hline $\begin{array}{l}\text { Culex infula } \\
\text { (Theobald, 1901) }\end{array}$ & India & ND & $\begin{array}{l}\text { ELISA and } \\
\text { Toxo-IFA }\end{array}$ & 119 & $2 / 16$ & $1.68 \%$ & [28] \\
\hline $\begin{array}{l}\text { Culex orientalis } \\
\text { (Edwards, 1921) }\end{array}$ & Korea & $\mathrm{G}-\mathrm{V}$ & RT-PCR & 498 & $5 / 83$ & $1 \%$ & {$[62]$} \\
\hline \multirow{5}{*}{$\frac{\text { Culex pipiens }}{\text { (Linnaeus, 1758) }}$} & Italy & G-III & RT-PCR & ND & $1 / 57$ & ND & [63] \\
\hline & Korea & G-I & RT-PCR & 736 & $4 / 64$ & $0.54 \%$ & [43] \\
\hline & Korea & G-I & RT-PCR & 11,237 & $4 / 804$ & $0.04 \%$ & [44] \\
\hline & Korea & $\mathrm{G}-\mathrm{V}$ & RT-PCR & 9295 & $1 / 264$ & $0.01 \%$ & [62] \\
\hline & China & G-I & RT-PCR & 1540 & $1 / 256$ & $0.06 \%$ & [64] \\
\hline$\frac{\text { Culex pipiens }}{\text { pallens }}$ & China & ND & RT-PCR & 6465 & $10 / 132$ & $0.15 \%$ & [38] \\
\hline \multirow{5}{*}{$\frac{\text { Culex pseudovishnui }}{\text { (Colless, 1957) }}$} & India & ND & ND & ND & 1 & ND & [65] \\
\hline & India & ND & $\begin{array}{l}\text { ELISA and } \\
\text { Toxo-IFA or } \\
\text { RT-PCR }\end{array}$ & ND & $3 / 107$ & ND & [66] \\
\hline & India & ND & $\begin{array}{l}\text { ELISA and } \\
\text { Toxo-IFA or } \\
\text { RT-PCR }\end{array}$ & 1406 & 1 & $0.07 \%$ & [67] \\
\hline & India & ND & ND & ND & ND & ND & [68] \\
\hline & India & ND & ND & ND & ND & ND & [37] \\
\hline \multirow{7}{*}{$\frac{\frac{\text { Culex }}{\text { quinquefasciatus }}}{(\text { Say, 1823) }}$} & India & ND & $\begin{array}{l}\text { ELISA and } \\
\text { Toxo-IFA }\end{array}$ & 59 & $1 / 13$ & $1.69 \%$ & [28] \\
\hline & India & ND & Isolation & 304 & $1 / 18$ & $0.33 \%$ & [31] \\
\hline & Malaysia & ND & $\begin{array}{l}\text { Isolation and } \\
\text { RT-PCR }\end{array}$ & 2400 & $1 / 48$ & $0.4 \%$ & [22] \\
\hline & Taiwan & G-I and III & RT-PCR & 1333 & $2 / 74$ & $0.15 \%$ & [19] \\
\hline & Taiwan & ND & Isolation & ND & 7 & ND & [20] \\
\hline & Thailand & ND & Isolation & 1023 & $2 / 25$ & $0.2 \%$ & [69] \\
\hline & Vietnam & G-III & RT-PCR & ND & 30 & ND & [70] \\
\hline $\begin{array}{l}\text { Culex rubithoracis } \\
\text { (Leicester, 1908) }\end{array}$ & Taiwan & ND & RT-PCR & 130 & $4 / 22$ & $3.08 \%$ & [24] \\
\hline \multirow{5}{*}{$\frac{\text { Culex sitiens }}{\text { (Wiedemann, }}$} & Australia & ND & RT-PCR & 18,680 & 5 & $0.03 \%$ & [51] \\
\hline & Australia & ND & RT-PCR & 22,833 & 1 & $0.004 \%$ & [71] \\
\hline & Australia & G-II & Isolation & 25,292 & 42 & $0.16 \%$ & [26] \\
\hline & Australia & G-I & Isolation & 44,755 & 1 & $0.002 \%$ & [72] \\
\hline & Malaysia & ND & $\begin{array}{l}\text { Isolation and } \\
\text { RT-PCR }\end{array}$ & 400 & $2 / 8$ & $0.5 \%$ & [21] \\
\hline
\end{tabular}


Table 1. Cont.

\begin{tabular}{|c|c|c|c|c|c|c|c|}
\hline $\begin{array}{l}\text { Mosquito } \\
\text { Species }\end{array}$ & $\begin{array}{l}\text { Country of } \\
\text { Sampling }\end{array}$ & $\begin{array}{l}\text { JEV } \\
\text { Genotype } \\
\text { and/or } \\
\text { Strain }\end{array}$ & $\begin{array}{l}\text { Detection } \\
\text { Method }\end{array}$ & $\begin{array}{l}\text { Total \# } \\
\text { Tested }\end{array}$ & $\begin{array}{c}\text { \# JEV } \\
\text { Positive } \\
\text { Pools/Total \# } \\
\text { of Pools }\end{array}$ & $\begin{array}{c}\text { MIR (\# } \\
\text { Positive } \\
\text { Pools/Total } \\
\text { Tested) } \times 100\end{array}$ & Reference \\
\hline & $\begin{array}{c}\text { Papua New } \\
\text { Guinea }\end{array}$ & G-II & Isolation & 245,483 & 3 & $0.001 \%$ & [73] \\
\hline & Taiwan & ND & RT-PCR & 604 & $1 / 34$ & $0.17 \%$ & [24] \\
\hline & Taiwan & ND & Isolation & ND & 2 & ND & [20] \\
\hline & Vietnam & G-I and III & RT-PCR & ND & 73 & ND & [70] \\
\hline$\frac{\text { Culex tarsalis }}{(\text { Coquillett, 1896) }}$ & China & G-III & RT-PCR & ND & 57 & ND & [32] \\
\hline \multirow{25}{*}{$\frac{\frac{\text { Culex }}{\text { tritaeniorhynchus }}}{\text { (Giles, 1901) }}$} & Cambodia & G-I & Isolation & 7218 & $1 / 729$ & $0.01 \%$ & [74] \\
\hline & China & $\mathrm{ND}$ & RT-PCR & 6610 & $31 / 135$ & $0.47 \%$ & [38] \\
\hline & China & ND & RT-PCR & 15,795 & $24 / 158$ & $0.15 \%$ & [33] \\
\hline & China & G-I & Isolation & 37,119 & 15 & $0.04 \%$ & [34] \\
\hline & China & G-I & RT-PCR & 3945 & $4 / 255$ & $0.1 \%$ & [64] \\
\hline & China & G-I & RT-PCR & 6490 & $15 / 149$ & $0.23 \%$ & [75] \\
\hline & China & G-I & RT-PCR & 2927 & $3 / 152$ & $0.1 \%$ & [76] \\
\hline & India & ND & $\begin{array}{l}\text { ELISA and } \\
\text { Toxo-IFA }\end{array}$ & 9937 & $10 / 245$ & $0.10 \%$ & [28] \\
\hline & India & ND & Isolation & 12,161 & $2 / 272$ & $0.02 \%$ & [31] \\
\hline & India & ND & Isolation & 206,424 & $58 / 4128$ & $0.03 \%$ & [46] \\
\hline & India & ND & $\begin{array}{l}\text { ELISA and } \\
\text { Toxo-IFA }\end{array}$ & ND & ND & ND & [35] \\
\hline & India & ND & $\begin{array}{l}\text { ELISA and } \\
\text { Toxo-IFA }\end{array}$ & 7485 & $4 / 177$ & $0.05 \%$ & [53] \\
\hline & India & ND & $\begin{array}{c}\text { ELISA and } \\
\text { Toxo-IFA }\end{array}$ & 45,100 & $62 / 902$ & $0.14 \%$ & [54] \\
\hline & India & ND & $\begin{array}{l}\text { ELISA and } \\
\text { Toxo-IFA }\end{array}$ & 21,005 & $13 / 429$ & $0.06 \%$ & [53] \\
\hline & India & ND & $\begin{array}{l}\text { ELISA and } \\
\text { Toxo-IFA }\end{array}$ & 14,358 & $14 / 309$ & $0.1 \%$ & [55] \\
\hline & India & ND & $\begin{array}{l}\text { ELISA and } \\
\text { Toxo-IFA }\end{array}$ & 100,611 & 64 & $0.06 \%$ & [56] \\
\hline & India & ND & $\begin{array}{l}\text { ELISA and } \\
\text { Toxo-IFA or } \\
\text { RT-PCR }\end{array}$ & 862 & 2 & $0.23 \%$ & [67] \\
\hline & Indonesia & ND & Isolation & 112,398 & $1 / 596$ & $0.0009 \%$ & [27] \\
\hline & Indonesia & ND & Isolation & 18,486 & $19 / 359$ & $0.1 \%$ & [47] \\
\hline & Japan & G-I & Isolation & 3328 & $3 / 141$ & $0.09 \%$ & [77] \\
\hline & Korea & G-I & RT-PCR & 2880 & $29 / 121$ & $1.01 \%$ & [43] \\
\hline & Korea & G-I and V & RT-PCR & 55,135 & $92 / 2031$ & $0.17 \%$ & [44] \\
\hline & Korea & ND & RT-PCR & 5909 & $50 / 207$ & $0.85 \%$ & [45] \\
\hline & Malaysia & ND & $\begin{array}{l}\text { Isolation and } \\
\text { RT-PCR }\end{array}$ & 1300 & $3 / 26$ & $0.23 \%$ & [21] \\
\hline & Malaysia & ND & $\begin{array}{l}\text { Isolation and } \\
\text { RT-PCR }\end{array}$ & 36,550 & $24 / 731$ & $0.07 \%$ & [22] \\
\hline
\end{tabular}


Table 1. Cont.

\begin{tabular}{|c|c|c|c|c|c|c|c|}
\hline $\begin{array}{l}\text { Mosquito } \\
\text { Species }\end{array}$ & $\begin{array}{l}\text { Country of } \\
\text { Sampling }\end{array}$ & $\begin{array}{l}\text { JEV } \\
\text { Genotype } \\
\text { and/or } \\
\text { Strain }\end{array}$ & $\begin{array}{l}\text { Detection } \\
\text { Method }\end{array}$ & $\begin{array}{l}\text { Total \# } \\
\text { Tested }\end{array}$ & $\begin{array}{c}\text { \# JEV } \\
\text { Positive } \\
\text { Pools/Total \# } \\
\text { of Pools }\end{array}$ & $\begin{array}{c}\text { MIR (\# } \\
\text { Positive } \\
\text { Pools/Total } \\
\text { Tested) } \times 100\end{array}$ & Reference \\
\hline & Singapore & G-II & RT-PCR & 882 & $5 / 88$ & $0.57 \%$ & [78] \\
\hline & Sri Lanka & ND & Isolation & 17,436 & 4 & $0.02 \%$ & [59] \\
\hline & Taiwan & $\mathrm{ND}$ & Isolation & 16,776 & $18 / 267$ & $0.11 \%$ & [41] \\
\hline & Taiwan & ND & RT-PCR & 28,773 & $95 / 1061$ & $0.33 \%$ & [24] \\
\hline & Taiwan & ND & RT-PCR & 37,500 & $25 / 750$ & $0.07 \%$ & [48] \\
\hline & Taiwan & $\mathrm{ND}$ & Isolation & $\mathrm{ND}$ & 97 & $\mathrm{ND}$ & [20] \\
\hline & Taiwan & G-I and III & RT-PCR & 89,189 & $468 / 2242$ & $0.52 \%$ & [19] \\
\hline & Taiwan & ND & Isolation & ND & $2 / 6$ & ND & [42] \\
\hline & Thailand & ND & $\begin{array}{l}\text { Isolation or } \\
\text { HI and CF } \\
\text { assays }\end{array}$ & 183,140 & 8 & $0.004 \%$ & [50] \\
\hline & Thailand & ND & Isolation & 290,126 & 34 & $0.01 \%$ & [79] \\
\hline & Vietnam & G-I and III & RT-PCR & ND & 3 & ND & [70] \\
\hline & Vietnam & G-I & Isolation & 4199 & $3 / 131$ & $0.07 \%$ & [80] \\
\hline \multirow{8}{*}{$\frac{\text { Culex vishnui }}{\text { (Theobald, 1901) }}$} & India & ND & $\begin{array}{l}\text { ELISA and } \\
\text { Toxo-IFA or } \\
\text { RT-PCR }\end{array}$ & 1512 & 3 & $0.2 \%$ & [67] \\
\hline & India & ND & ND & $\mathrm{ND}$ & ND & ND & [37] \\
\hline & India & ND & $\begin{array}{l}\text { ELISA and } \\
\text { Toxo-IFA }\end{array}$ & 2787 & $1 / 61$ & $0.04 \%$ & [53] \\
\hline & India & ND & Isolation & 54,007 & $22 / 1080$ & $0.04 \%$ & [46] \\
\hline & Indonesia & $\mathrm{ND}$ & Isolation & $\mathrm{ND}$ & 1 & ND & {$[47]$} \\
\hline & Malaysia & ND & $\begin{array}{c}\text { Isolation and } \\
\text { RT-PCR }\end{array}$ & 1650 & $4 / 33$ & $0.24 \%$ & [21] \\
\hline & Thailand & $\mathrm{ND}$ & Isolation & 8408 & 1 & $0.01 \%$ & [79] \\
\hline & Vietnam & G-I & Isolation & 1542 & $2 / 46$ & $0.13 \%$ & {$[80]$} \\
\hline \multirow{2}{*}{$\begin{array}{l}\text { Culex whitmorei } \\
\text { (Giles, 1904) }\end{array}$} & India & ND & $\begin{array}{l}\text { ELISA and } \\
\text { Toxo-IFA }\end{array}$ & 47 & $2 / 17$ & $4.26 \%$ & [28] \\
\hline & Sri Lanka & ND & Isolation & 167 & 1 & $0.6 \%$ & [59] \\
\hline $\begin{array}{c}\text { Mansonia } \\
\text { bonneae/dives } \\
\text { (Edwards, } \\
\text { 1930/Schiner, } \\
\text { 1868) }\end{array}$ & Malaysia & ND & ND & ND & ND & ND & [23] \\
\hline \multirow{2}{*}{$\begin{array}{c}\text { Mansonia } \\
\text { annulifera } \\
\text { (Theobald, 1901) }\end{array}$} & India & ND & $\begin{array}{l}\text { ELISA and } \\
\text { Toxo-IFA }\end{array}$ & ND & ND & ND & [35] \\
\hline & India & ND & $\begin{array}{l}\text { ELISA and } \\
\text { Toxo-IFA }\end{array}$ & 4530 & 3 & $0.07 \%$ & [56] \\
\hline \multirow{2}{*}{$\begin{array}{l}\text { Mansonia indiana } \\
\text { (Edwards, 1930) }\end{array}$} & India & ND & $\begin{array}{l}\text { ELISA and } \\
\text { Toxo-IFA }\end{array}$ & 12,362 & 12 & $0.1 \%$ & [56] \\
\hline & India & ND & $\begin{array}{l}\text { ELISA and } \\
\text { Toxo-IFA }\end{array}$ & 62 & $2 / 13$ & $3.23 \%$ & [28] \\
\hline
\end{tabular}


Table 1. Cont.

\begin{tabular}{|c|c|c|c|c|c|c|c|}
\hline $\begin{array}{l}\text { Mosquito } \\
\text { Species }\end{array}$ & $\begin{array}{l}\text { Country of } \\
\text { Sampling }\end{array}$ & $\begin{array}{l}\text { JEV } \\
\text { Genotype } \\
\text { and/or } \\
\text { Strain }\end{array}$ & $\begin{array}{l}\text { Detection } \\
\text { Method }\end{array}$ & $\begin{array}{l}\text { Total \# } \\
\text { Tested }\end{array}$ & $\begin{array}{c}\text { \# JEV } \\
\text { Positive } \\
\text { Pools/Total \# } \\
\text { of Pools }\end{array}$ & $\begin{array}{c}\text { MIR (\# } \\
\text { Positive } \\
\text { Pools/Total } \\
\text { Tested) } \times \mathbf{1 0 0}\end{array}$ & Reference \\
\hline \multirow{5}{*}{$\begin{array}{c}\text { Mansonia } \\
\text { uniformis } \\
\text { (Theobald, 1901) }\end{array}$} & India & ND & $\begin{array}{c}\text { ELISA and } \\
\text { Toxo-IFA }\end{array}$ & ND & ND & ND & [35] \\
\hline & India & ND & $\begin{array}{l}\text { ELISA and } \\
\text { Toxo-IFA }\end{array}$ & 14,503 & 5 & $0.03 \%$ & [56] \\
\hline & Malaysia & ND & ND & ND & ND & ND & [23] \\
\hline & Sri Lanka & ND & ND & ND & ND & ND & [59] \\
\hline & Taiwan & G-I and III & RT-PCR & 75 & $1 / 19$ & $1.33 \%$ & [19] \\
\hline
\end{tabular}

RT-PCR = reversed transcription polymerase chain reaction; $\mathrm{HI}=$ hemagglutination inhibition; $\mathrm{CF}=$ complement fixation; Toxo-IFA = indirect immunofluorescence assay on inoculated Toxorhynchites splendens mosquito larvae.

Using the data from 61 publications on the detection of JEV in field-collected mosquitoes, the MIR was calculated for 35 species. Differences in the total number of mosquitoes tested among studies ranged from 18 to 290,126 . This partly explains the large differences in the MIR for JEV between the different species (from 0.0009 to $5.56 \%$ ). If a comparison is made between those where larger numbers have been tested, it can be concluded that, for example, Culex pipiens (with MIR values from 0.01 to $0.54 \%$ ) and Culex tritaeniorhynchus (MIR from 0.0009 to $1.01 \%$ ) are often detected as JEV-infected in the field. Most studies do not differentiate between Culex pipiens pipiens and Culex pipiens molestus, therefore, in this review Culex pipiens refers to both, while Culex pipiens pallens is considered separately.

Culex quinquefasciatus was repeatedly found to be positive in Vietnam, although no MIR could be calculated for this study since the total number of tested specimens was not reported [70]. The detection of JEV in a specific field-collected mosquito species does not necessarily mean that this species is competent to transmit the virus to another host [81]. For a species to be considered competent, JEV needs to be able to disseminate in the vector after the blood meal and reach the saliva in order to be transmitted to other hosts. Table 2 gives an overview of field-collected mosquito species in which JEV has not been detected, despite screening efforts. The absence of field detection, however, cannot lead to the conclusion that these species are not JEV vectors. That would require additional studies, including vector competence studies, as described below. In several of the studies a very small number of mosquitoes was tested, e.g., three individuals for Aedes aegypti and one individual for Aedes lineatopennis [43], Anopheles ludlowae, or Culex brevipalpis [19], which precludes final conclusions.

Table 2. Overview of mosquito screening studies in which JEV was not detected.

\begin{tabular}{|c|c|c|c|c|c|c|}
\hline Mosquito Species & $\begin{array}{l}\text { Country of } \\
\text { Sampling }\end{array}$ & $\begin{array}{l}\text { JEV Genotype } \\
\text { and/or Strain }\end{array}$ & $\begin{array}{l}\text { Detection } \\
\text { Method }\end{array}$ & Total \# Tested & $\begin{array}{l}\text { \# JEV Positive } \\
\text { Pools }\end{array}$ & Reference \\
\hline $\begin{array}{c}\text { Aedes aegypti } \\
\text { (Linnaeus, 1762) }\end{array}$ & Taiwan & G-I and III & RT-PCR & 3 & $0 / 2$ pools & [19] \\
\hline $\begin{array}{l}\text { Aedes albolateralis } \\
\text { (Theobald, 1908) }\end{array}$ & Taiwan & G-I and III & RT-PCR & 1 & $0 / 1$ pools & [19] \\
\hline \multirow{2}{*}{ Aedes albopictus * } & Korea & $\mathrm{G}-\mathrm{V}$ & RT-PCR & 564 & $0 / 64$ pools & {$[62]$} \\
\hline & Korea & G-I & RT-PCR & 66 & $0 / 15$ pools & [43] \\
\hline $\begin{array}{l}\text { Aedes dorsalis } \\
\text { (Meigen, 1830) }\end{array}$ & Korea & $\mathrm{G}-\mathrm{V}$ & RT-PCR & 6 & $0 / 6$ pools & [62] \\
\hline $\begin{array}{c}\text { Aedes koreicus } \\
\text { (Edwards, 1917) }\end{array}$ & Korea & G-I & RT-PCR & 181 & $0 / 24$ pools & [43] \\
\hline
\end{tabular}


Table 2. Cont.

\begin{tabular}{|c|c|c|c|c|c|c|}
\hline Mosquito Species & $\begin{array}{l}\text { Country of } \\
\text { Sampling }\end{array}$ & $\begin{array}{l}\text { JEV Genotype } \\
\text { and/or Strain }\end{array}$ & $\begin{array}{l}\text { Detection } \\
\text { Method }\end{array}$ & Total \# Tested & $\begin{array}{l}\text { \# JEV Positive } \\
\text { Pools }\end{array}$ & Reference \\
\hline \multirow[b]{2}{*}{ Aedes lineatopennis * } & Korea & G-I & RT-PCR & 1 & $0 / 1$ pools & [43] \\
\hline & Thailand & ND & $\begin{array}{l}\text { Isolation or } \mathrm{HI} \\
\text { and } \mathrm{CF} \text { assays }\end{array}$ & 16,230 & 0 pools & {$[50]$} \\
\hline $\begin{array}{l}\text { Aedes mediolineatus } \\
\text { (Theobald, 1901) }\end{array}$ & Thailand & ND & $\begin{array}{l}\text { Isolation or } \mathrm{HI} \\
\text { and } C F \text { assays }\end{array}$ & 15,122 & 0 pools & {$[50]$} \\
\hline $\begin{array}{c}\text { Aedes nipponicus } \\
\text { (LaCasse \& Yamaguti, } \\
1948)\end{array}$ & Korea & G-I & RT-PCR & 1 & 0/1 pools & {$[43]$} \\
\hline $\begin{array}{l}\text { Aedes penghuensis } \\
\quad(\text { Lien, 1968) }\end{array}$ & Taiwan & G-I and III & RT-PCR & 283 & $0 / 10$ pools & [19] \\
\hline $\begin{array}{c}\text { Aedes togoi } \\
\text { (Theobald, 1907) }\end{array}$ & Taiwan & G-I and III & RT-PCR & 1 & $0 / 1$ pools & [19] \\
\hline Aedes vexans * $[81]$ & Thailand & ND & $\begin{array}{l}\text { Isolation or } \mathrm{HI} \\
\text { and CF assays }\end{array}$ & 11,022 & 0 pools & {$[50]$} \\
\hline $\begin{array}{l}\text { Aedes vexans nipponii } \\
\text { (Theobald, 1907) }\end{array}$ & Korea & G-I & RT-PCR & 2091 & 0/106 pools & {$[43]$} \\
\hline $\begin{array}{l}\text { Anopheles ludlowae } \\
\text { (Theobald, 1903) }\end{array}$ & Taiwan & G-I and III & RT-PCR & 1 & 0/1 pools & [19] \\
\hline \multirow{2}{*}{ Armigeres subalbatus * } & Korea & $\mathrm{G}-\mathrm{V}$ & RT-PCR & 1132 & 0/145 pools & [62] \\
\hline & Korea & G-I & RT-PCR & 23 & $0 / 9$ pools & [43] \\
\hline $\begin{array}{l}\text { Coquillettidia crassipes } \\
\text { (Van der Wulp, 1881) }\end{array}$ & Taiwan & G-I and III & RT-PCR & 47 & $0 / 3$ pools & [19] \\
\hline Coquillettidia ochracea * & Korea & $\mathrm{G}-\mathrm{V}$ & RT-PCR & 115 & $0 / 14$ pools & {$[62]$} \\
\hline \multirow{2}{*}{ Culex bitaeniorhynchus * } & Korea & $\mathrm{G}-\mathrm{V}$ & RT-PCR & 50 & $0 / 16$ pools & [62] \\
\hline & Taiwan & G-I and III & RT-PCR & 60 & $0 / 7$ pools & [19] \\
\hline $\begin{array}{l}\text { Culex brevipalpis } \\
\text { (Giles, 1902) }\end{array}$ & Taiwan & G-I and III & RT-PCR & 1 & $0 / 1$ pools & [19] \\
\hline Culex fuscanus * & Taiwan & G-I and III & RT-PCR & 4 & $0 / 3$ pools & [19] \\
\hline Culex fuscocephalus * & Thailand & ND & Isolation & 9140 & 0 pools & [79] \\
\hline Culex gelidus * & Thailand & ND & Isolation & 17,530 & 0 pools & [79] \\
\hline $\begin{array}{l}\text { Culex hayshii } \\
\text { (Yamada, 1917) }\end{array}$ & Korea & $\mathrm{G}-\mathrm{V}$ & RT-PCR & 4 & $0 / 2$ pools & [62] \\
\hline \multirow{2}{*}{$\begin{array}{l}\text { Culex inatomii (Kaminura } \\
\text { \& Wada, 1974) }\end{array}$} & Korea & $\mathrm{G}-\mathrm{V}$ & RT-PCR & 470 & $0 / 16$ pools & {$[62]$} \\
\hline & Korea & G-I & RT-PCR & 1 & $0 / 1$ pools & [43] \\
\hline \multirow{2}{*}{$\begin{array}{l}\text { Culex mimeticus } \\
\text { (Noè, 1899) }\end{array}$} & Korea & $\mathrm{G}-\mathrm{V}$ & RT-PCR & 1 & $0 / 1$ pools & [62] \\
\hline & Taiwan & G-I and III & RT-PCR & 1 & 0/1 pools & [19] \\
\hline $\begin{array}{l}\text { Culex murrelli } \\
\text { (Lien, 1968) }\end{array}$ & Taiwan & G-I and III & RT-PCR & 39 & $0 / 3$ pools & [19] \\
\hline $\begin{array}{l}\text { Culex nigropunctatus } \\
\text { (Edwards, 1926) }\end{array}$ & Taiwan & G-I and III & RT-PCR & 9 & $0 / 1$ pools & [19] \\
\hline Culex orientalis * & Korea & G-I & RT-PCR & 3 & $0 / 2$ pools & [43] \\
\hline Culex quinquefasciatus * & Thailand & ND & Isolation & 73 & 0 pools & [79] \\
\hline $\begin{array}{l}\text { Culex rubensis (Sasa \& } \\
\text { Takahashi, 1948) }\end{array}$ & Korea & $\mathrm{G}-\mathrm{V}$ & RT-PCR & 1 & $0 / 1$ pools & {$[62]$} \\
\hline
\end{tabular}


Table 2. Cont.

\begin{tabular}{|c|c|c|c|c|c|c|}
\hline Mosquito Species & $\begin{array}{l}\text { Country of } \\
\text { Sampling }\end{array}$ & $\begin{array}{l}\text { JEV Genotype } \\
\text { and/or Strain }\end{array}$ & $\begin{array}{l}\text { Detection } \\
\text { Method }\end{array}$ & Total \# Tested & $\begin{array}{l}\text { \# JEV Positive } \\
\text { Pools }\end{array}$ & Reference \\
\hline Culex rubithoracis * & Taiwan & G-I and III & RT-PCR & 65 & $0 / 8$ pools & [19] \\
\hline Culex sitiens * & Taiwan & G-I and III & RT-PCR & 6295 & $0 / 128$ pools & [19] \\
\hline Culex tritaeniorhynchus * & Korea & $\mathrm{G}-\mathrm{V}$ & RT-PCR & 10 & $0 / 7$ pools & [62] \\
\hline $\begin{array}{c}\text { Culex vagans } \\
\text { (Wiedemann, 1828) }\end{array}$ & Korea & $\mathrm{G}-\mathrm{V}$ & RT-PCR & 5 & $0 / 2$ pools & [62] \\
\hline Culex vishnui* & Thailand & ND & $\begin{array}{l}\text { Isolation or } \mathrm{HI} \\
\text { and } \mathrm{CF} \text { assays }\end{array}$ & 22,005 & 0 pools & {$[50]$} \\
\hline Culex whitmorei ${ }^{*}$ & Thailand & ND & Isolation & 530 & 0 pools & [79] \\
\hline $\begin{array}{l}\text { Culiseta bergrothi } \\
\text { (Edwards, 1921) }\end{array}$ & Korea & $\mathrm{G}-\mathrm{V}$ & RT-PCR & 1 & $0 / 1$ pools & {$[62]$} \\
\hline \multirow{2}{*}{ Mansonia uniformis * } & Korea & $\mathrm{G}-\mathrm{V}$ & RT-PCR & 2176 & $0 / 66$ pools & [62] \\
\hline & Korea & G-I & RT-PCR & 1 & $0 / 1$ pools & {$[43]$} \\
\hline $\begin{array}{l}\text { Tripteroides bambusa } \\
\text { (Yamada, 1917) }\end{array}$ & Korea & $\mathrm{G}-\mathrm{V}$ & RT-PCR & 30 & 0/9 pools & {$[62]$} \\
\hline $\begin{array}{l}\text { Uranotaenia macfarlanei } \\
\quad \text { (Edwards, 1914) }\end{array}$ & Taiwan & G-I and III & RT-PCR & 1 & $0 / 1$ pools & [19] \\
\hline
\end{tabular}

RT-PCR = reversed transcription polymerase chain reaction; $\mathrm{HI}$ = hemagglutination inhibition; $\mathrm{CF}=$ complement fixation * These species have been detected positive in other studies/regions.

\subsubsection{JEV Vector Competence Studies}

Vector competence is defined as the intrinsic ability of a mosquito to acquire the pathogen, and subsequently transmit the pathogen to a new host [82]. This parameter can be determined based on laboratory experiments that determine the infection, dissemination, and transmission rates. These describe, respectively, the presence of the virus in the whole body of the mosquito (detection in the legs, wings, and/or mosquito heads) and the number of mosquitoes with viral particles in their saliva after infection [83]. Only those mosquitoes in which the virus reaches the saliva are considered to be competent mosquitoes. Where most studies determine the presence of the virus in the saliva by qPCR or virus isolation, actual transmission competence can be verified by allowing infected mosquitoes to feed on naïve animals and check for viremia and seroconversion in the host. A detailed overview of vector competence studies for JEV can be found in Table 3 .

There are many variations in methodology between studies and differences in mosquito populations, which can influence the outcome of vector competence studies. From Table 3, it can be noted that differences in vector competence are reported between studies for the same mosquito species, e.g., the transmission ratio of $0 \%$ (New Zealand [84]) compared to $70 \%$ (UK [85]) for Culex quinquefasciatus. Populations differ genetically, depending on where they have been collected and how long the colony has been maintained in the laboratory [86]. Another influencing factor might be the viral strains used. For example, Culex tritaeniorhynchus showed higher viral titers in their saliva for G-III strains than for G-I and G-V [12]. However, in this study, no significant differences were recorded in transmission rate for all of the genotypes. This was also evidenced in a study conducted on Aedes albopictus and Culex pipiens in France and on Culex quinquefasciatus in the USA, which showed equivalent transmission ratios for G-III and G-V and G-I and G-III strains, respectively $[87,88]$. Another methodological difference is found in the titers used for blood feeding. Higher titers in the blood meal should make it more likely that the virus will disseminate in the mosquito and, thus, eventually be transmitted. JEV titers in spiked blood used for blood feeding are usually between $10^{5}$ and $10^{7} \mathrm{PFU} / \mathrm{mL}[15,84,89]$. These high titers are proven realistic as previous studies have shown viraemic reservoir birds (chicks and ducklings) with titers up to $10^{6.5} \mathrm{PFU} / \mathrm{mL}$ [90]. Also, temperature conditions 
can influence the outcome of vector competence studies, as higher temperatures generally increases the competence for flaviviruses [15]. In the competence studies for JEV, the temperatures ranged from 18 to $28{ }^{\circ} \mathrm{C}$. An appropriate temperature should be chosen, one that is relevant to the mosquito population in the area where the study is being conducted. This will be further discussed in the section on vectorial capacity. Finally, the methods used for virus detection (e.g., RT-PCR, virus isolation) can lead to different outcomes in vector competence for the same species. In order to minimize the possible differences in methodology, a standard protocol should be proposed, as suggested for West Nile virus by Vogels et al. [91] and for Zika virus by Azar et al. [92]. In the absence of such a protocol, it is difficult to compare across the different competent species.

Table 4 summarizes the potential and confirmed vectors for JEV. Potential vectors are only proven competent in vector competence experiments, while confirmed vectors are additionally found positive in the field. The following seventeen species can be identified as confirmed vectors: Aedes albopictus, Aedes vexans, Aedes vigilax, Anopheles tessellatus, Armigeres subalbatus, Culex annulirostris, Culex bitaeniorhynchus, Culex fuscocephala, Culex gelidus, Culex pipiens, Culex pipiens pallens, Culex pseudovishnui, Culex quinquefasciatus, Culex sitiens, Culex tarsalis, Culex tritaeniorhynchus, and Culex vishnui. In addition, the following 10 species are potential vectors: Aedes detritus, Aedes dorsalis, Aedes japonicus, Aedes kochi, Aedes nigromaculis, Aedes notoscriptus, Culiseta annulata, Culiseta incidens, Culiseta inornata, and Verrallina funerea. In these, no JEV has been detected in the field to date, which may be due to a lack of surveillance studies.

Based on the extent of their transmission rate, Armigeres subalbatus, Culex annulirostris, Culex bitaeniorhynchus, Culex gelidus, Culex pipiens, Culex pseudovishnui, Culex quinquefasciatus, and Culex tritaeniorhynchus may be considered the most competent vector species. However, these transmission rates, determined in a particular study, apply to specific mosquito populations tested under certain laboratory conditions and could, therefore, be different in other circumstances. 
Table 3. Detailed overview of vector competence studies in different mosquito species for JEV. Underlined species have been detected positive in the field (Table 1).

\begin{tabular}{|c|c|c|c|c|c|c|c|c|c|c|c|c|c|c|}
\hline $\begin{array}{l}\text { Mosquito } \\
\text { Species }\end{array}$ & $\begin{array}{l}\text { Origin of } \\
\text { Mosquito } \\
\text { Colony }\end{array}$ & $\begin{array}{c}\text { JEV } \\
\text { Strain } \\
\text { Used }\end{array}$ & $\begin{array}{l}\text { Cell } \\
\text { Type } \\
\text { Used for } \\
\text { Virus } \\
\text { Produc- } \\
\text { tion }\end{array}$ & $\begin{array}{c}\text { Virus } \\
\text { Titer in } \\
\text { Blood- } \\
\text { meal }\end{array}$ & $\begin{array}{l}\text { Blood } \\
\text { Origin }\end{array}$ & $\begin{array}{l}\text { Feeding } \\
\text { Method }\end{array}$ & $\begin{array}{l}\text { Inc. Tem- } \\
\text { perature }\end{array}$ & $\begin{array}{l}\text { Inc. } \\
\text { Period } \\
\text { (Days) }\end{array}$ & $\begin{array}{c}\# \\
\text { Mosquitoes }\end{array}$ & $\begin{array}{c}\% \\
\text { Infected } \\
*\end{array}$ & $\begin{array}{c}\% \\
\text { Dissemi- } \\
\text { nated } \\
* *\end{array}$ & $\begin{array}{l}\text { \% Trans- } \\
\text { mission } \\
\text { Compe- } \\
\text { tent } \\
* * *\end{array}$ & $\begin{array}{l}\text { Detec- } \\
\text { tion } \\
\text { Method }\end{array}$ & $\begin{array}{l}\text { Refer- } \\
\text { ence }\end{array}$ \\
\hline $\begin{array}{c}\text { Aedes } \\
\text { aegypti }\end{array}$ & $\begin{array}{l}\text { Australia, } \\
\text { Townsville }\end{array}$ & $\begin{array}{c}\text { G-II } \\
\text { (TS3306) }\end{array}$ & $\begin{array}{c}\text { C6/36 } \\
\text { and } \\
\text { porcine } \\
\text { stable- } \\
\text { equine } \\
\text { kidney } \\
\text { cells }\end{array}$ & $\begin{array}{c}10^{4.5 \pm 0.1} \\
\mathrm{CCID}_{50} / \mathrm{mL}\end{array}$ & $\begin{array}{l}\text { Heparinized } \\
\text { rabbit }\end{array}$ & $\begin{array}{c}\text { Glass } \\
\text { mem- } \\
\text { brane } \\
\text { feeder } \\
\text { with pig } \\
\text { intestine }\end{array}$ & $28^{\circ} \mathrm{C}$ & $14-15$ & 60 & $27 \%$ & $17 \%$ & ND & $\begin{array}{l}\text { Porcine } \\
\text { stable- } \\
\text { equine } \\
\text { kidney } \\
\text { cells }\end{array}$ & [93] \\
\hline \multirow{3}{*}{$\frac{\text { Aedes }}{\text { albopictus }}$} & $\begin{array}{l}\text { Australia, } \\
\text { Masig } \\
\text { Island }\end{array}$ & G-I (TS00) & $\begin{array}{l}\text { Porcine } \\
\text { stable } \\
\text { equine } \\
\text { kidney } \\
\text { and } \\
\text { C6/36 } \\
\text { cells }\end{array}$ & $\begin{array}{c}3.5 \pm 0.3 \\
\log _{10} \\
\operatorname{CCID}_{50} / \mathrm{mL}\end{array}$ & $\begin{array}{c}\text { Washed } \\
\text { defibri- } \\
\text { nated } \\
\text { sheep }\end{array}$ & $\begin{array}{l}\text { Cotton } \\
\text { pledged }\end{array}$ & $28^{\circ} \mathrm{C}$ & 14 & 25 & $20 \%$ & $16 \%$ & $16 \%$ & Vero cells & [94] \\
\hline & $\begin{array}{l}\text { France, } \\
\text { Montpel- } \\
\text { lier and } \\
\text { Nice }\end{array}$ & $\begin{array}{c}\text { G-III } \\
(\mathrm{RP}-9) \\
\text { and G-V } \\
(\mathrm{XZ0934)}\end{array}$ & $\begin{array}{l}\text { Chicken } \\
\text { fibroblast- } \\
\text { derived } \\
\text { DF1 cells }\end{array}$ & $\begin{array}{c}8 \times 10^{6} \\
\mathrm{FFU} / \mathrm{mL}\end{array}$ & $\begin{array}{l}\text { Washed } \\
\text { rabbit ery- } \\
\text { throcytes }\end{array}$ & $\begin{array}{l}\text { Cotton } \\
\text { pledgets }\end{array}$ & $26^{\circ} \mathrm{C}$ & $7-13$ & $5-20$ & $70-100 \%$ & $\underset{\diamond}{57-100 \%}$ & $20-63 \%$ & $\begin{array}{l}\text { BHK-21 } \\
\text { cells }\end{array}$ & [87] \\
\hline & $\begin{array}{c}\text { Taiwan, } \\
\text { Tapei and } \\
\text { Taichung } \\
\text { County }\end{array}$ & $\begin{array}{c}\text { ND } \\
\text { (Sanshia } \\
\text { MQ1-2) }\end{array}$ & $\begin{array}{l}\text { C6/36 } \\
\text { cells }\end{array}$ & $\begin{array}{l}5.42 \log _{10} \\
\text { WMICLD5 }_{0}\end{array}$ & NA & $\begin{array}{l}\text { Intraperi } \\
\text { toneal in- } \\
\text { oculated } \\
\text { mice }\end{array}$ & $26-28^{\circ} \mathrm{C}$ & 14 & 20 & ND & ND & $27-45 \%$ & $\begin{array}{l}\text { BHK-21 } \\
\text { cells }\end{array}$ & [95] \\
\hline $\begin{array}{c}\text { Aedes } \\
\text { detritus } \\
\text { (Haliday, } \\
\text { 1833) }\end{array}$ & $\begin{array}{c}\text { UK, } \\
\text { North- } \\
\text { west } \\
\text { England }\end{array}$ & $\begin{array}{c}\text { G-V } \\
\text { (Muar) }\end{array}$ & Vero cells & $\begin{array}{c}4 \log _{10} \\
\text { PFU /mL }\end{array}$ & $\begin{array}{l}\text { Defibrinated } \\
\text { horse }\end{array}$ & $\begin{array}{l}\text { Hemotek } \\
\text { with } \\
\text { Parafilm } \\
\text { mem- } \\
\text { brane }\end{array}$ & $\begin{array}{l}23 \text { and } \\
28{ }^{\circ} \mathrm{C}\end{array}$ & $0-21$ & $6-32$ & $32-100 \%$ & $20-100 \%$ & $3-67 \%$ & Vero cells & [85] \\
\hline
\end{tabular}


Table 3. Cont.

\begin{tabular}{|c|c|c|c|c|c|c|c|c|c|c|c|c|c|c|}
\hline $\begin{array}{l}\text { Mosquito } \\
\text { Species }\end{array}$ & $\begin{array}{l}\text { Origin of } \\
\text { Mosquito } \\
\text { Colony }\end{array}$ & $\begin{array}{c}\text { JEV } \\
\text { Strain } \\
\text { Used }\end{array}$ & $\begin{array}{l}\text { Cell } \\
\text { Type } \\
\text { Used for } \\
\text { Virus } \\
\text { Produc- } \\
\text { tion }\end{array}$ & $\begin{array}{c}\text { Virus } \\
\text { Titer in } \\
\text { Blood- } \\
\text { meal }\end{array}$ & $\begin{array}{c}\text { Blood } \\
\text { Origin }\end{array}$ & $\begin{array}{l}\text { Feeding } \\
\text { Method }\end{array}$ & $\begin{array}{l}\text { Inc. Tem- } \\
\text { perature }\end{array}$ & $\begin{array}{l}\text { Inc. } \\
\text { Period } \\
\text { (Days) }\end{array}$ & $\begin{array}{c}\# \\
\text { Mosquitoes }\end{array}$ & $\begin{array}{c}\% \\
\text { Infected } \\
*\end{array}$ & $\begin{array}{c}\% \\
\text { Dissemi- } \\
\text { nated } \\
* *\end{array}$ & $\begin{array}{l}\text { \% Trans- } \\
\text { mission } \\
\text { Compe- } \\
\text { tent } \\
* * *\end{array}$ & $\begin{array}{l}\text { Detec- } \\
\text { tion } \\
\text { Method }\end{array}$ & $\begin{array}{l}\text { Refer- } \\
\text { ence }\end{array}$ \\
\hline $\begin{array}{c}\text { Aedes } \\
\text { dorsalis }\end{array}$ & US & $\begin{array}{c}\text { G-III } \\
\text { (Nakayama) }\end{array}$ & ND & ND & $\begin{array}{l}\text { Defibrinated } \\
\text { rabbit }\end{array}$ & $\begin{array}{l}\text { Cotton } \\
\text { pledgets }\end{array}$ & $27^{\circ} \mathrm{C}$ & 16 & $2-10$ & ND & ND & $4 \% \#$ & $\begin{array}{l}\text { Development } \\
\text { of en- } \\
\text { cephalitis } \\
\text { in } \\
\text { laboratory- } \\
\text { reared } \\
\text { mice }\end{array}$ & [96] \\
\hline \multirow{3}{*}{$\begin{array}{c}\text { Aedes } \\
\text { japonicus } \\
\text { (Theobald, } \\
\text { 1901) }\end{array}$} & $\begin{array}{l}\text { Germany, } \\
\text { Stuttgart }\end{array}$ & ND & ND & ND & Human & $\begin{array}{l}\text { Cotton } \\
\text { pledgets }\end{array}$ & $25^{\circ} \mathrm{C}$ & $0-14$ & $3-4$ & $100 \%$ & ND & ND & RT-qPCR & [97] \\
\hline & $\begin{array}{l}\text { Japan, } \\
\text { Narita }\end{array}$ & $\begin{array}{c}\text { G-I } \\
\text { (17CxIT- } \\
\text { I4-D31), } 3 \\
\text { (JaGAr } \\
\text { 01) and V } \\
\text { (Muar) }\end{array}$ & $\begin{array}{l}\text { C6/36 } \\
\text { cells }\end{array}$ & $\begin{array}{c}8.9,8.6 \\
\text { and } 7.1 \\
\log _{10} \\
\text { FFU/mL }\end{array}$ & $\begin{array}{l}\text { Defibrinated } \\
\text { rabbit }\end{array}$ & $\begin{array}{c}\text { Hemotek } \\
\text { with pig } \\
\text { intestine } \\
\text { mem- } \\
\text { brane }\end{array}$ & $27^{\circ} \mathrm{C}$ & $7-14$ & $3-36$ & $2-19 \%$ & $2-19 \%$ & $2-16 \%$ & $\begin{array}{l}\text { RT-qPCR } \\
\text { or FFA in } \\
\text { Vero cells }\end{array}$ & [12] \\
\hline & $\begin{array}{c}\text { Japan, } \\
\text { Sapporo }\end{array}$ & $\begin{array}{c}\text { G-III } \\
\text { (JANAr- } \\
5681)\end{array}$ & $\begin{array}{l}\text { C6/36 } \\
\text { cells }\end{array}$ & $\begin{array}{c}6.2 \\
\text { PFU/mL } \\
\text { (blood) } \\
\text { and } 3.7 \\
\mathrm{PFU} / \mathrm{mL} \\
\text { (chicken) }\end{array}$ & ND & $\begin{array}{l}\text { Cotton } \\
\text { pledgets } \\
\text { or } \\
\text { viremic } \\
\text { chicken }\end{array}$ & $\begin{array}{l}20 \text { or } \\
28^{\circ} \mathrm{C}\end{array}$ & $0-20$ & 40 & $67.5 \%$ & ND & $50 \%$ & $\begin{array}{l}\text { BHK-21 } \\
\text { cells and } \\
\text { IFA }\end{array}$ & [98] \\
\hline $\begin{array}{c}\text { Aedes } \\
\text { kochi } \\
\text { (Dönitz, } \\
1901 \text { ) }\end{array}$ & $\begin{array}{c}\text { Australia, } \\
\text { Bamaga } \\
\text { and } \\
\text { Cairns } \\
\text { (wild) }\end{array}$ & $\begin{array}{c}\text { G-II } \\
(\text { TS3306) }\end{array}$ & $\begin{array}{l}\text { C6/36 } \\
\text { and } \\
\text { porcine } \\
\text { stable- } \\
\text { equine } \\
\text { kidney } \\
\text { cells }\end{array}$ & $\begin{array}{l}10^{4.5 \pm 0.1} \\
\operatorname{CCID}_{50} / \mathrm{mL}\end{array}$ & $\begin{array}{l}\text { Heparinized } \\
\text { rabbit }\end{array}$ & $\begin{array}{l}\text { Glass } \\
\text { mem- } \\
\text { brane } \\
\text { feeder } \\
\text { with pig } \\
\text { intestine } \\
\text { mem- } \\
\text { brane }\end{array}$ & $28^{\circ} \mathrm{C}$ & $14-15$ & 37 & $19 \%$ & ND & $6 \%$ & $\begin{array}{l}\text { Detection } \\
\text { of virus } \\
\text { in brain } \\
\text { aspirates } \\
\text { of } \\
\text { recipient } \\
\text { suckling } \\
\text { mice }\end{array}$ & [93] \\
\hline
\end{tabular}


Table 3. Cont.

\begin{tabular}{|c|c|c|c|c|c|c|c|c|c|c|c|c|c|c|}
\hline $\begin{array}{l}\text { Mosquito } \\
\text { Species }\end{array}$ & $\begin{array}{c}\text { Origin of } \\
\text { Mosquito } \\
\text { Colony }\end{array}$ & $\begin{array}{c}\text { JEV } \\
\text { Strain } \\
\text { Used }\end{array}$ & $\begin{array}{l}\text { Cell } \\
\text { Type } \\
\text { Used for } \\
\text { Virus } \\
\text { Produc- } \\
\text { tion }\end{array}$ & $\begin{array}{c}\text { Virus } \\
\text { Titer in } \\
\text { Blood- } \\
\text { meal }\end{array}$ & $\begin{array}{l}\text { Blood } \\
\text { Origin }\end{array}$ & $\begin{array}{l}\text { Feeding } \\
\text { Method }\end{array}$ & $\begin{array}{l}\text { Inc. Tem- } \\
\text { perature }\end{array}$ & $\begin{array}{c}\text { Inc. } \\
\text { Period } \\
\text { (Days) }\end{array}$ & $\begin{array}{c}\# \\
\text { Mosquitoes }\end{array}$ & $\begin{array}{c}\% \\
\text { Infected } \\
*\end{array}$ & $\begin{array}{c}\% \\
\text { Dissemi- } \\
\text { nated } \\
* *\end{array}$ & $\begin{array}{l}\text { \% Trans- } \\
\text { mission } \\
\text { Compe- } \\
\text { tent } \\
* * *\end{array}$ & $\begin{array}{l}\text { Detec- } \\
\text { tion } \\
\text { Method }\end{array}$ & $\begin{array}{l}\text { Refer- } \\
\text { ence }\end{array}$ \\
\hline $\begin{array}{c}\text { Aedes } \\
\text { nigromac- } \\
\text { ulis } \\
\text { (Ludlow, } \\
\text { 1906) }\end{array}$ & US & $\begin{array}{c}\text { G-III } \\
\text { (Nakayama) }\end{array}$ & ND & ND & $\begin{array}{l}\text { Defibrinated } \\
\text { rabbit }\end{array}$ & $\begin{array}{l}\text { Cotton } \\
\text { pledgets }\end{array}$ & $27^{\circ} \mathrm{C}$ & 16 & 11-100 & ND & ND & $4 \% \#$ & $\begin{array}{l}\text { Development } \\
\text { of en- } \\
\text { cephalitis } \\
\text { in } \\
\text { laboratory- } \\
\text { reared } \\
\text { mice } \\
\end{array}$ & [96] \\
\hline $\begin{array}{c}\text { Aedes } \\
\text { notoscrip- } \\
\text { tus(Skuse, } \\
1889 \text { ) }\end{array}$ & $\begin{array}{l}\text { Australia, } \\
\text { Close- } \\
\text { burn }\end{array}$ & $\begin{array}{c}\text { G-II } \\
(\text { TS3306) }\end{array}$ & $\begin{array}{l}\text { C6/36 } \\
\text { and } \\
\text { porcine } \\
\text { stable- } \\
\text { equine } \\
\text { kidney } \\
\text { cells }\end{array}$ & $\begin{array}{l}10^{4.5 \pm 0.1} \\
\mathrm{CCID}_{50} / \mathrm{mL}\end{array}$ & $\begin{array}{l}\text { Heparinized } \\
\text { rabbit }\end{array}$ & $\begin{array}{c}\text { Glass } \\
\text { mem- } \\
\text { brane } \\
\text { feeder } \\
\text { with pig } \\
\text { intestine }\end{array}$ & $28^{\circ} \mathrm{C}$ & $13 / 14$ & $11-48$ & $27 \%$ & $8 \%$ & $27 \%$ & $\begin{array}{c}\text { Porcine } \\
\text { stable- } \\
\text { equine } \\
\text { kidney } \\
\text { cells }\end{array}$ & [93] \\
\hline Aedes vexans & Guam & $\begin{array}{c}\text { ND (Oki- } \\
\text { nawa, } \\
\text { human } \\
1945)\end{array}$ & ND & ND & NA & $\begin{array}{l}\text { Inoculated } \\
\text { mice }\end{array}$ & ND & ND & ND & ND & ND & Successful & $\begin{array}{l}\text { Development } \\
\text { of en- } \\
\text { cephalitis } \\
\text { in } \\
\text { laboratory- } \\
\text { reared } \\
\text { mice }\end{array}$ & [99] \\
\hline $\begin{array}{c}\text { Aedes } \\
\text { vexans } \\
\text { nipponii }\end{array}$ & $\begin{array}{l}\text { Japan, } \\
\text { Sapporo }\end{array}$ & $\begin{array}{c}\text { G-III } \\
\text { (JANAr- } \\
5681)\end{array}$ & $\begin{array}{l}\text { C6/36 } \\
\text { cells }\end{array}$ & $\begin{array}{c}6.2 \\
\mathrm{PFU} / \mathrm{mL} \\
\text { (blood) } \\
\text { and } 3.7 \\
\mathrm{PFU} / \mathrm{mL} \\
\text { (chicken) }\end{array}$ & ND & $\begin{array}{l}\text { Cotton } \\
\text { pledgets } \\
\text { or } \\
\text { viremic } \\
\text { chicken }\end{array}$ & $\begin{array}{l}20 \text { or } \\
28^{\circ} \mathrm{C}\end{array}$ & $0-20$ & 12 & $25 \%$ & ND & ND & $\begin{array}{c}\text { BHK-21 } \\
\text { cells and } \\
\text { IFA }\end{array}$ & [98] \\
\hline
\end{tabular}


Table 3. Cont.

\begin{tabular}{|c|c|c|c|c|c|c|c|c|c|c|c|c|c|c|}
\hline $\begin{array}{l}\text { Mosquito } \\
\text { Species }\end{array}$ & $\begin{array}{l}\text { Origin of } \\
\text { Mosquito } \\
\text { Colony }\end{array}$ & $\begin{array}{l}\text { JEV } \\
\text { Strain } \\
\text { Used }\end{array}$ & $\begin{array}{l}\text { Cell } \\
\text { Type } \\
\text { Used for } \\
\text { Virus } \\
\text { Produc- } \\
\text { tion }\end{array}$ & $\begin{array}{c}\text { Virus } \\
\text { Titer in } \\
\text { Blood- } \\
\text { meal }\end{array}$ & $\begin{array}{l}\text { Blood } \\
\text { Origin }\end{array}$ & $\begin{array}{l}\text { Feeding } \\
\text { Method }\end{array}$ & $\begin{array}{l}\text { Inc. Tem- } \\
\text { perature }\end{array}$ & $\begin{array}{c}\text { Inc. } \\
\text { Period } \\
\text { (Days) }\end{array}$ & $\begin{array}{c}\# \\
\text { Mosquitoes }\end{array}$ & $\begin{array}{c}\% \\
\text { Infected } \\
*\end{array}$ & $\begin{array}{c}\% \\
\text { Dissemi- } \\
\text { nated } \\
* *\end{array}$ & $\begin{array}{l}\% \text { Trans- } \\
\text { mission } \\
\text { Compe- } \\
\text { tent } \\
* * *\end{array}$ & $\begin{array}{l}\text { Detec- } \\
\text { tion } \\
\text { Method }\end{array}$ & $\begin{array}{l}\text { Refer- } \\
\text { ence }\end{array}$ \\
\hline \multirow[t]{2}{*}{$\frac{\text { Aedes }}{\text { vigilax }}$} & $\begin{array}{l}\text { Australia, } \\
\text { Cairns } \\
\text { (wild) }\end{array}$ & $\begin{array}{c}\text { G-II } \\
(\mathrm{TS} 3306)\end{array}$ & $\begin{array}{c}\text { C6/36 } \\
\text { and } \\
\text { porcine } \\
\text { stable- } \\
\text { equine } \\
\text { kidney } \\
\text { cells }\end{array}$ & $\begin{array}{l}10^{4.5 \pm 0.1} \\
\mathrm{CCID}_{50} / \mathrm{mL}\end{array}$ & $\begin{array}{l}\text { Heparinized } \\
\text { rabbit }\end{array}$ & $\begin{array}{c}\text { Glass } \\
\text { mem- } \\
\text { brane } \\
\text { feeder } \\
\text { with pig } \\
\text { intestine } \\
\text { mem- } \\
\text { brane }\end{array}$ & $28^{\circ} \mathrm{C}$ & $14-15$ & 75 & $57 \%$ & ND & $17 \%$ & $\begin{array}{l}\text { Detection } \\
\text { of virus } \\
\text { in brain } \\
\text { aspirates } \\
\text { of } \\
\text { recipient } \\
\text { suckling } \\
\text { mice }\end{array}$ & [93] \\
\hline & $\begin{array}{l}\text { Australia, } \\
\text { Redlands } \\
\text { Shire }\end{array}$ & $\begin{array}{c}\text { G-II } \\
\text { (TS3306) }\end{array}$ & $\begin{array}{l}\text { C6/36 } \\
\text { and } \\
\text { porcine } \\
\text { stable- } \\
\text { equine } \\
\text { kidney } \\
\text { cells }\end{array}$ & $\begin{array}{c}10^{7.1 \pm 0.1} \\
\mathrm{CCID}_{50} / \mathrm{mL}\end{array}$ & $\begin{array}{l}\text { Heparinized } \\
\text { rabbit }\end{array}$ & $\begin{array}{c}\text { Glass } \\
\text { mem- } \\
\text { brane } \\
\text { feeder } \\
\text { with pig } \\
\text { intestine }\end{array}$ & $28^{\circ} \mathrm{C}$ & $9-13$ & $4-62$ & $19-39 \%$ & $18-39 \%$ & $0 \%$ & $\begin{array}{c}\text { Porcine } \\
\text { stable- } \\
\text { equine } \\
\text { kidney } \\
\text { cells }\end{array}$ & [93] \\
\hline$\frac{\text { Anopheles }}{\underline{\text { tessellatus }}}$ & India & $\begin{array}{c}\text { G-I } \\
(733913)\end{array}$ & NA & ND & $\begin{array}{l}\text { Viremic } \\
\text { chickens }\end{array}$ & NA & ND & 11 & 13 & ND & ND & $31 \%$ & $\begin{array}{l}\text { Transmission } \\
\text { to } \\
\text { chickens }\end{array}$ & [100] \\
\hline $\begin{array}{l}\text { Armigeres } \\
\text { subalbatus } \\
\end{array}$ & $\begin{array}{l}\text { Taiwan, } \\
\text { Liu-Chiu }\end{array}$ & $\begin{array}{l}\text { G-III } \\
\text { (T1P1) }\end{array}$ & $\mathrm{C} 6 / 36$ & $\begin{array}{c}1.25 \times \\
10^{7} \\
\mathrm{PFU} / \mathrm{mL}\end{array}$ & Rabbit & $\begin{array}{l}\text { Drop of } \\
\text { blood }\end{array}$ & ND & $1-20$ & $8-14$ & ND & ND & $0-79 \%$ & IFAT & [101] \\
\hline
\end{tabular}


Table 3. Cont.

\begin{tabular}{|c|c|c|c|c|c|c|c|c|c|c|c|c|c|c|}
\hline $\begin{array}{l}\text { Mosquito } \\
\text { Species }\end{array}$ & $\begin{array}{c}\text { Origin of } \\
\text { Mosquito } \\
\text { Colony }\end{array}$ & $\begin{array}{c}\text { JEV } \\
\text { Strain } \\
\text { Used }\end{array}$ & $\begin{array}{l}\text { Cell } \\
\text { Type } \\
\text { Used for } \\
\text { Virus } \\
\text { Produc- } \\
\text { tion }\end{array}$ & $\begin{array}{c}\text { Virus } \\
\text { Titer in } \\
\text { Blood- } \\
\text { meal }\end{array}$ & $\begin{array}{l}\text { Blood } \\
\text { Origin }\end{array}$ & $\begin{array}{l}\text { Feeding } \\
\text { Method }\end{array}$ & $\begin{array}{l}\text { Inc. Tem- } \\
\text { perature }\end{array}$ & $\begin{array}{l}\text { Inc. } \\
\text { Period } \\
\text { (Days) }\end{array}$ & $\begin{array}{c}\# \\
\text { Mosquitoes }\end{array}$ & $\begin{array}{c}\% \\
\text { Infected } \\
*\end{array}$ & $\begin{array}{c}\% \\
\text { Dissemi- } \\
\text { nated } \\
* *\end{array}$ & $\begin{array}{l}\text { \% Trans- } \\
\text { mission } \\
\text { Compe- } \\
\text { tent } \\
* * *\end{array}$ & $\begin{array}{l}\text { Detec- } \\
\text { tion } \\
\text { Method }\end{array}$ & $\begin{array}{l}\text { Refer- } \\
\text { ence }\end{array}$ \\
\hline \multirow[b]{2}{*}{$\frac{\text { Culex }}{\text { annulirostris }}$} & Guam & $\begin{array}{l}\text { ND (Oki- } \\
\text { nawa, } \\
\text { human } \\
\text { 1945) }\end{array}$ & ND & ND & NA & $\begin{array}{l}\text { Inoculated } \\
\text { mice }\end{array}$ & ND & ND & ND & ND & ND & Successful & $\begin{array}{l}\text { encephalitis } \\
\text { in } \\
\text { laboratory- } \\
\text { reared } \\
\text { mice }\end{array}$ & [99] \\
\hline & $\begin{array}{l}\text { Australia, } \\
\text { Bamaga } \\
\text { and } \\
\text { Cairns } \\
\text { (wild) }\end{array}$ & $\begin{array}{c}\text { G-II } \\
(\mathrm{TS} 3306)\end{array}$ & $\begin{array}{c}\text { C6/36 } \\
\text { and } \\
\text { porcine } \\
\text { stable- } \\
\text { equine } \\
\text { kidney } \\
\text { cells }\end{array}$ & $\begin{array}{c}10^{4.5 \pm 0.1} \\
\mathrm{CCID}_{50} / \mathrm{mL}\end{array}$ & $\begin{array}{l}\text { Heparinized } \\
\text { rabbit }\end{array}$ & $\begin{array}{c}\text { Glass } \\
\text { mem- } \\
\text { brane } \\
\text { feeder } \\
\text { with pig } \\
\text { intestine } \\
\text { mem- } \\
\text { brane }\end{array}$ & $28^{\circ} \mathrm{C}$ & $14-15$ & $25-57$ & $93 \%$ & ND & $56 \%$ & $\begin{array}{l}\text { Detection } \\
\text { of virus } \\
\text { in brain } \\
\text { aspirates } \\
\text { of } \\
\text { recipient } \\
\text { suckling } \\
\text { mice }\end{array}$ & [93] \\
\hline \multirow{3}{*}{$\frac{\frac{\text { Culex }}{\text { bitaenior- }}}{\text { hynchus }}$} & India & $\begin{array}{c}\text { G-I } \\
(733913)\end{array}$ & NA & ND & $\begin{array}{c}\text { Viremic } \\
\text { ducklings }\end{array}$ & NA & ND & $9-12$ & 1 & $9-100 \%$ & ND & $100 \%$ & $\begin{array}{c}\text { Transmission } \\
\text { to } \\
\text { ducklings }\end{array}$ & [102] \\
\hline & India & $\begin{array}{c}\text { G-I } \\
(733913)\end{array}$ & NA & ND & $\begin{array}{l}\text { Viremic } \\
\text { chickens }\end{array}$ & NA & ND & $10-12$ & 24 & $47-62 \%$ & ND & $64-89 \%$ & $\begin{array}{l}\text { Transmission } \\
\text { to } \\
\text { chickens }\end{array}$ & [103] \\
\hline & India & $\begin{array}{c}\text { G-I } \\
(733913)\end{array}$ & NA & ND & $\begin{array}{l}\text { Viremic } \\
\text { chickens }\end{array}$ & NA & ND & ND & ND & ND & ND & Successful & $\begin{array}{l}\text { Transmission } \\
\text { to } \\
\text { chickens }\end{array}$ & [104] \\
\hline
\end{tabular}


Table 3. Cont.

\begin{tabular}{|c|c|c|c|c|c|c|c|c|c|c|c|c|c|c|}
\hline $\begin{array}{l}\text { Mosquito } \\
\text { Species }\end{array}$ & $\begin{array}{l}\text { Origin of } \\
\text { Mosquito } \\
\text { Colony }\end{array}$ & $\begin{array}{l}\text { JEV } \\
\text { Strain } \\
\text { Used }\end{array}$ & $\begin{array}{l}\text { Cell } \\
\text { Type } \\
\text { Used for } \\
\text { Virus } \\
\text { Produc- } \\
\text { tion }\end{array}$ & $\begin{array}{c}\text { Virus } \\
\text { Titer in } \\
\text { Blood- } \\
\text { meal }\end{array}$ & $\begin{array}{l}\text { Blood } \\
\text { Origin }\end{array}$ & $\begin{array}{l}\text { Feeding } \\
\text { Method }\end{array}$ & $\begin{array}{l}\text { Inc. Tem- } \\
\text { perature }\end{array}$ & $\begin{array}{c}\text { Inc. } \\
\text { Period } \\
\text { (Days) }\end{array}$ & $\begin{array}{c}\# \\
\text { Mosquitoes }\end{array}$ & $\begin{array}{c}\% \\
\text { Infected } \\
*\end{array}$ & $\begin{array}{c}\% \\
\text { Dissemi- } \\
\text { nated } \\
* *\end{array}$ & $\begin{array}{c}\% \text { Trans- } \\
\text { mission } \\
\text { Compe- } \\
\text { tent } \\
* * *\end{array}$ & $\begin{array}{l}\text { Detec- } \\
\text { tion } \\
\text { Method }\end{array}$ & $\begin{array}{l}\text { Refer- } \\
\text { ence }\end{array}$ \\
\hline \multirow{2}{*}{$\begin{array}{c}\text { Culex } \\
\text { fuscocephala } \\
\end{array}$} & Taiwan & $\begin{array}{c}\text { ND } \\
\text { (TaiAn } \\
171)\end{array}$ & NA & $\begin{array}{c}10^{-0.89}- \\
10^{-1.91} \\
\text { mouse } \\
\text { LD50 }\end{array}$ & NA & $\begin{array}{l}\text { Viremic } \\
\text { pigs }\end{array}$ & ND & $12-21$ & ND & ND & ND & $0-68 \%$ & $\begin{array}{l}\text { Transmission } \\
\text { to } \\
\text { chickens }\end{array}$ & [105] \\
\hline & $\begin{array}{l}\text { Thailand, } \\
\text { Chieng- } \\
\text { mai } \\
\text { valley }\end{array}$ & $\begin{array}{c}\text { ND } \\
\text { (BKM- } \\
984-70)\end{array}$ & NA & $\begin{array}{l}8 \text { PFU per } \\
\text { mosquito }\end{array}$ & NA & $\begin{array}{l}\text { Viremic } \\
\text { chicken }\end{array}$ & ND & $10-27$ & ND & $95-100 \%$ & ND & $10-20 \%$ & $\begin{array}{c}\text { Transmission } \\
\text { to } \\
\text { chickens }\end{array}$ & [106] \\
\hline \multirow[t]{2}{*}{$\frac{\text { Culex }}{\text { gelidus }}$} & $\begin{array}{l}\text { Australia, } \\
\text { Cairns } \\
\text { (wild) }\end{array}$ & $\begin{array}{c}\text { G-II } \\
(\mathrm{TS} 3306)\end{array}$ & $\begin{array}{l}\text { C6/36 } \\
\text { and } \\
\text { porcine } \\
\text { stable- } \\
\text { equine } \\
\text { kidney } \\
\text { cells }\end{array}$ & $\begin{array}{l}10^{4.5 \pm 0.1} \\
\mathrm{CCID}_{50} / \mathrm{mL}\end{array}$ & $\begin{array}{l}\text { Heparinized } \\
\text { rabbit }\end{array}$ & $\begin{array}{c}\text { Glass } \\
\text { mem- } \\
\text { brane } \\
\text { feeder } \\
\text { with pig } \\
\text { intestine } \\
\text { mem- } \\
\text { brane }\end{array}$ & $28^{\circ} \mathrm{C}$ & $14-15$ & 4 & $100 \%$ & ND & $100 \%$ & $\begin{array}{l}\text { Detection } \\
\text { of virus } \\
\text { in brain } \\
\text { aspirates } \\
\text { of } \\
\text { recipient } \\
\text { suckling } \\
\text { mice }\end{array}$ & [93] \\
\hline & $\begin{array}{c}\text { US, } \\
\text { Malayan } \\
\text { strain }\end{array}$ & $\begin{array}{c}\text { ND } \\
(\text { FM380) }\end{array}$ & ND & ND & NA & $\begin{array}{l}\text { Viraemic } \\
\text { chicken }\end{array}$ & $27^{\circ} \mathrm{C}$ & $6-21$ & $4-43$ & ND & ND & $8-63 \%$ & $\begin{array}{l}\text { Development } \\
\text { of en- } \\
\text { cephalitis } \\
\text { in } \\
\text { laboratory- } \\
\text { reared } \\
\text { mice }\end{array}$ & [107] \\
\hline
\end{tabular}


Table 3. Cont.

\begin{tabular}{|c|c|c|c|c|c|c|c|c|c|c|c|c|c|c|}
\hline $\begin{array}{l}\text { Mosquito } \\
\text { Species }\end{array}$ & $\begin{array}{l}\text { Origin of } \\
\text { Mosquito } \\
\text { Colony }\end{array}$ & $\begin{array}{l}\text { JEV } \\
\text { Strain } \\
\text { Used }\end{array}$ & $\begin{array}{l}\text { Cell } \\
\text { Type } \\
\text { Used for } \\
\text { Virus } \\
\text { Produc- } \\
\text { tion }\end{array}$ & $\begin{array}{c}\text { Virus } \\
\text { Titer in } \\
\text { Blood- } \\
\text { meal }\end{array}$ & $\begin{array}{l}\text { Blood } \\
\text { Origin }\end{array}$ & $\begin{array}{l}\text { Feeding } \\
\text { Method }\end{array}$ & $\begin{array}{l}\text { Inc. Tem- } \\
\text { perature }\end{array}$ & $\begin{array}{c}\text { Inc. } \\
\text { Period } \\
\text { (Days) }\end{array}$ & $\begin{array}{c}\# \\
\text { Mosquitoes }\end{array}$ & $\begin{array}{c}\% \\
\text { Infected } \\
*\end{array}$ & $\begin{array}{c}\% \\
\text { Dissemi- } \\
\text { nated } \\
* *\end{array}$ & $\begin{array}{c}\% \text { Trans- } \\
\text { mission } \\
\text { Compe- } \\
\text { tent } \\
* * *\end{array}$ & $\begin{array}{l}\text { Detec- } \\
\text { tion } \\
\text { Method }\end{array}$ & $\begin{array}{l}\text { Refer- } \\
\text { ence }\end{array}$ \\
\hline \multirow{3}{*}{$\frac{\text { Culex }}{\text { pipiens }}$} & $\begin{array}{l}\text { China, } \\
\text { Shangai }\end{array}$ & $\begin{array}{c}\text { G-I (SH7), } \\
\text { G-III } \\
\text { (SH15) }\end{array}$ & $\begin{array}{l}\text { C6/36 } \\
\text { cells }\end{array}$ & $\begin{array}{c}4.9-8.3 \\
\log \\
\text { TCID }_{50} / \mathrm{mL}\end{array}$ & $\begin{array}{l}\text { Defibrinated } \\
\text { mice }\end{array}$ & $\begin{array}{l}\text { Hemotek } \\
\text { mem- } \\
\text { brane } \\
\text { feeding } \\
\text { and } \\
\text { cotton } \\
\text { pledgets }\end{array}$ & ND & $7-14$ & $11-52$ & $45 \%$ & $30 \% \diamond$ & $23 \%$ & $\begin{array}{l}\text { TCID }_{50} \\
\text { assay on } \\
\text { BHK-21 } \\
\text { cells }\end{array}$ & [108] \\
\hline & $\begin{array}{l}\text { Pennsylvania, } \\
\text { US }\end{array}$ & $\begin{array}{c}\text { G-III } \\
\text { (Nakayama) }\end{array}$ & $\begin{array}{l}\text { C6/36 } \\
\text { cells }\end{array}$ & $\begin{array}{l}8.1 \log _{10} \\
\mathrm{PFU} / \mathrm{mL}\end{array}$ & Goose & $\begin{array}{l}\text { Cotton } \\
\text { pledgets }\end{array}$ & $26^{\circ} \mathrm{C}$ & 14 & $5-50$ & $10 \%$ & $40 \%$ & $0 \%$ & Vero cells & [84] \\
\hline & $\begin{array}{c}\text { UK, } \\
\text { Liverpool }\end{array}$ & $\begin{array}{c}\text { G-II } \\
(\mathrm{CNS138-} \\
11)\end{array}$ & Vero cells & $\begin{array}{c}10^{6} \\
\mathrm{PFU} / \mathrm{mL}\end{array}$ & $\begin{array}{l}\text { Heparinized } \\
\text { human }\end{array}$ & $\begin{array}{l}\text { Hemotek } \\
\text { with } \\
\text { collagen } \\
\text { mem- } \\
\text { brane }\end{array}$ & $18^{\circ} \mathrm{C}$ & 21 & 18 & $100 \%$ & ND & $72 \%$ & $\begin{array}{c}\text { Semi- } \\
\text { quantitative } \\
\text { qPCR }\end{array}$ & [89] \\
\hline $\begin{array}{c}\text { Culex } \\
\text { pipiens } \\
\text { molestus } \\
\text { (Forsskål, } \\
\text { 1775) }\end{array}$ & $\begin{array}{l}\text { Taiwan, } \\
\text { Taipei }\end{array}$ & $\mathrm{ND}(\mathrm{SH})$ & $\begin{array}{c}\mathrm{C} 6 / 36 \\
\text { cells and } \\
\text { suckling } \\
\text { mice } \\
\text { brains }\end{array}$ & $\begin{array}{l}5.54 \log _{10} \\
\mathrm{PFU} / \mathrm{mL}\end{array}$ & $\begin{array}{l}\text { Defibrinated } \\
\text { rabbit }\end{array}$ & $\begin{array}{l}\text { Hanging } \\
\text { drop } \\
\text { method }\end{array}$ & $28-32{ }^{\circ} \mathrm{C}$ & 14 & $3-5$ & ND & ND & $91 \%$ & $\begin{array}{l}\text { Inoculation } \\
\text { of brain } \\
\text { tissue } \\
\text { aspirates } \\
\text { from } \\
\text { recipient } \\
\text { mice on } \\
\text { to } \\
\text { C6/36 cells }\end{array}$ & [109] \\
\hline
\end{tabular}


Table 3. Cont.

\begin{tabular}{|c|c|c|c|c|c|c|c|c|c|c|c|c|c|c|}
\hline $\begin{array}{l}\text { Mosquito } \\
\text { Species }\end{array}$ & $\begin{array}{c}\text { Origin of } \\
\text { Mosquito } \\
\text { Colony }\end{array}$ & $\begin{array}{c}\text { JEV } \\
\text { Strain } \\
\text { Used }\end{array}$ & $\begin{array}{l}\text { Cell } \\
\text { Type } \\
\text { Used for } \\
\text { Virus } \\
\text { Produc- } \\
\text { tion }\end{array}$ & $\begin{array}{c}\text { Virus } \\
\text { Titer in } \\
\text { Blood- } \\
\text { meal }\end{array}$ & $\begin{array}{l}\text { Blood } \\
\text { Origin }\end{array}$ & $\begin{array}{l}\text { Feeding } \\
\text { Method }\end{array}$ & $\begin{array}{l}\text { Inc. Tem- } \\
\text { perature }\end{array}$ & $\begin{array}{c}\text { Inc. } \\
\text { Period } \\
\text { (Days) }\end{array}$ & $\begin{array}{c}\# \\
\text { Mosquitoes }\end{array}$ & $\begin{array}{c}\% \\
\text { Infected } \\
*\end{array}$ & $\begin{array}{c}\% \\
\text { Dissemi- } \\
\text { nated } \\
* *\end{array}$ & $\begin{array}{c}\text { \% Trans- } \\
\text { mission } \\
\text { Compe- } \\
\text { tent } \\
* * *\end{array}$ & $\begin{array}{l}\text { Detec- } \\
\text { tion } \\
\text { Method }\end{array}$ & $\begin{array}{l}\text { Refer- } \\
\text { ence }\end{array}$ \\
\hline & $\begin{array}{c}\text { US, } \\
\text { Oakland }\end{array}$ & $\begin{array}{c}\text { G-III } \\
\text { (Nakayama) }\end{array}$ & ND & ND & $\begin{array}{l}\text { Defibrinated } \\
\text { rabbit }\end{array}$ & $\begin{array}{l}\text { Cotton } \\
\text { pledgets }\end{array}$ & $27^{\circ} \mathrm{C}$ & $7-20$ & 1 & ND & ND & $22 \% \#$ & $\begin{array}{l}\text { Develop- } \\
\text { ment of } \\
\text { en- } \\
\text { cephalitis } \\
\text { in } \\
\text { laboratory- } \\
\text { reared } \\
\text { mice }\end{array}$ & [96] \\
\hline & $\begin{array}{l}\text { Tashkent, } \\
\text { Uzbek- } \\
\text { istan }\end{array}$ & $\begin{array}{c}\mathrm{ND} \\
\text { (ROK- } \\
2.0028)\end{array}$ & Vero cells & $\begin{array}{c}10^{4} \\
\mathrm{PFU} / \mathrm{mL}\end{array}$ & NA & $\begin{array}{l}\text { Viremic } \\
\text { chicken }\end{array}$ & $26^{\circ} \mathrm{C}$ & $16-27$ & $13-53$ & $47-56 \%$ & $25-26 \%$ & $8 \%$ & Vero cells & [110] \\
\hline \multirow[t]{2}{*}{$\frac{\frac{\text { Culex }}{\text { pipiens }}}{\text { pallens }}$} & Japan & $\begin{array}{c}\text { G-III } \\
\text { (JaGAr } \\
01)\end{array}$ & ND & ND & NA & $\begin{array}{l}\text { Infected } \\
\text { lizards }\end{array}$ & ND & ND & ND & ND & ND & Successful & $\begin{array}{l}\text { Transmission } \\
\text { from } \\
\text { infected } \\
\text { mosquitoes } \\
\text { to unin- } \\
\text { fected } \\
\text { lizards } \\
\text { and from } \\
\text { infected } \\
\text { lizards to } \\
\text { mice via } \\
\text { mosquito }\end{array}$ & [111] \\
\hline & $\begin{array}{c}\text { Japan, } \\
\text { Sapporo }\end{array}$ & $\begin{array}{c}\text { G-III } \\
\text { (JANAr- } \\
5681 \text { ) }\end{array}$ & $\begin{array}{l}\mathrm{C} 6 / 36 \\
\text { cells }\end{array}$ & $\begin{array}{c}6.2 \\
\mathrm{PFU} / \mathrm{mL} \\
\text { (blood) } \\
\text { and } 3.7 \\
\mathrm{PFU} / \mathrm{mL} \\
\text { (chicken) }\end{array}$ & ND & $\begin{array}{l}\text { Cotton } \\
\text { pledgets } \\
\text { or } \\
\text { viremic } \\
\text { chicken }\end{array}$ & $\begin{array}{l}20 \text { or } \\
28^{\circ} \mathrm{C}\end{array}$ & $0-20$ & 10 & $30 \%$ & ND & ND & $\begin{array}{c}\text { BHK-21 } \\
\text { cells and } \\
\text { IFA }\end{array}$ & [98] \\
\hline
\end{tabular}


Table 3. Cont.

\begin{tabular}{|c|c|c|c|c|c|c|c|c|c|c|c|c|c|c|}
\hline $\begin{array}{l}\text { Mosquito } \\
\text { Species }\end{array}$ & $\begin{array}{l}\text { Origin of } \\
\text { Mosquito } \\
\text { Colony }\end{array}$ & $\begin{array}{l}\text { JEV } \\
\text { Strain } \\
\text { Used }\end{array}$ & $\begin{array}{l}\text { Cell } \\
\text { Type } \\
\text { Used for } \\
\text { Virus } \\
\text { Produc- } \\
\text { tion }\end{array}$ & $\begin{array}{c}\text { Virus } \\
\text { Titer in } \\
\text { Blood- } \\
\text { meal }\end{array}$ & $\begin{array}{c}\text { Blood } \\
\text { Origin }\end{array}$ & $\begin{array}{l}\text { Feeding } \\
\text { Method }\end{array}$ & $\begin{array}{l}\text { Inc. Tem- } \\
\text { perature }\end{array}$ & $\begin{array}{l}\text { Inc. } \\
\text { Period } \\
\text { (Days) }\end{array}$ & $\begin{array}{c}\# \\
\text { Mosquitoes }\end{array}$ & $\begin{array}{c}\% \\
\text { Infected } \\
*\end{array}$ & $\begin{array}{c}\% \\
\text { Dissemi- } \\
\text { nated } \\
* *\end{array}$ & $\begin{array}{c}\text { \% Trans- } \\
\text { mission } \\
\text { Compe- } \\
\text { tent } \\
* * *\end{array}$ & $\begin{array}{l}\text { Detec- } \\
\text { tion } \\
\text { Method }\end{array}$ & $\begin{array}{l}\text { Refer- } \\
\text { ence }\end{array}$ \\
\hline & $\begin{array}{c}\text { Korea, } \\
\text { Gyeonggi } \\
\text { Province }\end{array}$ & $\begin{array}{c}\mathrm{ND} \\
\text { (ROK- } \\
2.0028)\end{array}$ & Vero cells & $\begin{array}{c}10^{5.2} \\
\mathrm{PFU} / \mathrm{mL}\end{array}$ & NA & $\begin{array}{l}\text { Viremic } \\
\text { chicken }\end{array}$ & $26^{\circ} \mathrm{C}$ & $13-34$ & 32 & $6 \%$ & $0 \%$ & ND & Vero cells & [112] \\
\hline $\begin{array}{l}\text { Culex } \\
\text { pipiens } \\
\text { pipiens }\end{array}$ & $\begin{array}{c}\text { UK, } \\
\text { Caldbeck }\end{array}$ & $\begin{array}{c}\text { G-III } \\
\text { (SA14) }\end{array}$ & Vero cells & $\begin{array}{l}1.8 \times 10^{6} \\
\mathrm{PFU} / \mathrm{mL}\end{array}$ & $\begin{array}{l}\text { Defibrinated } \\
\text { horse }\end{array}$ & $\begin{array}{c}\text { Hemotek } \\
\text { with } \\
\text { parafilm } \\
\text { mem- } \\
\text { brane }\end{array}$ & $\begin{array}{l}20 \text { and } \\
25^{\circ} \mathrm{C}\end{array}$ & 14 & $20-56$ & $69-90 \%$ & $12-70 \%$ & $0-70 \%$ & $\begin{array}{l}\text { RT-PCR } \\
\text { and } \\
\text { isolation } \\
\text { in Vero } \\
\text { cells }\end{array}$ & [15] \\
\hline \multirow[b]{2}{*}{$\frac{\frac{\text { Culex }}{\text { pseudov- }}}{\underline{\text { ishnui }}}$} & India & $\begin{array}{c}\text { G-III } \\
\text { (P20778) }\end{array}$ & NA & ND & $\begin{array}{l}\text { Viremic } \\
\text { chicks }\end{array}$ & NA & ND & 8 & ND & ND & $60 \%$ & $75 \%$ & $\begin{array}{l}\text { Transmission } \\
\text { to } \\
\text { chickens }\end{array}$ & [113] \\
\hline & India & $\begin{array}{c}\text { G-III } \\
\text { (P20778) }\end{array}$ & NA & ND & ND & ND & ND & $1-10$ & ND & ND & $49 \%$ & $51 \%$ & $\begin{array}{l}\text { Antigen } \\
\text { detection } \\
\text { is } \\
\text { mosquito } \\
\text { heads resp. } \\
\text { salivary } \\
\text { glands }\end{array}$ & [114] \\
\hline
\end{tabular}


Table 3. Cont.

\begin{tabular}{|c|c|c|c|c|c|c|c|c|c|c|c|c|c|c|}
\hline $\begin{array}{l}\text { Mosquito } \\
\text { Species }\end{array}$ & $\begin{array}{c}\text { Origin of } \\
\text { Mosquito } \\
\text { Colony }\end{array}$ & $\begin{array}{c}\text { JEV } \\
\text { Strain } \\
\text { Used }\end{array}$ & $\begin{array}{l}\text { Cell } \\
\text { Type } \\
\text { Used for } \\
\text { Virus } \\
\text { Produc- } \\
\text { tion }\end{array}$ & $\begin{array}{c}\text { Virus } \\
\text { Titer in } \\
\text { Blood- } \\
\text { meal }\end{array}$ & $\begin{array}{l}\text { Blood } \\
\text { Origin }\end{array}$ & $\begin{array}{l}\text { Feeding } \\
\text { Method }\end{array}$ & $\begin{array}{l}\text { Inc. Tem- } \\
\text { perature }\end{array}$ & $\begin{array}{c}\text { Inc. } \\
\text { Period } \\
\text { (Days) }\end{array}$ & $\begin{array}{c}\# \\
\text { Mosquitoes }\end{array}$ & $\begin{array}{c}\% \\
\text { Infected } \\
*\end{array}$ & $\begin{array}{c}\% \\
\text { Dissemi- } \\
\text { nated } \\
* *\end{array}$ & $\begin{array}{l}\text { \% Trans- } \\
\text { mission } \\
\text { Compe- } \\
\text { tent } \\
* * *\end{array}$ & $\begin{array}{l}\text { Detec- } \\
\text { tion } \\
\text { Method }\end{array}$ & $\begin{array}{l}\text { Refer- } \\
\text { ence }\end{array}$ \\
\hline \multirow{5}{*}{$\frac{\frac{\text { Culex }}{\text { quinquefa- }}}{\text { asciatus }}$} & $\begin{array}{l}\text { Australia, } \\
\text { Mareeba } \\
\text { (wild) }\end{array}$ & $\begin{array}{c}\text { G-II } \\
(\text { TS3306) }\end{array}$ & $\begin{array}{l}\text { C6/36 } \\
\text { and } \\
\text { porcine } \\
\text { stable- } \\
\text { equine } \\
\text { kidney } \\
\text { cells }\end{array}$ & $\begin{array}{c}10^{4.5 \pm 0.1} \\
\mathrm{CCID}_{50} / \mathrm{mL}\end{array}$ & $\begin{array}{l}\text { Heparinized } \\
\text { rabbit } \\
\text { blood }\end{array}$ & $\begin{array}{c}\text { Glass } \\
\text { mem- } \\
\text { brane } \\
\text { feeder } \\
\text { with pig } \\
\text { intestine } \\
\text { mem- } \\
\text { brane }\end{array}$ & $28^{\circ} \mathrm{C}$ & $14-15$ & 27 & $56 \%$ & ND & $0 \%$ & $\begin{array}{c}\text { Detection } \\
\text { of virus } \\
\text { in brain } \\
\text { aspirates } \\
\text { of } \\
\text { recipient } \\
\text { suckling } \\
\text { mice }\end{array}$ & [93] \\
\hline & $\begin{array}{l}\text { Australia, } \\
\text { Gold } \\
\text { coast }\end{array}$ & $\begin{array}{c}\text { G-II } \\
(\text { TS3306) }\end{array}$ & $\begin{array}{l}\text { C6/36 } \\
\text { and } \\
\text { porcine } \\
\text { stable- } \\
\text { equine } \\
\text { kidney } \\
\text { cells }\end{array}$ & $\begin{array}{c}10^{4.5 \pm 0.1} \\
\mathrm{CCID}_{50} / \mathrm{mL}\end{array}$ & $\begin{array}{l}\text { Heparinized } \\
\text { rabbit }\end{array}$ & $\begin{array}{l}\text { Glass } \\
\text { mem- } \\
\text { brane } \\
\text { feeder } \\
\text { with pig } \\
\text { intestine }\end{array}$ & $28^{\circ} \mathrm{C}$ & $17 / 19$ & $8-51$ & $98 \%$ & $28 \%$ & $50 \%$ & $\begin{array}{c}\text { Porcine } \\
\text { stable- } \\
\text { equine } \\
\text { kidney } \\
\text { cells }\end{array}$ & [93] \\
\hline & $\begin{array}{l}\text { New- } \\
\text { Zealand, } \\
\text { Welling- } \\
\text { ton }\end{array}$ & $\begin{array}{c}\text { G-III } \\
\text { (Nakayama) }\end{array}$ & $\begin{array}{l}\text { C6/36 } \\
\text { cells }\end{array}$ & $\begin{array}{l}8.1 \log _{10} \\
\mathrm{PFU} / \mathrm{mL}\end{array}$ & Goose & $\begin{array}{l}\text { Cotton } \\
\text { pledgets }\end{array}$ & $24{ }^{\circ} \mathrm{C}$ & 14 & $6-36$ & $17 \%$ & $0 \%$ & ND & Vero cells & [84] \\
\hline & $\begin{array}{c}\text { US, } \\
\text { Rutgers }\end{array}$ & $\begin{array}{c}\text { G-III } \\
\text { (Nakayama) }\end{array}$ & $\begin{array}{l}\text { C6/36 } \\
\text { cells }\end{array}$ & $\begin{array}{l}8.1 \log _{10} \\
\mathrm{PFU} / \mathrm{mL}\end{array}$ & Goose & $\begin{array}{l}\text { Cotton } \\
\text { pledgets }\end{array}$ & $26^{\circ} \mathrm{C}$ & 14 & $43-50$ & $86 \%$ & $0 \%$ & $0 \%$ & Vero cells & [84] \\
\hline & Brazil & $\begin{array}{c}\text { G-V } \\
\text { (Muar) }\end{array}$ & Vero cells & $\begin{array}{c}4 \log _{10} \\
\mathrm{PFU} / \mathrm{mL}\end{array}$ & $\begin{array}{l}\text { Defibrinated } \\
\text { horse }\end{array}$ & $\begin{array}{c}\text { Hemotek } \\
\text { with } \\
\text { Parafilm } \\
\text { mem- } \\
\text { brane }\end{array}$ & $\begin{array}{l}23 \text { and } \\
28{ }^{\circ} \mathrm{C}\end{array}$ & $0-21$ & $3-32$ & $25-100 \%$ & $21-70 \%$ & $3-70 \%$ & Vero cells & [85] \\
\hline
\end{tabular}


Table 3. Cont.

\begin{tabular}{|c|c|c|c|c|c|c|c|c|c|c|c|c|c|c|}
\hline $\begin{array}{l}\text { Mosquito } \\
\text { Species }\end{array}$ & $\begin{array}{c}\text { Origin of } \\
\text { Mosquito } \\
\text { Colony }\end{array}$ & $\begin{array}{c}\text { JEV } \\
\text { Strain } \\
\text { Used }\end{array}$ & $\begin{array}{l}\text { Cell } \\
\text { Type } \\
\text { Used for } \\
\text { Virus } \\
\text { Produc- } \\
\text { tion }\end{array}$ & $\begin{array}{c}\text { Virus } \\
\text { Titer in } \\
\text { Blood- } \\
\text { meal }\end{array}$ & $\begin{array}{l}\text { Blood } \\
\text { Origin }\end{array}$ & $\begin{array}{l}\text { Feeding } \\
\text { Method }\end{array}$ & $\begin{array}{l}\text { Inc. Tem- } \\
\text { perature }\end{array}$ & $\begin{array}{l}\text { Inc. } \\
\text { Period } \\
\text { (Days) }\end{array}$ & $\begin{array}{c}\# \\
\text { Mosquitoes }\end{array}$ & $\begin{array}{c}\% \\
\text { Infected } \\
*\end{array}$ & $\begin{array}{c}\% \\
\text { Dissemi- } \\
\text { nated } \\
* *\end{array}$ & $\begin{array}{l}\text { \% Trans- } \\
\text { mission } \\
\text { Compe- } \\
\text { tent } \\
* * *\end{array}$ & $\begin{array}{l}\text { Detec- } \\
\text { tion } \\
\text { Method }\end{array}$ & $\begin{array}{l}\text { Refer- } \\
\text { ence }\end{array}$ \\
\hline & US & $\begin{array}{c}\text { G-III } \\
\text { (Nakayama) }\end{array}$ & ND & ND & $\begin{array}{l}\text { Defibrinated } \\
\text { rabbit }\end{array}$ & $\begin{array}{l}\text { Cotton } \\
\text { pledgets }\end{array}$ & $27^{\circ} \mathrm{C}$ & $11-25$ & $1-9$ & ND & ND & $3 \% \#$ & $\begin{array}{l}\text { Development } \\
\text { of en- } \\
\text { cephalitis } \\
\text { in } \\
\text { laboratory- } \\
\text { reared } \\
\text { mice }\end{array}$ & [96] \\
\hline Culex sitiens & $\begin{array}{l}\text { Australia, } \\
\text { Coomera } \\
\text { Islands }\end{array}$ & $\begin{array}{c}\text { G-II } \\
(\text { TS3306) }\end{array}$ & $\begin{array}{l}\text { C6/36 } \\
\text { and } \\
\text { porcine } \\
\text { stable- } \\
\text { equine } \\
\text { kidney } \\
\text { cells }\end{array}$ & $\begin{array}{l}10^{4.5 \pm 0.1} \\
\mathrm{CCID} \\
50 / \mathrm{mL}\end{array}$ & $\begin{array}{l}\text { Heparinized } \\
\text { rabbit }\end{array}$ & $\begin{array}{c}\text { Glass } \\
\text { mem- } \\
\text { brane } \\
\text { feeder } \\
\text { with pig } \\
\text { intestine }\end{array}$ & $28^{\circ} \mathrm{C}$ & $5-14$ & $15-36$ & $83-92 \%$ & $6-33 \%$ & $7-67 \%$ & $\begin{array}{c}\text { Porcine } \\
\text { stable- } \\
\text { equine } \\
\text { kidney } \\
\text { cells }\end{array}$ & [93] \\
\hline Culex tarsalis & US & $\begin{array}{c}\text { G-II } \\
\text { (Nakayama) }\end{array}$ & ND & ND & $\begin{array}{l}\text { Defibrinated } \\
\text { rabbit }\end{array}$ & $\begin{array}{l}\text { Cotton } \\
\text { pledgets }\end{array}$ & $27^{\circ} \mathrm{C}$ & $6-10$ & $1-12$ & ND & ND & $1 \%{ }^{\#}$ & $\begin{array}{l}\text { Development } \\
\text { of en- } \\
\text { cephalitis } \\
\text { in } \\
\text { laboratory- } \\
\text { reared } \\
\text { mice }\end{array}$ & [96] \\
\hline$\frac{\text { Culex }}{\text { tritaeniorh- }}$ & $\begin{array}{l}\text { Japan, } \\
\text { Sapporo }\end{array}$ & $\begin{array}{c}\text { G-III } \\
\text { (JANAr- } \\
5681)\end{array}$ & $\begin{array}{l}\text { C6/36 } \\
\text { cells }\end{array}$ & $\begin{array}{c}6.2 \\
\text { PFU/mL } \\
\text { (blood) } \\
\text { and } 3.7 \\
\mathrm{PFU} / \mathrm{mL} \\
\text { (chicken) }\end{array}$ & ND & $\begin{array}{l}\text { Cotton } \\
\text { pledgets } \\
\text { or } \\
\text { viremic } \\
\text { chicken }\end{array}$ & $\begin{array}{c}20 \text { or } 28 \\
{ }^{\circ} \mathrm{C}\end{array}$ & $0-20$ & 15 & $100 \%$ & ND & $100 \%$ & $\begin{array}{c}\text { BHK-21 } \\
\text { cells and } \\
\text { IFA }\end{array}$ & [98] \\
\hline
\end{tabular}


Table 3. Cont.

\begin{tabular}{|c|c|c|c|c|c|c|c|c|c|c|c|c|c|c|}
\hline $\begin{array}{l}\text { Mosquito } \\
\text { Species }\end{array}$ & $\begin{array}{l}\text { Origin of } \\
\text { Mosquito } \\
\text { Colony }\end{array}$ & $\begin{array}{c}\text { JEV } \\
\text { Strain } \\
\text { Used }\end{array}$ & $\begin{array}{l}\text { Cell } \\
\text { Type } \\
\text { Used for } \\
\text { Virus } \\
\text { Produc- } \\
\text { tion }\end{array}$ & $\begin{array}{c}\text { Virus } \\
\text { Titer in } \\
\text { Blood- } \\
\text { meal }\end{array}$ & $\begin{array}{c}\text { Blood } \\
\text { Origin }\end{array}$ & $\begin{array}{l}\text { Feeding } \\
\text { Method }\end{array}$ & $\begin{array}{l}\text { Inc. Tem- } \\
\text { perature }\end{array}$ & $\begin{array}{c}\text { Inc. } \\
\text { Period } \\
\text { (Days) }\end{array}$ & $\begin{array}{c}\# \\
\text { Mosquitoes }\end{array}$ & $\begin{array}{c}\% \\
\text { Infected } \\
*\end{array}$ & $\begin{array}{c}\% \\
\text { Dissemi- } \\
\text { nated } \\
* *\end{array}$ & $\begin{array}{l}\text { \% Trans- } \\
\text { mission } \\
\text { Compe- } \\
\text { tent } \\
* * *\end{array}$ & $\begin{array}{l}\text { Detec- } \\
\text { tion } \\
\text { Method }\end{array}$ & $\begin{array}{l}\text { Refer- } \\
\text { ence }\end{array}$ \\
\hline & $\begin{array}{l}\text { Japan, } \\
\text { Narita }\end{array}$ & $\begin{array}{c}\text { G-I } \\
\text { (17CxIT- } \\
\text { I4-D31), } 3 \\
\text { (JaGAr } \\
\text { 01) and 5 } \\
\text { (Muar) }\end{array}$ & $\begin{array}{l}\text { C6/36 } \\
\text { cells }\end{array}$ & $\begin{array}{c}8.9,8.6 \\
\text { and } 7.1 \\
\log _{10} \\
\mathrm{FFU} / \mathrm{mL}\end{array}$ & $\begin{array}{l}\text { Defibrinated } \\
\text { rabbit }\end{array}$ & $\begin{array}{c}\text { Hemotek } \\
\text { with pig } \\
\text { intestine } \\
\text { mem- } \\
\text { brane }\end{array}$ & $27^{\circ} \mathrm{C}$ & $7-14$ & $27-51$ & $85-99 \%$ & $81-96 \%$ & $76-89 \%$ & $\begin{array}{l}\text { RT-qPCR } \\
\text { or Vero } \\
\text { cells }\end{array}$ & [12] \\
\hline & $\begin{array}{c}\text { Korea, } \\
\text { Gyeonggi } \\
\text { Province }\end{array}$ & $\begin{array}{c}\mathrm{ND} \\
(\mathrm{ROK}- \\
2.0028)\end{array}$ & Vero cells & $\begin{array}{c}10^{4.3} \text { or } \\
10^{5.2}\end{array}$ & NA & $\begin{array}{l}\text { Viremic } \\
\text { chicken }\end{array}$ & $26^{\circ} \mathrm{C}$ & $13-34$ & $10-18$ & $100 \%$ & $80-93 \%$ & $50 \%$ & Vero cells & [112] \\
\hline & $\begin{array}{l}\text { Taiwan, } \\
\text { Taipei }\end{array}$ & $\mathrm{ND}(\mathrm{SH})$ & $\begin{array}{c}\mathrm{C} 6 / 36 \\
\text { cells and } \\
\text { suckling } \\
\text { mice } \\
\text { brains }\end{array}$ & $\begin{array}{l}5.48 \log _{10} \\
\mathrm{PFU} / \mathrm{mL}\end{array}$ & $\begin{array}{l}\text { Defibrinated } \\
\text { rabbit }\end{array}$ & $\begin{array}{c}\text { Hanging } \\
\text { drop } \\
\text { method }\end{array}$ & $28-32{ }^{\circ} \mathrm{C}$ & 14 & $6-8$ & ND & ND & $100 \%$ & $\begin{array}{l}\text { Inoculation } \\
\text { of brain } \\
\text { tissue } \\
\text { aspirates } \\
\text { from } \\
\text { recipient } \\
\text { mice on } \\
\text { to C6/36 } \\
\text { cells }\end{array}$ & [109] \\
\hline Culex vishnui & India & $\begin{array}{c}\text { G-III } \\
\text { (P20778) }\end{array}$ & ND & ND & ND & $\begin{array}{c}\text { Oral } \\
\text { infection }\end{array}$ & ND & $1-10$ & 100 & ND & $34 \%$ & $48 \%$ & $\begin{array}{l}\text { Antigen } \\
\text { detection } \\
\text { in } \\
\text { mosquito } \\
\text { heads } \\
\text { resp. } \\
\text { salivary } \\
\text { glands }\end{array}$ & [115] \\
\hline
\end{tabular}


Table 3. Cont.

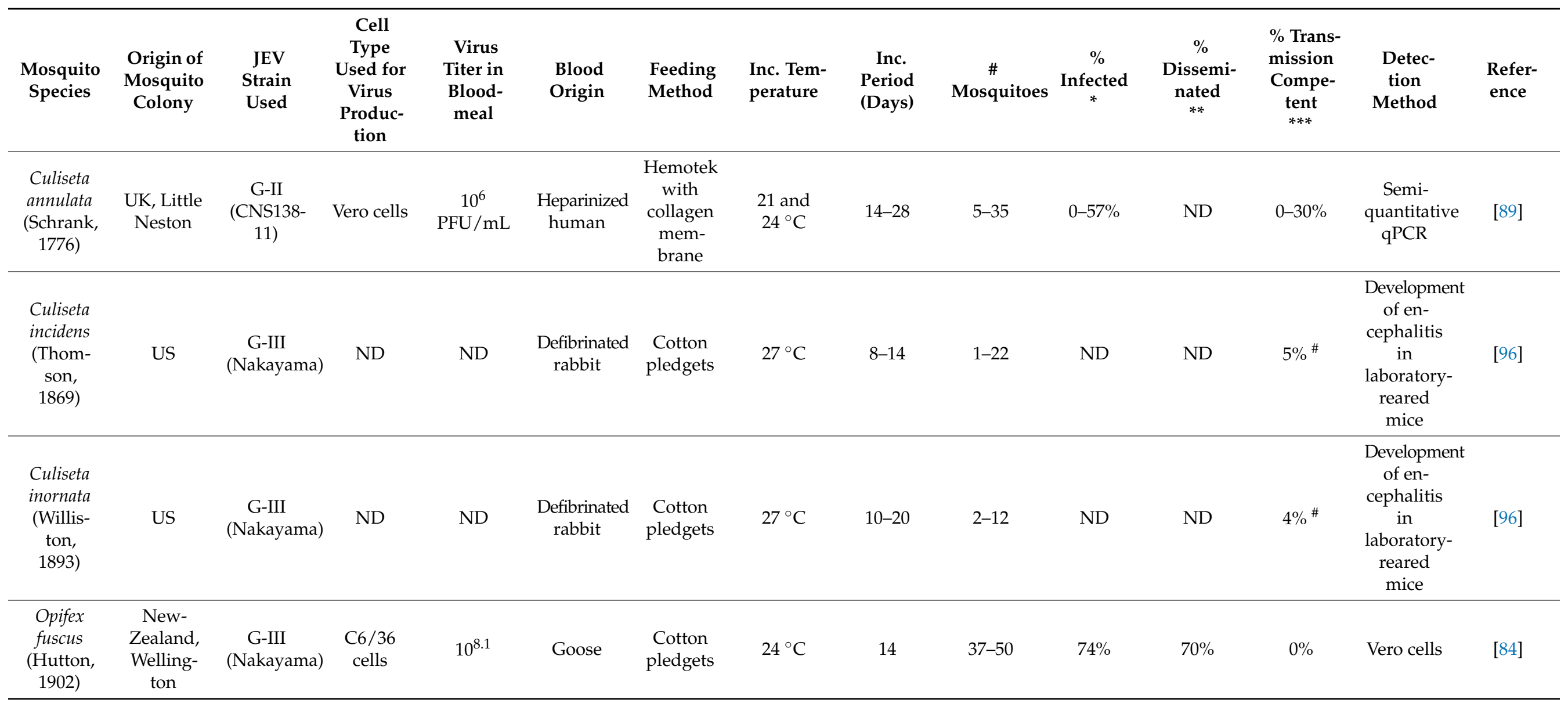


Table 3. Cont.

\begin{tabular}{|c|c|c|c|c|c|c|c|c|c|c|c|c|c|c|}
\hline $\begin{array}{l}\text { Mosquito } \\
\text { Species }\end{array}$ & $\begin{array}{c}\text { Origin of } \\
\text { Mosquito } \\
\text { Colony }\end{array}$ & $\begin{array}{c}\text { JEV } \\
\text { Strain } \\
\text { Used }\end{array}$ & $\begin{array}{l}\text { Cell } \\
\text { Type } \\
\text { Used for } \\
\text { Virus } \\
\text { Produc- } \\
\text { tion }\end{array}$ & $\begin{array}{c}\text { Virus } \\
\text { Titer in } \\
\text { Blood- } \\
\text { meal }\end{array}$ & $\begin{array}{c}\text { Blood } \\
\text { Origin }\end{array}$ & $\begin{array}{l}\text { Feeding } \\
\text { Method }\end{array}$ & $\begin{array}{l}\text { Inc. Tem- } \\
\text { perature }\end{array}$ & $\begin{array}{l}\text { Inc. } \\
\text { Period } \\
\text { (Days) }\end{array}$ & $\begin{array}{c}\# \\
\text { Mosquitoes }\end{array}$ & $\begin{array}{c}\% \\
\text { Infected } \\
*\end{array}$ & $\begin{array}{c}\% \\
\text { Dissemi- } \\
\text { nated } \\
* *\end{array}$ & $\begin{array}{l}\text { \% Trans- } \\
\text { mission } \\
\text { Compe- } \\
\text { tent } \\
* * *\end{array}$ & $\begin{array}{c}\text { Detec- } \\
\text { tion } \\
\text { Method }\end{array}$ & $\begin{array}{l}\text { Refer- } \\
\text { ence }\end{array}$ \\
\hline $\begin{array}{l}\text { Verrallina } \\
\text { funerea }\end{array}$ & $\begin{array}{c}\text { Australia, } \\
\text { Cairns } \\
\text { (wild s) }\end{array}$ & $\begin{array}{c}\text { G-II } \\
\text { (TS3306) }\end{array}$ & $\begin{array}{l}\text { C6/36 } \\
\text { and } \\
\text { porcine } \\
\text { stable- } \\
\text { equine } \\
\text { kidney } \\
\text { cells }\end{array}$ & $\begin{array}{l}10^{4.5 \pm 0.1} \\
\mathrm{CCID}_{50} / \mathrm{mL}\end{array}$ & $\begin{array}{l}\text { Heparinized } \\
\text { rabbit }\end{array}$ & $\begin{array}{c}\text { Glass } \\
\text { mem- } \\
\text { brane } \\
\text { feeder } \\
\text { with pig } \\
\text { intestine } \\
\text { mem- } \\
\text { brane }\end{array}$ & $28^{\circ} \mathrm{C}$ & 14-15 & 36 & $11 \%$ & ND & $7 \%$ & $\begin{array}{c}\text { Detection } \\
\text { of virus } \\
\text { in brain } \\
\text { aspirates } \\
\text { of } \\
\text { recipient } \\
\text { suckling } \\
\text { mice }\end{array}$ & [93] \\
\hline & & $\begin{array}{l}{ }^{*} \text { Infe } \\
\text { when } \\
\text { mosq } \\
\text { indice } \\
\text { IFAT } \\
\text { infect }\end{array}$ & $\begin{array}{l}\text { n rate }=\text { vi } \\
\text { dicated with } \\
\text { oes feed on } \\
\text { lack of dat } \\
\text { direct imm } \\
\text { dose } 50 \% \text { a }\end{array}$ & $\begin{array}{l}\text { s detected in } \mathrm{m} \\
=\text { disseminatic } \\
\text { aïve animals; th } \\
\text { in the given stu } \\
\text { nofluorescent a } \\
\text { ay; WMICLD50 }\end{array}$ & $\begin{array}{l}\text { losquito body; } \\
\text { on rate calculat } \\
\text { he Hemotek sy } \\
\text { udy; }{ }^{\#}=\text { estima } \\
\text { antibody test; } \mathrm{F} \\
0 \text { = weanling } \mathrm{m}\end{array}$ & $\begin{array}{l}* \text { Dissemin } \\
\text { ed on total } \\
\text { stem is an a } \\
\text { ted percent } \\
\text { FU = focus } \\
\text { ice intracra }\end{array}$ & $\begin{array}{l}\text { on rate }=\text { viru } \\
\text { mber of succe } \\
\text { ficial feeding } \\
\text { (minimum } \\
\text { rming unit; } P \\
1 \text { lethal dose }\end{array}$ & $\begin{array}{l}\text { detected i } \\
\text { fully infect } \\
\text { stem usin } \\
\text { lues) due } \\
\mathrm{J}=\text { plaque } \\
\% \text { assay. }\end{array}$ & $\begin{array}{l}\text { egs, wings, and } \\
\text { mosquitoes; } \\
\text { n electric heatin } \\
\text { incomplete data } \\
\text { rming units; CC }\end{array}$ & $\begin{array}{l}\text { /or mosqu } \\
\text { Transmiss } \\
\text { g element } \\
\text { a in the giv } \\
\text { IID }_{50}=\text { cel }\end{array}$ & $\begin{array}{l}\text { heads, calcu } \\
\text { rates = virus } \\
\text { naintain the } \\
\text { study; NA = } \\
\text { lture infecti }\end{array}$ & $\begin{array}{l}\text { ed on total } n \\
\text { tected in sal } \\
\text { nperature of } \\
\text { t applicable; } \\
\text { dose } 50 \% \text { a }\end{array}$ & $\begin{array}{l}\text { mber of mc } \\
\text { ya and/or b } \\
\text { the blood } m \\
\text { FFA = fluor } \\
\text { say; TCID } 50\end{array}$ & $\begin{array}{l}\text { oes, exce } \\
\text { ig infect } \\
37^{\circ} \mathrm{C} ; \mathrm{N} \\
\text { t foci assa } \\
\text { sue cultu }\end{array}$ \\
\hline
\end{tabular}


Table 4. Potential and confirmed vectors for JEV. Potential vectors are only proven competent in vector competence experiments while confirmed vectors are additionally found positive in the field. Most efficient confirmed vectors are based on the extent of their transmission rate $(>70 \%)$ calculated in vector competence studies.

\begin{tabular}{|c|c|c|c|}
\hline Mosquito Species & Potential Vectors & $\begin{array}{l}\text { Confirmed } \\
\text { Vectors }\end{array}$ & References \\
\hline Aedes albopictus & & $x$ & {$[19,20,88,95,116]$} \\
\hline Aedes detritus & $x$ & & [85] \\
\hline Aedes dorsalis & $x$ & & [96] \\
\hline Aedes japonicus & $x$ & & {$[12,97,98]$} \\
\hline Aedes kochi & $x$ & & {$[93]$} \\
\hline Aedes nigromaculis & $x$ & & [96] \\
\hline Aedes notoscriptus & $x$ & & [93] \\
\hline Aedes vexans & & $X$ & {$[19,20,99]$} \\
\hline Aedes vigilax & & $x$ & {$[25,26,93]$} \\
\hline Anopheles tessellatus & & $x$ & {$[19,100]$} \\
\hline Armigeres subalbatus & & $x$ & {$[19,20,28,32,34,101]$} \\
\hline Culex annulirostris & & $x$ & {$[39,93,99]$} \\
\hline $\begin{array}{c}\text { Culex } \\
\text { bitaeniorhynchus }\end{array}$ & & $x$ & {$[21,28,43-45,102-104]$} \\
\hline Culex fuscocephala & & $X$ & {$[19,22,27,31,46,48-50,105,106]$} \\
\hline Culex gelidus & & $X$ & {$[22,23,27,31,46,50-61,93,107,115]$} \\
\hline Culex pipiens & & $X$ & {$[15,43,44,62-64,84,87,89,96,108-110]$} \\
\hline Culex pipiens pallens & & $x$ & {$[38,98,111,112]$} \\
\hline Culex pseudovishnui & & $x$ & {$[37,65-68,113,114]$} \\
\hline $\begin{array}{c}\text { Culex } \\
\text { quinquefasciatus }\end{array}$ & & $x$ & {$[19,20,22,28,31,69,70,84,85,93,96]$} \\
\hline Culex sitiens & & $X$ & {$[20,21,24,26,51,70-73,93]$} \\
\hline Culex tarsalis & & $x$ & {$[32,96]$} \\
\hline $\begin{array}{l}\text { Culex } \\
\text { tritaeniorhynchus }\end{array}$ & & $x$ & $\begin{array}{c}{[12,19,21,24,27,28,31,33-35,38,41-} \\
44,46,47,50,53-56,59,64,67,70,74- \\
80,98,109,112]\end{array}$ \\
\hline Culex vishnui & & $x$ & {$[21,37,46,47,53,67,79,80,114]$} \\
\hline Culiseta annulata & $x$ & & [89] \\
\hline Culiseta incidens & $\mathrm{X}$ & & [96] \\
\hline Culiseta inornata & $X$ & & {$[96]$} \\
\hline Verrallina funerea & $x$ & & [93] \\
\hline
\end{tabular}

\subsubsection{Vectorial Capacity}

Vector competence is only one of the factors that determines whether a specific species will play a role in virus transmission under field conditions. Therefore, the term vectorial capacity was introduced that also takes additional factors, e.g., environmental, behavioral, cellular, and biochemical variables into account [116]. More specifically, vectorial capacity is determined by the density of vectors (abundance) in relation to the host; the probability that the vector feeds on a host; the vector competence; the daily survival rate of a vector; the EIP; and the probability of vectors surviving the EIP $[14,82,117]$. The EIP is the time interval between the acquisition of the virus and the moment that sufficient virus is present 
in the saliva to allow further transmission. Vectorial capacity is, therefore, not a single value for a single species, but specific to the vector population at the prevailing climatic conditions in a particular area at a certain moment.

Temperature is one of the most important climatic factors that influences vector capacity, because it has a direct effect on both the daily mosquito survival and the EIP [14], as the proliferation rate of JEV and the metabolism of mosquitoes are affected by temperature. JEV-endemic areas generally have a tropical climate, characterized by warm temperatures and frequent rainfall, and the coolest temperatures are around 20 to $23^{\circ} \mathrm{C}$. As a result, JEV can be transmitted throughout the year in southern tropical areas, although with a higher intensity during the rainy season [3]. When JEV would be introduced in temperate regions where temperatures vary more with the seasons, there would probably not be a year-round JEV transmission. Rather a higher transmission rate would be expected during summer, compared to winter, when few or no vectors are present $[118,119]$. Low temperatures have been shown to limit the spread of many arboviruses and pose challenges for viruses to overwinter [16]. Nevertheless, several studies have shown that certain mosquitoes, for example Aedes japonicus, can transmit JEV vertically to its F1 larvae, providing a potential mechanism of JEV overwintering [98,120].

The abundance of a vector species in a certain region is an important part of the vector capacity calculation. Culex tritaeniorhynchus is considered the primary vector for JEV in most endemic areas in Asia, including Japan and Korea [12,121], and Culex annulirostris in Australia [122]. However, although Culex pipiens is not considered a primary vector, given its high abundance in temperate zones (including Europe) and its competence for JEV, the potential contribution of this vector species to the spread of JEV upon introduction should not be underestimated. In this respect, Aedes japonicus also might play a role as it is known to be abundant in certain regions [123-127] and present far beyond its endemic zone (Figure 3). It is one of the world's most invasive Culicidae species, with a confirmed presence in Europe. While Aedes japonicus is a proven vector for JEV [12,97], it has, however, never been found to be positive in the field. For this reason, it is considered a potential secondary vector [12]. In addition, other species, e.g., Aedes albopictus, Aedes dorsalis, and Culiseta annulata, although with lower transmission rates, may contribute to JEV transmission upon introduction $[83,87,89,121,128]$.

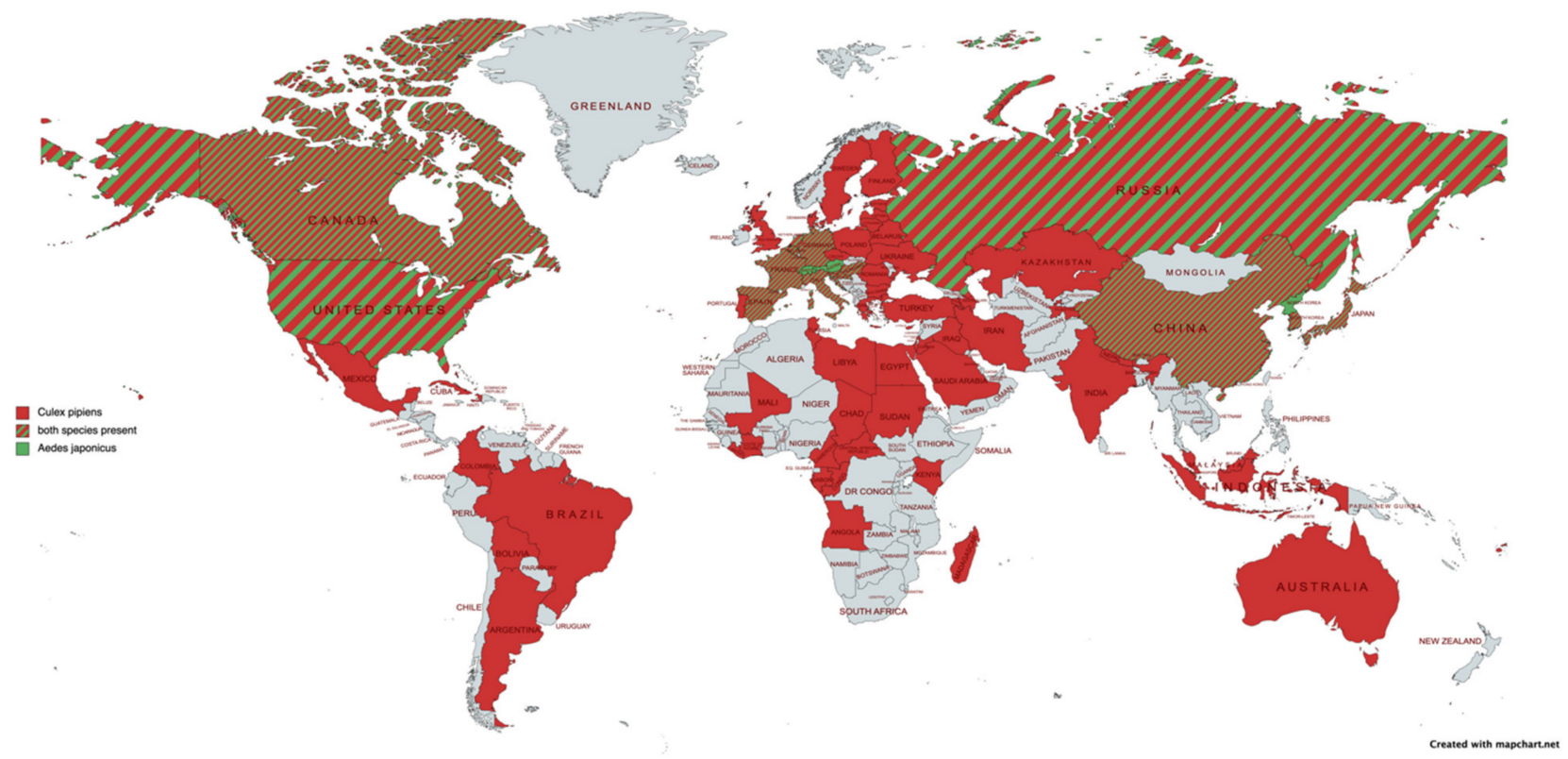

Figure 3. Map showing the worldwide distribution of Aedes japonicus (green) and Culex pipiens (red). This map was created based on a study by Peach et al. [129], the Invasive Species Compendium of CABI [130], and the ECDC mosquito maps [131]. 
Overall vector capacity is the most significant, as well as the most difficult, to calculate. Some of its components are highly variable, e.g., vector-host interactions, vector density, and the probability of daily survival, whereby the latter two can be high in ideal environmental conditions yet decrease very rapidly in the case of unsuitable weather conditions or, for example, human activities involving large-scale vector control measures.

\subsection{Mosquito Immunity Controlling JEV Replication and Dissemination}

Not every infection of a mosquito results in JEV transmission to a new host during a subsequent blood meal. Mechanisms may prevent the development of a virus in a mosquito host that inhibit viral development, dissemination, and transmission. These mechanisms are known as vector immunity.

Key aspects of mosquito immunity include physical barriers, molecular pathways, antimicrobial peptides, and vector microbiome. Over the past thirty years, arbovirus research, focusing mainly on Aedes spp. mosquitoes and other flaviviruses, e.g., dengue, West Nile and Zika virus, has identified several mechanisms that limit the replication and dissemination of viruses in mosquitoes [132-137].

Recently, comprehensive reviews of the existing knowledge on insect immunity were published [135,137-140] and we refer readers to those for in depth insights in known molecular mechanisms underlying this immunity. In this review, we provide a summary of the limited existing knowledge on immune mechanisms, which counteract JEV replication in mosquitoes.

\subsubsection{Physical and Physiological Barriers}

A virus that is ingested through an infectious blood meal must overcome several physical and physiological barriers within a mosquito (Figure 4) before it reaches the saliva and can be successfully transmitted during a subsequent blood meal. These barriers can occur due to genetic (e.g., expression of receptors) or nongenetic determinants (e.g., leaky gut syndrome, i.e., a phenomenon whereby the integrity of the gut wall is compromised) $[14,83]$.

A potential physical mosquito barrier that JEV could encounter is the peritrophic membrane [91]. This membrane forms a physical barrier between the intestinal contents and the epithelia of the midgut. It consists of an extracellular network of chitin, sugars, and proteins. An increase in the thickness of this membrane could, therefore, reduce the chances of a pathogen crossing the intestinal barrier. However, arboviral binding to midgut epithelial cells may occur before the formation of this membrane [141].

There are four main physiological barriers in the mosquito vector, as follows: the midgut infection barrier (1), the midgut escape barrier (2), the salivary gland infection barrier (3), and finally the salivary gland escape barrier (4).

The midgut infection barrier (1) is characterized by the inability of viruses to enter the intestinal cells or to multiply or disseminate to other cells. The midgut escape barrier (2) is the barrier preventing the virus from traversing the basal lamina, that borders the midgut, avoiding the dissemination of the virus throughout the mosquito body. Several mechanisms have been described for how some viruses can cross the basal lamina, as follows: possibly through a "leaky" basal lamina, caused by breakdown and resynthesis after blood feeding, allowing the virus particles to enter the tracheal system and/or hemocoel [142]. This midgut escape barrier has been shown to be temperature dependent for JEV in Culex pipiens pipiens [15]. It was demonstrated that at $20^{\circ} \mathrm{C} \mathrm{JEV}$ was only detected in the epithelial cells in the posterior part of the midgut and in no other tissues, whereas at $25{ }^{\circ} \mathrm{C} \mathrm{JEV}$ could disseminate to the saliva as JEV RNA was found in the expectorated saliva of $70 \%$ of the mosquitoes after 14 days. This indicates that, at $20^{\circ} \mathrm{C}$, the virus was unable to overcome the midgut barrier and consequently could not disseminate to secondary organs, such as the salivary glands. However, it was unclear from these observed results whether the restriction to the midgut was due to lower temperatures that activated antiviral control by 
the mosquitoes or whether it limited virus replication [15]. It may be that an increase in temperature causes further virus replication, as well as escape from the midgut.

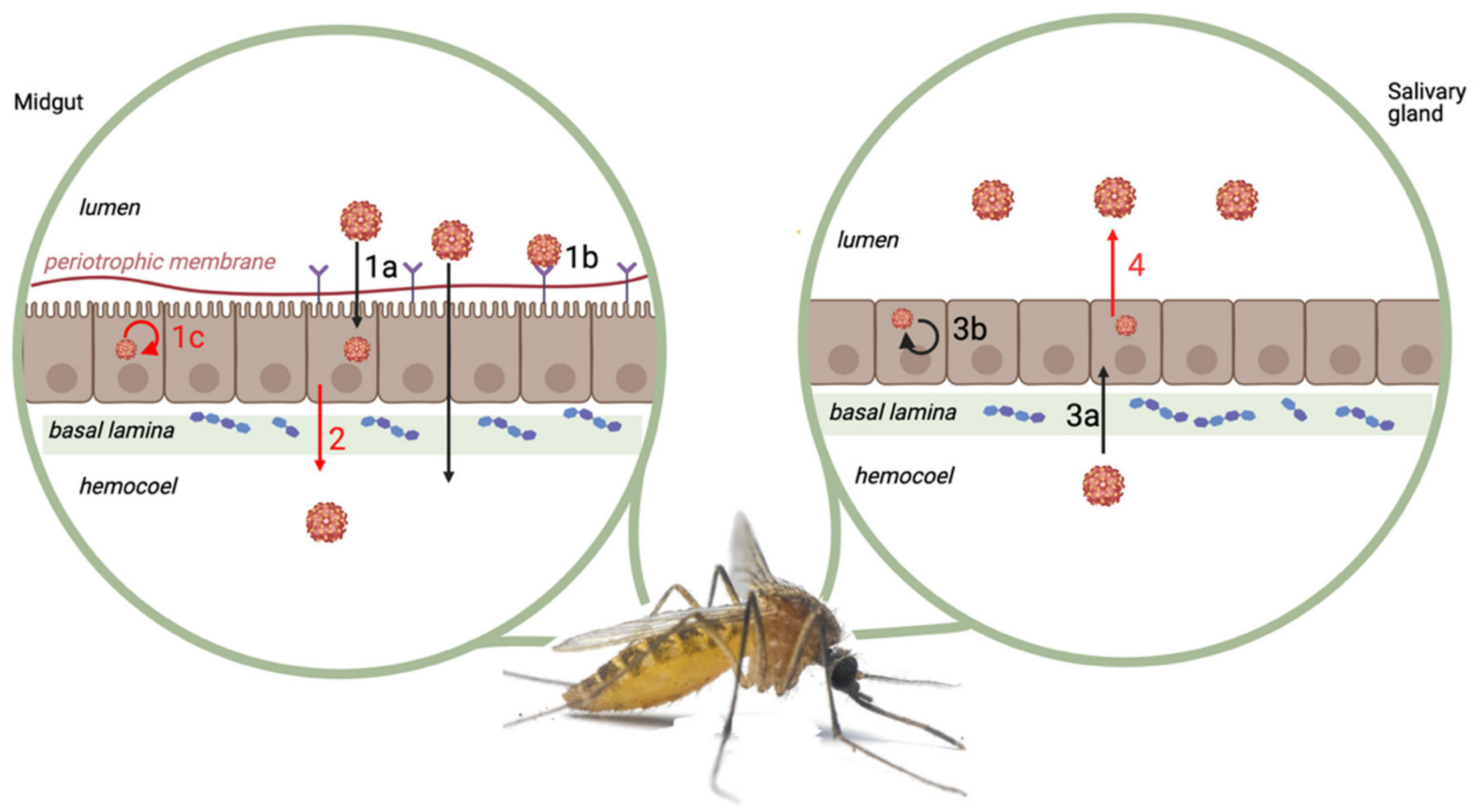

Figure 4. Four major mosquito barriers. (1) Midgut infection barrier, which results from either the inability of the virus to enter the midgut cells (1a), the absence of suitable receptors (1b), and/or the inability of the virus to replicate within the midgut cells (1c). (2) Midgut escape barriers. (3) Salivary gland infection barrier, which can result from either the ability of the virus to enter the salivary gland cells (3a) and/or the ability of the virus to replicate within the salivary gland cells (3b). (4) Salivary gland escape barrier. Barriers for which JEV specific information exist are shown in red. Adapted from Vogels et al., 2017 [91]. Created with BioRender.com.

The salivary gland infection barrier (3) is constituted by the basal lamina surrounding the salivary gland, which determines if the virus can disseminate from the midgut and infected fat body via the hemocoel to salivary gland tissue [143]. A study by Takahashi [144] discusses the susceptibility for JEV of each secretory part of salivary glands on transmission efficiency of Culex tritaeniorhynchus. They concluded that the salivary gland infection barrier is not a single factor, but that each of its three major secretory parts, i.e., lateral neck cells, lateral acinar cells, and median acinar cells, represent a different level of the barrier. The lateral neck cells are usually the most susceptible and excrete the highest amount of virus in the saliva [144,145].

The salivary gland escape barrier (4) is evidenced by the absence of viral particles in the saliva of infected mosquitoes. This arises from the inability of the viral particles to breach the cell membrane of the salivary gland cells [145]. If a particular virus cannot cross this barrier, no viral particles are found in the mosquito's saliva, thus preventing transmission. However, if this barrier is crossed, the infected mosquitoes can inoculate virus-infected saliva to a new host during blood feeding.

The analysis of published vector competence studies showed that in four species (Aedes aegypti, Aedes vigilax, Culex pipiens pallens, and Opifex fuscus [84,93,112]) JEV was only found in the body and legs/wings or optionally the mosquito head, but not in the saliva. A possible explanation is that, in these species, JEV could not cross either the salivary gland infection barrier or the salivary gland escape barrier.

The studies conducted on Aedes japonicus [12,97] showed that this species was susceptible to JEV infection. The dissemination rate of the virus was found to be $100 \%$ and in $67-100 \%$ (depending on genotype used) of these mosquitoes the virus was found in their saliva [12]. This underlines the importance of all of the barriers as a vector competence indicator for this species, since once the midgut is passed and the mosquito is thus "infected", 
the virus disseminates "easily" to the salivary glands of the infected mosquitoes, through which it can be transmitted.

\subsubsection{Molecular Pathways}

RNA interference (RNAi) by small interfering RNA (siRNA) is the central antiviral mechanism in insects, particularly through RNA silencing [137]. This mechanism of small interfering RNA is activated by the binding of dsRNA, which are among others formed during the replication of RNA viruses, to a Dicer-2(dcr2)-R2D2 complex (Figure 5). This complex consists of an RNase III enzyme, which cleaves the dsRNA, and a protein R2D2. The result of this cleavage step is the production of silencing RNAs, which subsequently activate the RNAi pathway upon binding to a multiprotein, the RNA-induced silencing complex. Thereafter, the single-stranded RNA functions as a guide strand to specifically detect and degrade the viral RNA by Argonaute2 (Ago2), a host endonuclease. We only found one study specifically for JEV in relation to this pathway. This study showed that Ago2 suppresses the growth of JEV in the salivary glands of Aedes aegypti. RNAi may, therefore, contribute to the low susceptibility of this species for JEV [146].

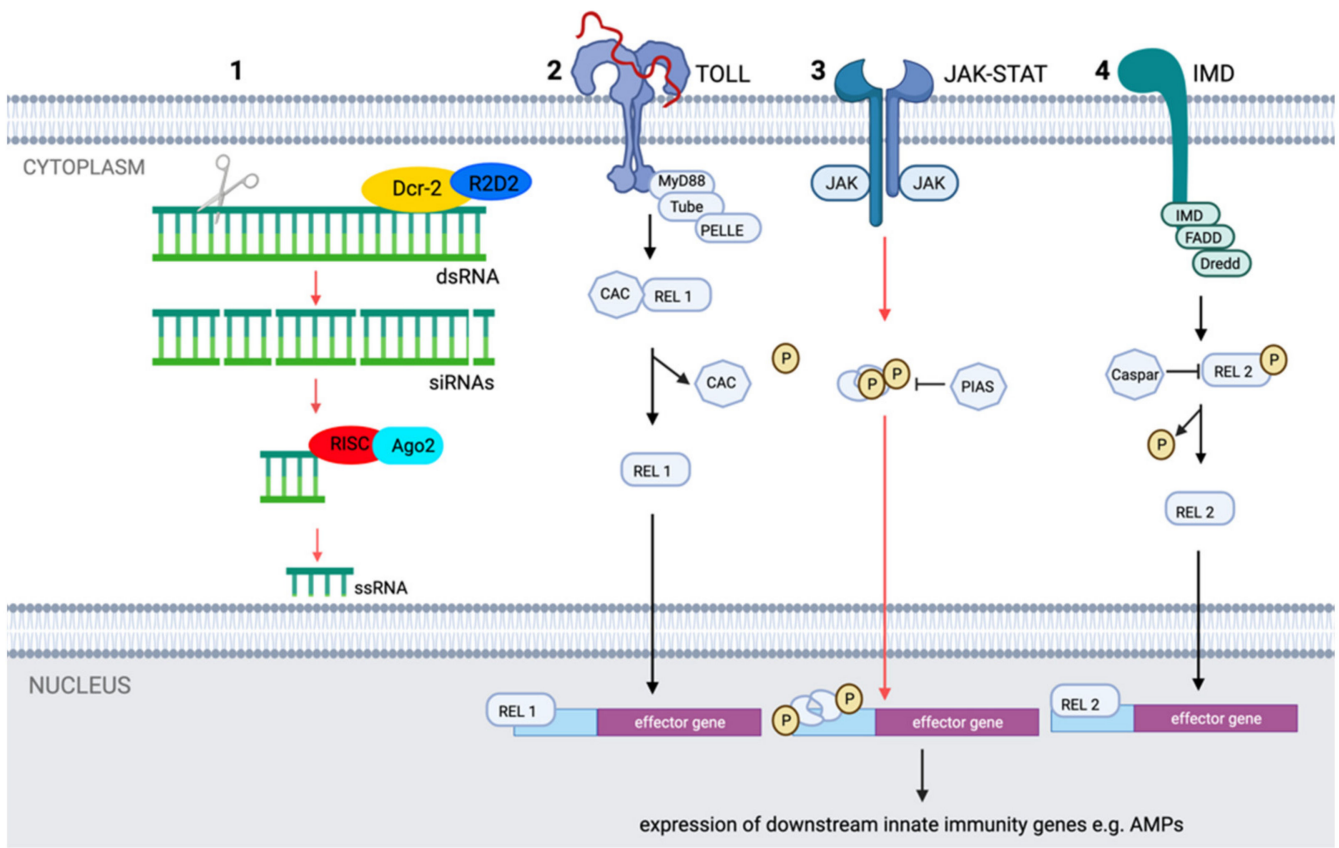

Figure 5. The major Culicidae innate immune pathways RNAi (1), Toll (2), JAK-STAT (3), and immune deficiency pathways (IMD) (4). All the names of the genes shown correspond to the nomenclature adapted from Terradas et al., (2017) [147] and Lee et al., (2019) [137]. Molecular pathways for which JEV specific information exist are shown in red. Created with BioRender.com.

Besides the small interfering RNA pathway, there are two other known small RNAbased silencing pathways in insects, the microRNA and PIWI-interacting pathways. These all use small RNAs to guide sequence-specific recognition, however, they differ in origin, biogenesis, nature, fate of their targets after recognition, and their biological function [140]. For more detailed explanations of these pathways, we refer the reader to other research [148-150].

In addition to RNAi pathways, several other molecular pathways exist that can protect mosquitoes from viral infection, including the Janus kinase-signal transducer and activator of transcription (JAK-STAT), Toll, and immune deficiency pathways (Figure 5). Activation of these initiates the formation of multiprotein complexes consisting of protein kinases, transcription factors, and other regulatory molecules in order to regulate the expression of downstream innate immunity genes, e.g., the genes that encode for antimicrobial peptides (see section below) and the key factors that regulate the innate immune system [137]. 
The only study that has addressed such pathways in relation to JEV was a study by Lin et al. [151]. In their study, they examined the immune response of mosquitoes to the virus in JEV-infected C6/36 Aedes albopictus cells in order to investigate the regulation of the AaSTAT (an Aedes albopictus specific cloned mosquito STAT) pathway. Decreased DNA binding activity, as well as decreased tyrosine phosphorylation of AaSTAT, were observed in core extracts from JEV-infected cells, suggesting that JEV infection may disrupt tyrosine phosphorylation of AaSTAT, probably through the induction of cellular phosphatase(s) or the inactivation of JAK or other tyrosine kinase(s) by viral products.

\subsubsection{Antimicrobial Peptides}

As mentioned above, the formation of a multiprotein complex regulates the activation of downstream signaling and effector responses. This induces the synthesis and secretion of soluble effector molecules, e.g., antimicrobial peptides (AMPs). The AMPs are constitutively released by epithelial cells, such as in the midgut of mosquitoes, where they prevent overgrowth of the gut microbiota, thus, playing an important role in tuning the immune response by tolerating symbiosis and controlling microbial growth [152]. The AMPs in mosquitoes are primarily regulated by the Imd pathway [153].

Recent studies have shown that the AMP defensin, which is one of the crucial immune effectors in insects [154], plays an important role in facilitating JEV infection and potential transmission in mosquitoes. An initial study by Liu et al. [155] showed that mosquito defensins (Culex pipiens pallens defensin A and Aedes albopictus defensin C) facilitate the adsorption of JEV to target cells by binding to a specific part of the viral envelope protein of JEV. Moreover, under natural conditions, the local infection of the midgut leads to rapid upregulation and extracellular secretion of defensins [156]. In a subsequent study, the same group showed that defensin regulates cell-surface proteins [157]. A potential antiviral cellsurface protein (HSC70B) was significantly downregulated by both JEV infection and by defensin treatment. This protein inhibits JEV adsorption, indicating that mosquito defensin indirectly affects JEV adsorption by regulating cell-surface antiviral protein expression. Together, these two studies show that defensins have a (in)direct effect on both JEV infection and transmission.

\subsubsection{Vector Microbiome}

The microbiome of insects is composed of bacteria, fungi, viruses, and helminths and has the ability to reduce the vector competence for arboviruses and other pathogens. This reduction can occur through different mechanisms, e.g., the activation of the immune response, competition for resources, changing the physical status, or the production of antiviral molecules [152,158]. These symbiotic microorganisms reside in the gut, lumen and/or hemocoel of arthropod vectors [152]. In the context of vector immunity, the gut is of particular importance because it is the first and most extensive area exposed to pathogens [159]. There is a known high diversity in the composition of the microbial community in the midgut as they are frequently acquired from the habitats and are, thus, shaped by the environmental conditions [152]. As mentioned in the previous section, symbiosis of the microbiota is regulated by AMPs. Furthermore, reactive oxygen species play a key role in the regulation of vector microbiota homeostasis.

The gut microbiome is also involved in the formation of the peritrophic membrane [160], one of the physical barriers between the intestinal contents and the epithelia of the midgut, as discussed earlier in the section on physical and physiological barriers.

Wolbachia is the most extensively studied bacteria of the mosquito microbiome. In Aedes aegypti, Wolbachia infection has been found to increase the resistance to RNA virus infection. The molecular mechanisms involved in its protection are, however, not yet fully understood [161]. In contrast, in Armigeres subalbatus, no significant difference was shown between Wolbachia-infected and -free colonies. In their study, it is suggested that Wolbachia does not play a role in the resistance of salivary gland cells to JEV infection. Therefore, it is 
probable that the salivary gland escape barrier is not impaired by Wolbachia infection in this species [162].

The microbiome seems to specifically influence vector competence for JEV in Culex bitaeniorhynchus, since Mourya and Soman [163] showed that tetracycline treatment of this species increased their infection rate. Namely, twice as many (i.e., $43.41 \%$ ) of the antibiotic-treated mosquitoes were positive for JEV after an infected bloodmeal, compared to untreated mosquitoes (22.5\%). Similar observations have already been made in several other studies focusing on other arboviruses [161,164-168].

\section{Conclusions}

In this review, the current knowledge on the vector competence and vector capacity of mosquitoes for JEV is presented, as well as the limited knowledge on the underlying mechanisms that influence these parameters, e.g., vector immunity, abundance, and the effects of climate change.

Regarding vector competence, differences in methodology make it difficult to compare studies and draw definitive conclusions on which species are more competent than others, as their transmission rates may differ due to a difference in methodology. Results from vector-competence studies, combined with field-detection studies, indicate that 17 species are important to take into account. These all have the potential to transmit JEV and have already been found to be positive in the field, which makes them currently known vectors for JEV. Among these, Culex tritaeniorhynchus and Culex annulirostris are considered primary vectors in endemic areas. Additionally, Culex pipiens, and potentially Aedes japonicus, could be considered as important vectors in the case of the introduction of JEV into new areas.

The information gathered on vector immunity provides an indication of the underlying mechanisms that determine vector competence. However, very little is known about the barriers and conditions for the replication and transmission of JEV at the mosquito species level. A better understanding of the immunity, physiology, genetics, and microbiome of mosquito vectors in relation to JEV will be required in order to identify novel innovative vector control strategies that could help in reducing JEV transmission. We therefore advocate to invest in such studies.

\section{Methods}

A PubMed database search (on 14 December 2021) using the query term "Japanese encephalitis virus" yielded 5027 articles. Based on the title we retained all articles which could contain pertinent information on JEV-mosquito interactions (Figure 6). From this, an initial selection was made by excluding articles on diagnostic methods, vaccine production or vaccination studies, virus propagation techniques, case studies, epidemiological studies, and articles on the immunological relationship of JEV with other viruses. This resulted in 193 potentially relevant articles, which we screened for relevance by reading the abstracts, after which we excluded all articles that addressed biocontrol strategies, surveillance studies without species specification, insect-specific flaviviruses, and ecological studies. This resulted in a total of 114 manuscripts specifically dealing with JEVvector interactions, from which we then extracted the data reported in this review. For some articles $[20,23,29,30,37,50,52,57-59,61,65,68,99,100,102-107,111,113,114]$ the full text was not available, for these the information in the tables was taken from the abstracts. 
PubMed: "Japanese Encephalitis Virus" 5027 results

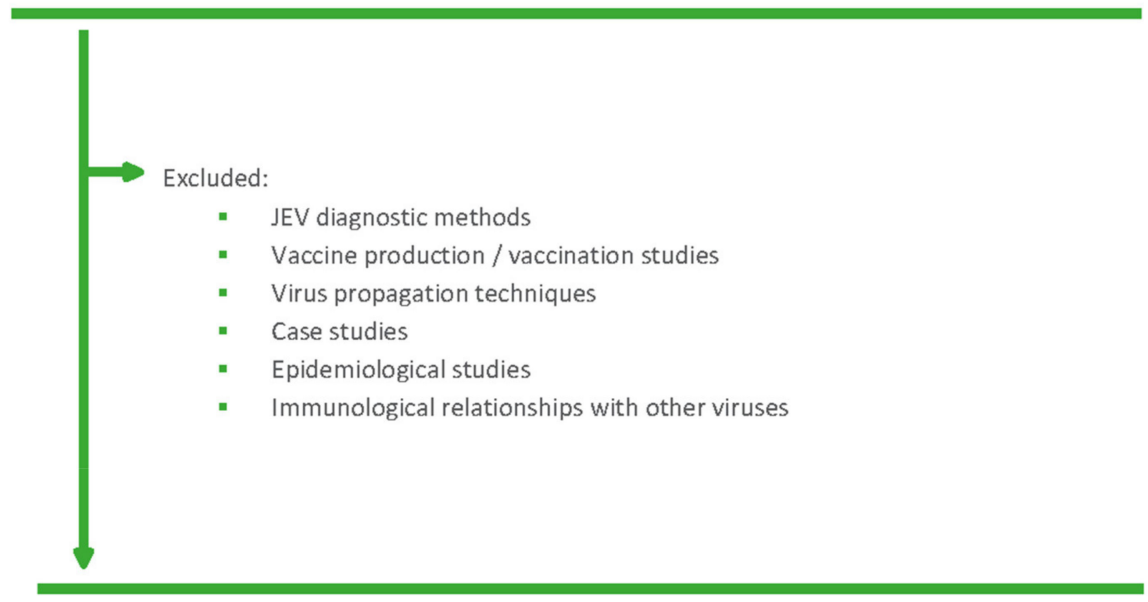

193 articles identified potentially dealing with JEV-vector interaction

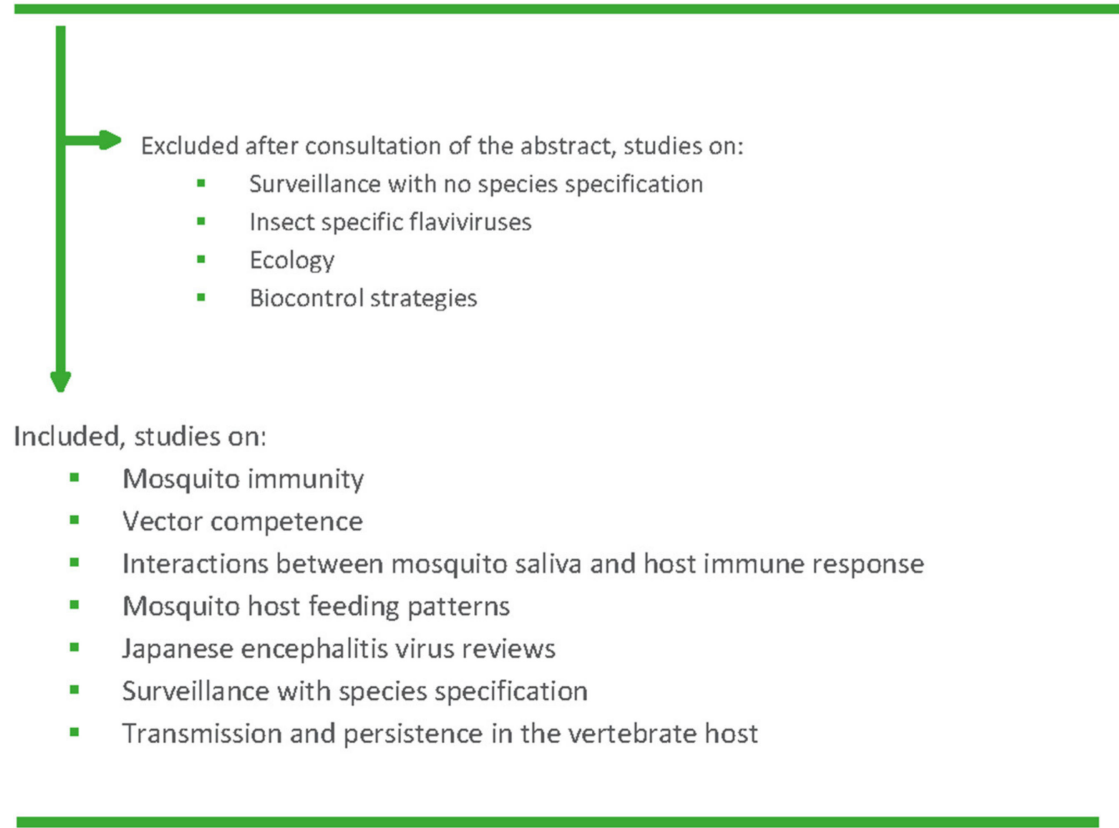

Finally, 114 articles identified dealing with JEV-vector interactions

Figure 6. Flowchart of the articles identified and screened for this review.

Author Contributions: Conceptualization, C.V.d.E., C.S. and N.D.R.; methodology, C.V.d.E.; validation, C.V.d.E., C.S., S.M. and N.D.R.; formal analysis, C.V.d.E., C.S., S.M. and N.D.R.; investigation, C.V.d.E.; writing - original draft preparation, C.V.d.E., C.S., S.M. and N.D.R.; writing-review and editing, C.V.d.E., C.S., S.M. and N.D.R.; visualization, C.V.d.E.; supervision, C.S., S.M. and N.D.R.; project administration, S.M. and N.D.R.; funding acquisition, N.D.R. All authors have read and agreed to the published version of the manuscript.

Funding: This research received no external funding.

Institutional Review Board Statement: Not applicable.

Informed Consent Statement: Not applicable.

Conflicts of Interest: The authors declare no conflict of interest. 


\section{References}

1. Gould, E.; Pettersson, J.; Higgs, S.; Charrel, R.; de Lamballerie, X. Emerging arboviruses: Why today? One Health 2017, 4, 1-13. [CrossRef]

2. $\quad$ Ricklin, M.E.; García-Nicolás, O.; Brechbühl, D.; Python, S.; Zumkehr, B.; Nougairede, A.; Charrel, R.N.; Posthaus, H.; Oevermann, A.; Summerfield, A. Vector-free transmission and persistence of Japanese encephalitis virus in pigs. Nat. Commun. 2016, 7, 10832. [CrossRef] [PubMed]

3. The World Organisation for Animal Health; World Health Organization. Japanese Encephalitis. OIE Technical Disease Cards. 2019. Available online: https://www.oie.int/fileadmin/Home/eng/Animal_Health_in_the_World/docs/pdf/Disease_cards / JAPANESE_ENCEPHALITIS.pdf (accessed on 24 March 2021).

4. Hubálek, Z.; Rudolf, I.; Nowotny, N. Arboviruses pathogenic for domestic and wild animals. Adv. Virus Res. 2014, 89, 201-275. [CrossRef] [PubMed]

5. Simon, L.V.; Kruse, B.; The World Organisation for Animal Health; World Health Organization. Japanese Encephalitis; StatPearls Publishing: Treasure Island, FL, USA, 2019.

6. Spickler, A.R. Japanese Encephalitis; Center for Food Security and Public Health Established at Iowa State: Ames, IA, USA, 2016.

7. Solomon, T.; Ni, H.; Beasley, D.W.C.; Ekkelenkamp, M.; Cardosa, M.J.; Barrett, A.D.T. Origin and evolution of Japanese encephalitis virus in southeast Asia. J. Virol. 2003, 77, 3091-3098. [CrossRef] [PubMed]

8. European Center of Disease Control. Facts about Japanese Encephalitis. Factsheet. 2017. Available online: https://www.ecdc. europa.eu/en/japanese-encephalitis/facts (accessed on 9 February 2021).

9. Le Flohic, G.; Porphyre, V.; Barbazan, P.; Gonzalez, J.-P. Review of climate, landscape, and viral genetics as drivers of the Japanese encephalitis virus ecology. PLoS Negl. Trop. Dis. 2013, 7, e2208. [CrossRef] [PubMed]

10. Schuh, A.J.; Li, L.; Tesh, R.B.; Innis, B.L.; Barrett, A.D.T. Genetic characterization of early isolates of Japanese encephalitis virus: Genotype II has been circulating since at least 1951. J. Gen. Virol. 2010, 91, 95-102. [CrossRef] [PubMed]

11. Nga, P.T.; Parquet, M.D.C.; Cuong, V.D.; Ma, S.-P.; Hasebe, F.; Inoue, S.; Makino, Y.; Takagi, M.; Nam, V.S.; Morita, K. Shift in Japanese encephalitis virus (JEV) genotype circulating in northern Vietnam: Implications for frequent introductions of JEV from southeast Asia to East Asia. J. Gen. Virol. 2004, 85, 1625-1631. [CrossRef] [PubMed]

12. Faizah, A.N.; Kobayashi, D.; Amoa-Bosompem, M.; Higa, Y.; Tsuda, Y.; Itokawa, K.; Miura, K.; Hirayama, K.; Sawabe, K.; Isawa, H. Evaluating the competence of the primary vector, Culex tritaeniorhynchus, and the invasive mosquito species, Aedes japonicus japonicus, in transmitting three Japanese encephalitis virus genotypes. PLoS Negl. Trop. Dis. 2020, 14, e0008986. [CrossRef]

13. Oliveira, A.R.S.; Piaggio, J.; Cohnstaedt, L.W.; McVey, D.S.; Cernicchiaro, N. Introduction of the Japanese encephalitis virus (JEV) in the United States-A qualitative risk assessment. Transbound. Emerg. Dis. 2019, 66, 1558-1574. [CrossRef] [PubMed]

14. Rückert, C.; Ebel, G.D. How do virus-mosquito interactions lead to viral emergence? Trends Parasitol. 2018, 34, 310-321. [CrossRef] [PubMed]

15. Folly, A.J.; Dorey-Robinson, D.; Hernández-Triana, L.M.; Ackroyd, S.; Vidana, B.; Lean, F.Z.X.; Hicks, D.; Nuñez, A.; Johnson, N. Temperate conditions restrict Japanese encephalitis virus infection to the mid-gut and prevents systemic dissemination in Culex pipiens mosquitoes. Sci. Rep. 2021, 11, 6133. [CrossRef] [PubMed]

16. Ciota, A.T.; Keyel, A.C. The role of temperature in transmission of zoonotic arboviruses. Viruses 2019, 11, 1013. [CrossRef] [PubMed]

17. Gu, W.; Lampman, R.; Novak, R.J. Problems in estimating mosquito infection rates using minimum infection rate. J. Med. Entomol. 2003, 40, 595-596. [CrossRef] [PubMed]

18. Gu, W.; Unnasch, T.R.; Katholi, C.R.; Lampman, R.; Novak, R.J. Fundamental issues in mosquito surveillance for arboviral transmission. Trans. R. Soc. Trop. Med. Hyg. 2008, 102, 817. [CrossRef] [PubMed]

19. Su, C.-L.; Yang, C.-F.; Teng, H.-J.; Lu, L.-C.; Lin, C.; Tsai, K.-H.; Chen, Y.-Y.; Chen, L.-Y.; Chang, S.-F.; Shu, P.-Y. Molecular epidemiology of Japanese encephalitis virus in mosquitoes in Taiwan during 2005-2012. PLoS Negl. Trop. Dis. 2014, 8, 3122. [CrossRef] [PubMed]

20. Weng, M.H.; Lien, J.C.; Wang, Y.M.; Lin, C.C.; Lin, H.C.; Chin, C. Isolation of Japanese encephalitis virus from mosquitoes collected in northern Taiwan between 1995 and 1996. J. Microbiol. Immunol. Infect. 1999, 32, 9-13.

21. Vythilingam, I.; Oda, K.; Chew, T.K.; Mahadevan, S.; Vijayamalar, B.; Morita, K.; Tsuchie, H.; Igarashi, A. Isolation of Japanese encephalitis virus from mosquitoes collected in Sabak Bernam, Selangor, Malaysia in 1992. J. Am. Mosq. Control Assoc. 1995, 11, 94-98.

22. Vythilingam, I.; Oda, K.; Mahadevan, S.; Abdullah, G.; Thim, C.S.; Hong, C.C.; Vijayamalar, B.; Sinniah, M.; Igarashi, A. Abundance, parity, and Japanese encephalitis virus infection of mosquitoes (Diptera: Culicidae) in Sepang District, Malaysia. J. Med. Entomol. 1997, 34, 257-262. [CrossRef]

23. Simpson, D.I.H.; Bowen, E.T.W.; Way, H.J.; Platt, G.S.; Hill, M.N.; Kamath, S.; Wah, L.T.; Bendell, P.J.E.; Heathcote, O.H.U. Arbovirus infections in Sarawak, October 1968-February 1970, Japanese encephalitis virus isolations from mosquitoes. Ann. Trop. Med. Parasitol. 1974, 68, 393-404. [CrossRef]

24. Weng, M.-H.; Lien, J.-C.; Ji, D.-D. Monitoring of Japanese encephalitis virus infection in mosquitoes (Diptera: Culicidae) at Guandu Nature Park, Taipei, 2002-2004. J. Med. Entomol. 2005, 42, 1085-1088. [CrossRef]

25. Hanna, J.N.; Ritchie, S.A.; Hills, S.L.; Hurk, A.F.V.D.; Phillips, D.A.; Pyke, A.T.; Lee, J.M.; Johansen, C.A.; MacKenzie, J.S. Japanese encephalitis in north Queensland, Australia, 1998. Med. J. Aust. 1999, 170, 533-536. [CrossRef] [PubMed] 
26. Johansen, C.A.; Hurk, A.F.V.D.; Pyke, A.T.; Zborowski, P.; Phillips, D.A.; MacKenzie, J.S.; Ritchie, S.A. Entomological investigations of an outbreak of Japanese encephalitis virus in the Torres Strait, Australia, in 1998. J. Med. Entomol. 2001, 38, 581-588. [CrossRef]

27. Olson, J.G.; Ksiazek, T.G.; Lee, V.H.; Tan, R.; Shope, R.E. Isolation of Japanese encephalitis virus from Anopheles annularis and Anopheles vagus in Lombok, Indonesia. Trans. R. Soc. Trop. Med. Hyg. 1985, 79, 845-847. [CrossRef]

28. Thenmozhi, V.; Balaji, T.; Selvam, A.; Venkatasubramani, K.; Dhananjeyan, K.J. A longitudinal study on abundance and infection frequency of Japanese encephalitis vectors in Tirunelveli District, Tamil Nadu, India. Int. J. Mosq. Res. 2015, 2, 166-169.

29. Chakravarty, S.K.; Sarkar, J.K.; Chakravarty, M.S.; Mukherjee, M.K.; Mukherjee, K.K.; Das, B.C.; Hati, A.K. The first epidemic of Japanese encephalitis studied in India-Virological studies. Indian J. Med. Res. 1975, 63, 77-82.

30. Banerjee, K.; Mahadev, P.V.; Ilkal, M.A.; Mishra, A.C.; Dhanda, V.; Modi, G.B.; Geevarghese, G.; Kaul, H.N.; Shetty, P.S.; George, P.J. Isolation of Japanese encephalitis virus from mosquitoes collected in Bankura District (West Bengal) during October 1974 to December 1975. Indian J. Med. Res. 1979, 69, 201-205. [PubMed]

31. Mourya, D.T.; Ilkal, M.A.; Mishra, A.C.; Jacob, P.G.; Pant, U.; Ramanujam, S.; Mavale, M.S.; Bhat, H.R.; Dhanda, V. Isolation of Japanese encephalitis virus from mosquitoes collected in Karnataka state, India from 1985 to 1987. Trans. R. Soc. Trop. Med. Hyg. 1989, 83, 550-552. [CrossRef]

32. Liu, H.; Lu, H.-J.; Liu, Z.-J.; Jing, J.; Ren, J.-Q.; Liu, Y.-Y.; Lu, F.; Jin, N.-Y. Japanese encephalitis virus in mosquitoes and swine in Yunnan province, China 2009-2010. Vector-Borne Zoonotic Dis. 2013, 13, 41-49. [CrossRef] [PubMed]

33. Li, L.; Guo, X.; Zhao, Q.; Tong, Y.; Fan, H.; Sun, Q.; Xing, S.; Zhou, H.; Zhang, J. Investigation on mosquito-borne biruses at Lancang river and $\mathrm{Nu}$ river watersheds in southwestern China. Vector-Borne Zoonotic Dis. 2017, 17, 804-812. [CrossRef] [PubMed]

34. Feng, Y.; Fu, S.; Zhang, H.; Li, M.; Zhou, T.; Wang, J.; Zhang, Y.; Wang, H.; Tang, Q.; Liang, G. Distribution of mosquitoes and mosquito-borne viruses along the China-Myanmar border in Yunnan province. Jpn. J. Infect. Dis. 2012, 65, 215-221. [CrossRef] [PubMed]

35. Dhanda, V.; Thenmozhi, V.; Kumar, N.P.; Hiriyan, J.; Arunachalam, N.; Balasubramanian, A.; Ilango, A.; Gajanana, A. Virus isolation from wild-caught mosquitoes during a Japanese encephalitis outbreak in Kerala in 1996. Indian J. Med. Res. 1997, 106, 4-6.

36. Thenmozhi, V.; Rajendran, R.; Ayanar, K.; Manavalan, R.; Tyagi, B.K. Long-term study of Japanese encephalitis virus infection in Anopheles subpictus in Cuddalore District, Tamil Nadu, south India. Trop. Med. Int. Health 2006, 11, 288-293. [CrossRef]

37. George, S.; Jacob, P.G.; Rao, J.A. Isolation of Japanese encephalitis \& West Nile viruses from mosquitoes collected in Kolar District of Karnataka state during 1977-1979. Indian J. Med. Res. 1987, 85, 235-238. [PubMed]

38. Shi, Q.; Song, X.; Lv, Y.; Huang, X.; Kou, J.; Wang, H.W.; Zhang, H.; Cheng, P.; Gong, M. Potential risks associated with Japanese encephalitis prevalence in Shandong province, China. Vector-Borne Zoonotic Dis. 2019, 19, 640-645. [CrossRef] [PubMed]

39. Phillips, D.; Poidinger, M.; Mackenzie, J.; Van Den Hurk, A.; Ritchie, S.A.; Broom, A. Isolation of Japanese encephalitis virus from Culex annulirostris in Australia. Am. J. Trop. Med. Hyg. 1997, 56, 80-84. [CrossRef]

40. Cates, M.D.; Detels, R. Japanese encephalitis virus in Taiwan: Preliminary evidence for Culex annulus Theob. as a vector. J. Med. Entomol. 1969, 6, 327-328. [CrossRef] [PubMed]

41. Cross, J.H.; Lien, J.C.; Huang, W.C.; Lien, S.C.; Chiu, S.F. Japanese encephalitis virus surveillance in Taiwan. II. Isolations from mosquitoes and bats in Taipei area 1969-1970. Taiwan Yi Xue Hui Za Zhi 1971, 70, 681-686.

42. Okuno, T.; Tseng, P.T.; Liu, S.Y.; Hsu, S.T.; Huang, C.T. Rates of infection with Japanese encephalitis virus of two culicine species of mosquito in Taiwan. Bull. World Health Organ. 1971, 44, 599-604. [PubMed]

43. Seo, H.-J.; Kim, H.C.; Klein, T.A.; Ramey, A.M.; Lee, J.-H.; Kyung, S.-G.; Park, J.-Y.; Cho, Y.S.; Cho, I.-S.; Yeh, J.-Y. Molecular detection and genotyping of Japanese encephalitis virus in mosquitoes during a 2010 outbreak in the Republic of Korea. PLoS ONE 2013, 8, e55165. [CrossRef] [PubMed]

44. Kim, H.C.; Takhampunya, R.; Tippayachai, B.; Chong, S.-T.; Park, J.-Y.; Kim, M.-S.; Seo, H.-J.; Yeh, J.-Y.; Lee, W.-J.; Lee, D.-K.; et al. Japanese encephalitis virus in culicine mosquitoes (Diptera: Culicidae) of the Republic of Korea, 2008-2010. Mil. Med. 2015, 180, 158-167. [CrossRef] [PubMed]

45. Kim, H.C.; Klein, T.A.; Takhampunya, R.; Evans, B.P.; Mingmongkolchai, S.; Kengluecha, A.; Grieco, J.; Masuoka, P.; Kim, M.-S.; Chong, S.-T.; et al. Japanese encephalitis virus in culicine mosquitoes (Diptera: Culicidae) collected at Daeseongdong, a village in the demilitarized zone of the Republic of Korea. J. Med. Entomol. 2011, 48, 1250-1256. [CrossRef] [PubMed]

46. Gajanana, A.; Rajendran, R.; Samuel, P.P.; Thenmozhi, V.; Tsai, T.F.; Kimura-Kuroda, J.; Reuben, R. Japanese encephalitis in south Arcot District, Tamil Nadu, India: A three-year longitudinal study of vector abundance and infection frequency. J. Med. Entomol. 1997, 34, 651-659. [CrossRef] [PubMed]

47. Olson, J.G.; Ksiazek, T.G.; Tan, R.; Atmosoedjono, S.; Lee, V.H.; Converse, J.D. Correlation of population indices of female Culex tritaeniorhynchus with Japanese encephalitis viral activity in Kapuk, Indonesia. Southeast Asian J. Trop. Med. Public Health 1985, 16, 337-342.

48. Chen, Y.-C.; Wang, C.-Y.; Teng, H.-J.; Chen, C.-F.; Chang, M.-C.; Lu, L.-C.; Lin, C.; Jian, S.-W.; Wu, H.-S. Comparison of the efficacy of CO2-baited and unbaited light traps, gravid traps, backpack aspirators, and sweep net collections for sampling mosquitoes infected with Japanese encephalitis virus. J. Vector Ecol. 2011, 36, 68-74. [CrossRef] [PubMed]

49. Hsu, S.H.; Huang, W.C.; Cross, J.H. The isolation of Japanese encephalitis virus from Taiwan mosquitoes by mosquito cell cultures and mouse inoculation. J. Med. Entomol. 1978, 14, 698-701. [CrossRef] [PubMed] 
50. Gould, D.J.; Edelman, R.; Grossman, R.A.; Nisalak, A.; Sullivan, M.F. Study of Japanese encephalitis virus in Chiangmai Valley, Thailand. IV. Vector studies. Am. J. Epidemiol. 1974, 100, 49-56. [CrossRef]

51. Ritchie, S.A.; Hurk, A.F.V.D.; Zborowski, P.; Kerlin, T.J.; Banks, D.; Walker, J.A.; Lee, J.M.; Montgomery, B.L.; Smith, G.A.; Pyke, A.T.; et al. Operational trials of remote mosquito trap systems for Japanese encephalitis virus surveillance in the Torres Strait, Australia. Vector-Borne Zoonotic Dis. 2007, 7, 497-506. [CrossRef] [PubMed]

52. Tewari, S.C.; Thenmozhi, V.; Rajendran, R.; Appavoo, N.C.; Gajanana, A. Detection of Japanese encephalitis virus antigen in desiccated mosquitoes: An improved surveillance system. Trans. R. Soc. Trop. Med. Hyg. 1999, 93, 525-526. [CrossRef]

53. Tewari, S.C.; Thenmozhi, V.; Arunachalam, N.; Philip Samuel, P.; Tyagi, B.K. Desiccated vector mosquitoes used for the surveillance of Japanese encephalitis virus activity in endemic southern India. Trop. Med. Int. Health 2008, 13, 286-290. [CrossRef]

54. Rajendran, R.; Thenmozhi, V.; Tewari, S.C.; Balasubramanian, A.; Ayanar, K.; Manavalan, R.; Gajanana, A.; Kabilan, L.; Thakare, J.P.; Satyanarayana, K. Longitudinal studies in south Indian villages on Japanese encephalitis virus infection in mosquitoes and seroconversion in goats. Trop. Med. Int. Health 2003, 8, 174-181. [CrossRef] [PubMed]

55. Samuel, P.P.; Ramesh, D.; Muniaraj, M.; Thenmozhi, V.; Venkatesh, A.; Nagaraj, J.; Tyagi, B. Seasonal abundance role of predominant Japanese encephalitis vectors Culex tritaeniorhynchus and Cx. gelidus Theobald in Cuddalore District, Tamil Nadu. Indian J. Med. Res. 2015, 142, 23. [CrossRef] [PubMed]

56. Arunachalam, N.; Samuel, P.P.; Hiriyan, J.; Thenmozhi, V.; Gajanana, A. Japanese encephalitis in Kerala, south India: Can Mansonia (Diptera: Culicidae) play a supplemental role in transmission? J. Med. Entomol. 2004, 41, 456-461. [CrossRef] [PubMed]

57. Van Peenen, P.F.D.; Joseph, P.L.; Atmosoedjono, S.; Irsiana, R.; Saroso, J.S. Japanese encephalitis virus from pigs and mosquitoes in Jakarta, Indonesia. Trans. R. Soc. Trop. Med. Hyg. 1975, 69, 477-479. [CrossRef]

58. Simpson, D.; Bowen, E.; Platt, G.; Way, H.; Smith, C.; Peto, S.; Kamath, S.; Lim, B.L.; Lim, T.W. Japanese encephalitis in Sarawak: Virus isolation and serology in a Land Dyak village. Trans. R. Soc. Trop. Med. Hyg. 1970, 64, 503-510. [CrossRef]

59. Peiris, J.S.M.; Amerasinghe, F.P.; Amerasinghe, P.H.; Ratnayake, C.B.; Karunaratne, S.H.P.P.; Tsai, T.F. Japanese encephalitis in Sri Lanka-The study of an epidemic: Vector incrimination, porcine infection and human disease. Trans. R. Soc. Trop. Med. Hyg. 1992, 86, 307-313. [CrossRef]

60. Simasathien, P.; Rohitayodhin, S.; Nisalak, A.; Singharaj, P.; Halstead, S.B.; Russell, P.K. Recovery of Japanese encephalitis virus from wild caught mosquitoes in Thailand. Southeast Asian J. Trop. Med. Public Health 1972, 3, 52-54.

61. Thi-Kim-Thoa, N.; Ngo-Thi-Vien Tran-Tuyet-Mai Thi-Ngoc-Xuan, N. Japanese encephalitis vectors: Isolation of virus from culicine mosquitoes in the Saigon area. Southeast Asian J. Trop. Med. Public Health 1974, 5, 408-412. [PubMed]

62. Kim, H.; Cha, G.-W.; Jeong, Y.E.; Lee, W.-G.; Chang, K.S.; Roh, J.Y.; Yang, S.C.; Park, M.Y.; Park, C.; Shin, E.-H. Detection of Japanese encephalitis virus genotype V in Culex orientalis and Culex pipiens (Diptera: Culicidae) in Korea. PLoS ONE 2015, 10, e0116547. [CrossRef]

63. Ravanini, P.; Huhtamo, E.; Ilaria, V.; Crobu, M.G.; Nicosia, A.M.; Servino, L.; Rivasi, F.; Allegrini, S.; Miglio, U.; Magri, A.; et al. Japanese encephalitis virus RNA detected in Culex pipiens mosquitoes in Italy. Eurosurveillance 2012, 17, 20221. [CrossRef]

64. Fang, Y.; Zhang, Y.; Zhou, Z.-B.; Xia, S.; Shi, W.-Q.; Xue, J.-B.; Li, Y.-Y.; Wu, J.-T. New strains of Japanese encephalitis virus circulating in Shanghai, China after a ten-year hiatus in local mosquito surveillance. Parasites Vectors 2019, 12, 22. [CrossRef]

65. Dhanda, V.; Mourya, D.T.; Mishra, A.C.; Ilkal, M.A.; Pant, U.; Jacob, P.G.; Bhat, H.R. Japanese encephalitis virus infection in mosquitoes reared from field-collected immatures and in wild-caught males. Am. J. Trop. Med. Hyg. 1989, 41, 732-736. [CrossRef] [PubMed]

66. Borah, J.; Dutta, P.; Khan, S.A.; Mahanta, J. Epidemiological concordance of Japanese encephalitis virus infection among mosquito vectors, amplifying hosts and humans in India. Epidemiol. Infect. 2013, 141, 74-80. [CrossRef] [PubMed]

67. Nyari, N.; Singh, D.; Kakkar, K.; Sharma, S.; Pandey, S.N.; Dhole, T.N. Entomological and serological investigation of Japanese encephalitis in endemic area of eastern Uttar Pradesh, India. J. Vector Borne Dis. 2015, 52, 321-328. [PubMed]

68. Naik, P.S.; Ilkal, M.A.; Pant, U.; Kulkarni, S.M.; Dhanda, V. Isolation of Japanese encephalitis virus from Culex pseudovishnui Colless, 1957 (Diptera: Culicidae) in Goa. Indian J. Med. Res. 1990, 91, 331-333.

69. Nitatpattana, N.; Apiwathnasorn, C.; Barbazan, P.; Leemingsawat, S.; Yoksan, S.; Gonzalez, J.-P. First isolation of Japanese encephalitis from Culex quinquefasciatus in Thailand. Southeast Asian J. Trop. Med. Public Health 2005, 36, 875-878.

70. Lindahl, J.F.; Ståhl, K.; Chirico, J.; Boqvist, S.; Thu, H.T.V.; Magnusson, U. Circulation of Japanese encephalitis virus in pigs and mosquito vectors within Can Tho City. PLoS Negl. Trop. Dis. 2013, 7, e2153. [CrossRef]

71. Hurk, A.F.V.D.; MacKenzie, J.S.; Smith, I.L.; Ritchie, S.A.; Smith, G.A.; Northill, J.A.; Montgomery, B.L.; Zborowski, P. Short report: The first isolation of Japanese encephalitis virus from mosquitoes collected from mainland Australia. Am. J. Trop. Med. Hyg. 2006, 75, 21-25. [CrossRef]

72. Nisbet, D.J.; Foley, P.N.; Van Den Hurk, A.F.; Mackenzie, J.S. Flavivirus isolations from mosquitoes collected from Saibai Island in the Torres Strait, Australia, during an incursion of Japanese encephalitis virus. Med. Veter. Entomol. 2004, 18, $281-287$.

73. Johansen, C.A.; van den Hurk, A.F.; Ritchie, S.A.; Zborowski, P.; Nisbet, D.J.; Paru, R.; Bockarie, M.J.; MacDonald, J.; Drew, A.C.; Khromykh, T.I.; et al. Isolation of Japanese encephalitis virus from mosquitoes (Diptera: Culicidae) collected in the western province of Papua New Guinea, 1997-1998. Am. J. Trop. Med. Hyg. 2000, 62, 631-638. [CrossRef]

74. Duong, V.; Choeung, R.; Gorman, C.; Laurent, D.; Crabol, Y.; Mey, C.; Peng, B.; Di Francesco, J.; Hul, V.; Sothy, H.; et al. Isolation and full-genome sequences of Japanese encephalitis virus genotype I strains from Cambodian human patients, mosquitoes and pigs. J. Gen. Virol. 2017, 98, 2287-2296. [CrossRef] 
75. Fang, Y.; Li, X.-S.; Zhang, W.; Xue, J.-B.; Wang, J.-Z.; Yin, S.-Q.; Li, S.-G.; Li, X.-H.; Zhang, Y. Molecular epidemiology of mosquito-borne viruses at the China-Myanmar border: Discovery of a potential epidemic focus of Japanese encephalitis. Infect. Dis. Poverty 2021, 10, 57. [CrossRef] [PubMed]

76. Fang, Y.; Zhang, W.; Xue, J.-B.; Zhang, Y. Monitoring mosquito-borne arbovirus in various insect regions in China in 2018. Front. Cell Infect. Microbiol. 2021, 11, 640993. [CrossRef] [PubMed]

77. Kuwata, R.; Sugiyama, H.; Yonemitsu, K.; Van Dung, N.; Terada, Y.; Taniguchi, M.; Shimoda, H.; Takano, A.; Maeda, K. Isolation of Japanese encephalitis virus and a novel insect-specific flavivirus from mosquitoes collected in a cowshed in Japan. Arch. Virol. 2015, 160, 2151-2159. [CrossRef]

78. Yap, G.; Mailepessov, D.; Lim, X.F.; Chan, S.; How, C.B.; Humaidi, M.; Yeo, G.; Chong, C.S.; Lam-Phua, S.G.; Lee, R.; et al. Detection of Japanese encephalitis virus in Culex mosquitoes in Singapore. Am. J. Trop. Med. Hyg. 2020, 103, 1234-1240. [CrossRef]

79. Leake, C.; Ussery, M.; Nisalak, A.; Hoke, C.H.; Andre, R.G.; Burke, D.S. Virus isolations from mosquitoes collected during the 1982 Japanese encephalitis epidemic in northern Thailand. Trans. R. Soc. Trop. Med. Hyg. 1986, 80, 831-837. [CrossRef]

80. Kuwata, R.; Trang, B.M.; Tsuda, Y.; Sawabe, K.; Nga, P.T.; Sasaki, T.; Yen, N.T.; Kobayashi, M.; Takagi, M.; Loan, D.P.; et al. Surveillance of Japanese encephalitis virus infection in mosquitoes in Vietnam from 2006 to 2008. Am. J. Trop. Med. Hyg. 2013, 88, 681-688. [CrossRef] [PubMed]

81. Pearce, J.C.; Learoyd, T.P.; Langendorf, B.J.; Logan, J.G. Japanese encephalitis: The vectors, ecology and potential for expansion. J. Travel Med. 2018, 25, S16-S26. [CrossRef]

82. Souza-Neto, J.A.; Powell, J.R.; Bonizzoni, M. Aedes aegypti vector competence studies: A review. Infect. Genet. Evol. 2019, 67, 191-209. [CrossRef]

83. Schulz, C.; Becker, S.C. Mosquitoes as arbovirus vectors: From species identification to vector competence. Mosquito-Borne Dis. 2018, 10, 163-212. [CrossRef]

84. Kramer, L.D.; Chin, P.; Cane, R.P.; Kauffman, E.B.; Mackereth, G. Vector competence of New Zealand mosquitoes for selected arboviruses. Am. J. Trop. Med. Hyg. 2011, 85, 182-189. [CrossRef]

85. Mackenzie-Impoinvil, L.; Impoinvil, D.E.; Galbraith, S.E.; Dillon, R.J.; Ranson, H.; Johnson, N.; Fooks, A.R.; Solomon, T.; Baylis, M. Evaluation of a temperate climate mosquito, Ochlerotatus detritus (=Aedes detritus), as a potential vector of Japanese encephalitis virus. Med. Vet. Entomol. 2015, 29, 1-9. [CrossRef]

86. Conn, J.E.; Lainhart, W.; Rios, C.T.; Vinetz, J.M.; Bickersmith, S.A.; Moreno, M. Changes in genetic diversity from field to laboratory during colonization of Anopheles darlingi Root (Diptera: Culicidae). Am. J. Trop. Med. Hyg. 2015, 93, 998-1001. [CrossRef]

87. De Wispelaere, M.; Desprès, P.; Choumet, V. European Aedes albopictus and Culex pipiens are competent vectors for Japanese encephalitis virus. PLoS Negl. Trop. Dis. 2017, 11, e0005294. [CrossRef]

88. Huang, Y.-J.S.; Hettenbach, S.M.; Park, S.L.; Higgs, S.; Barrett, A.D.T.; Hsu, W.-W.; Harbin, J.N.; Cohnstaedt, L.W.; VanLandingham, D.L. Differential infectivities among different Japanese encephalitis virus genotypes in Culex quinquefasciatus mosquitoes. PLoS Negl. Trop. Dis. 2016, 10, e0005038. [CrossRef] [PubMed]

89. Chapman, G.E.; Sherlock, K.; Hesson, J.C.; Blagrove, M.S.C.; Lycett, G.J.; Archer, D.; Solomon, T.; Baylis, M. Laboratory transmission potential of British mosquitoes for equine arboviruses. Parasites Vectors 2020, 13, 413. [CrossRef] [PubMed]

90. Cleton, N.B.; Bosco-Lauth, A.; Page, M.J.; Bowen, R.A. Age-related susceptibility to Japanese encephalitis virus in domestic ducklings and chicks. Am. J. Trop. Med. Hyg. 2014, 90, 242-246. [CrossRef] [PubMed]

91. Vogels, C.B.; Göertz, G.P.; Pijlman, G.P.; Koenraadt, C.J. Vector competence of European mosquitoes for West Nile virus. Emerg. Microbes Infect. 2017, 6, e96. [CrossRef] [PubMed]

92. Azar, S.R.; Weaver, S.C. Vector competence: What has Zika virus taught us? Viruses 2019, 11, 867. [CrossRef] [PubMed]

93. Van Den Hurk, A.F.; Nisbet, D.J.; Hall, R.A.; Kay, B.H.; Mackenzie, J.S.; Ritchie, S.A. Vector competence of Australian mosquitoes (Diptera: Culicidae) for Japanese encephalitis virus. J. Med. Entomol. 2003, 40, 82-90. [CrossRef] [PubMed]

94. Nicholson, J.; Ritchie, S.A.; Van Den Hurk, A.F. Aedes albopictus (Diptera: Culicidae) as a potential vector of endemic and exotic arboviruses in Australia. J. Med. Entomol. 2014, 51, 661-669. [CrossRef] [PubMed]

95. Weng, M.H.; Lien, J.C.; Wang, Y.U.M.; Wu, H.L.; Chin, C. Susceptibility of three laboratory strains of Aedes albopictus (Diptera: Culicidae) to Japanese encephalitis virus from Taiwan. J. Med. Entomol. 1997, 34, 745-747. [CrossRef] [PubMed]

96. Reeves, W.C.; Hammon, W.M. Laboratory transmission of Japanese B encephalitis virus by seven species (three genera) of North American mosquitoes. J. Exp. Med. 1946, 83, 185-194. [CrossRef] [PubMed]

97. Huber, K.; Jansen, S.; Leggewie, M.; Badusche, M.; Schmidt-Chanasit, J.; Becker, N.; Tannich, E.; Becker, S.C. Aedes japonicus japonicus (Diptera: Culicidae) from Germany have vector competence for Japanese encephalitis virus but are refractory to infection with West Nile virus. Parasitol. Res. 2014, 113, 3195-3199. [CrossRef] [PubMed]

98. Takashima, I.; Rosen, L. Horizontal and vertical transmission of Japanese encephalitis virus by Aedes japonicus (Diptera: Culicidae). J. Med. Entomol. 1989, 26, 454-458. [CrossRef] [PubMed]

99. Hodes, H.L. Experimental transmission of Japanese B. encephalitis by mosquitoes and mosquito larvae. Bull. Johns Hopkins Hosp. 1946, 79, 358. [PubMed]

100. Banerjee, K.; Deshmukh, P.K.; Ilkal, M.A.; Dhanda, V. Experimental transmission of Japanese encephalitis virus through Anopheles tessellatus and Culex fatigans mosquitoes. Indian J. Med. Res. 1977, 65, 746-752. [PubMed] 
101. Chen, W.-J.; Dong, C.-F.; Chiou, L.-Y.; Chuang, W.-L. Potential role of Armigeres subalbatus (Diptera: Culicidae) in the transmission of Japanese encephalitis virus in the absence of rice culture on Liu-Chiu islet, Taiwan. J. Med. Entomol. 2000, 37, 108-113. [CrossRef]

102. Dhanda, V.; Banerjee, K.; Deshmukh, P.K.; Ilkal, M.A. Experimental viraemia and transmission of Japanese encephalitis virus by mosquitoes in domestic ducks. Indian J. Med. Res. 1977, 66, 881-888. [PubMed]

103. Banerjee, K.; Deshmukh, P.K.; Ilkal, M.A.; Dhanda, V. Transmission of Japanese encephalitis virus by Culex bitaeniorhynchus Giles. Indian J. Med. Res. 1978, 67, 889-893. [PubMed]

104. Banerjee, K.; Deshmukh, P.K.; Ilkal, M.A.; Dhanda, V. Comparative susceptibility of three species of mosquitoes to infection with Japanese encephalitis virus. Indian J. Med. Res. 1983, 78, 603-606. [PubMed]

105. Okuno, T.; Mitchell, C.J.; Chen, P.S.; Hsu, S.; Ryu, E. Experimental transmission of Japanese encephalitis virus by Culex tritaeniorhynchus and C. fuscocephalus. Ann. Trop. Med. Parasitol. 1975, 69, 203-206. [CrossRef]

106. Sullivan, M.J.; Edelman, R.; Muangman, D.; Gould, D.J. Experimental transmission of Japanese encephalitis virus by Culex fuscocephala. Am. J. Trop. Med. Hyg. 1972, 21, 482-486. [CrossRef]

107. Gould, D.J.; Barnett, H.C.; Suyemoto, W. Transmission of Japanese encephalitis virus by Culex gelidus Theobald. Trans. R. Soc. Trop. Med. Hyg. 1962, 56, 429-435. [CrossRef]

108. Hameed, M.; Liu, K.; Anwar, N.; Wahaab, A.; Safdar, A.; Di, D.; Boruah, P.; Xu, J.; Wang, X.; Li, B.; et al. The emerged genotype I of Japanese encephalitis virus shows an infectivity similar to genotype III in Culex pipiens mosquitoes from China. PLoS Negl. Trop. Dis. 2019, 13, e0007716. [CrossRef]

109. Weng, M.-H.H.; Lien, J.-C.C.; Lin, C.-C.C.; Yao, C.-W.W. Vector competence of Culex pipiens molestus (Diptera: Culicidae) from Taiwan for a sympatric strain of Japanese encephalitis virus. J. Med. Entomol. 2000, 37, 780-783. [CrossRef] [PubMed]

110. Turell, M.J.; Mores, C.N.; Dohm, D.J.; Komilov, N.; Paragas, J.; Lee, J.S.; Shermuhemedova, D.; Endy, T.P.; Kodirov, A.; Khodjaev, S. Laboratory transmission of Japanese encephalitis and West Nile viruses by molestus form of Culex pipiens (Diptera: Culicidae) collected in Uzbekistan in 2004. J. Med. Entomol. 2006, 43, 296-300. [CrossRef]

111. Doi, R.; Oya, A.; Shirasaka, A.; Yabe, S.; Sasa, M. Studies on Japanese encephalitis virus infection of reptiles. II. Role of lizards on hibernation of Japanese encephalitis virus. Jpn. J. Exp. Med. 1983, 53, 125-134. [PubMed]

112. Turell, M.J.; Mores, C.N.; Dohm, D.J.; Lee, W.-J.; Kim, H.-C.; Klein, T.A. Laboratory transmission of Japanese encephalitis, West Nile, and Getah viruses by mosquitoes (Diptera: Culicidae) collected near Camp Greaves, Gyeonggi province, Republic of Korea 2003. J. Med. Entomol. 2006, 43, 1076-1081. [CrossRef] [PubMed]

113. Mourya, D.T.; Mishra, A.C.; Soman, R.S. Transmission of Japanese encephalitis virus in Culex pseudovishnui \& C. tritaeniorhynchus mosquitoes. Indian J. Med. Res. 1991, 93, 250-252. [PubMed]

114. Mourya, D.T.; Mishra, A.C. Antigen distribution pattern of Japanese encephalitis virus in Culex tritaeniorhynchus, C. vishnui \& C. pseudovishnui. Indian J. Med. Res. 2000, 111, 157-161. [PubMed]

115. Heathcote, O.H.U. Japanese encephalitis in Sarawak: Studies on juvenile mosquito populations. Trans. R. Soc. Trop. Med. Hyg. 1970, 64, 483-488. [CrossRef]

116. Beerntsen, B.T.; James, A.A.; Christensen, B.M. Genetics of mosquito vector competence. Microbiol. Mol. Biol. Rev. 2000, 64, 115-137. [CrossRef]

117. Kauffman, E.B.; Kramer, L.D. Zika virus mosquito vectors: Competence, biology, and vector control. J. Infect. Dis. 2017, 216, S976-S990. [CrossRef]

118. Rocklöv, J.; Dubrow, R. Author Correction: Climate change: An enduring challenge for vector-borne disease prevention and control. Nat. Immunol. 2020, 21, 695. [CrossRef]

119. Githeko, A.K.; Lindsay, S.W.; Confalonieri, U.E.; Patz, J.A. Climate change and vector-borne diseases: A regional analysis. Bull. World Health Organ. 2000, 78, 1136-1147.

120. Rosen, L.; Tesh, R.B.; Lien, J.C.; Cross, J.H. Transovarial transmission of Japanese encephalitis virus by mosquitoes. Science 1978, 199, 909-911. [CrossRef] [PubMed]

121. Xia, H.; Wang, Y.; Atoni, E.; Zhang, B.; Yuan, Z. Mosquito-associated viruses in China. Virol. Sin. 2018, 33, 5-20. [CrossRef] [PubMed]

122. Yun, S.-I.; Lee, Y.-M. Early events in Japanese encephalitis virus infection: Viral entry. Pathogens 2018, 7, 68. [CrossRef]

123. Larish, L.B.; Savage, H.M. Introduction and establishment of Aedes (Finlaya) Japonicus japonicus (Theobald) on the island of Hawaii: Implications for arbovirus transmission. J. Am. Mosq. Control Assoc. 2005, 21, 318-321. [CrossRef]

124. Smitz, N.; De Wolf, K.; Deblauwe, I.; Kampen, H.; Schaffner, F.; De Witte, J.; Schneider, A.; Verlé, I.; Vanslembrouck, A.; Dekoninck, W.; et al. Population genetic structure of the Asian bush mosquito, Aedes japonicus (Diptera, Culicidae), in Belgium suggests multiple introductions. Parasites Vectors 2021, 14, 179. [CrossRef] [PubMed]

125. Versteirt, V.; Schaffner, F.; Garros, C.; Dekoninck, W.; Coosemans, M.; Van Bortel, W. Introduction and establishment of the exotic mosquito species Aedes japonicus japonicus (Diptera: Culicidae) in Belgium. J. Med. Entomol. 2009, 46, 1464-1467. [CrossRef]

126. Kaufman, M.G.; Fonseca, D.M. Invasion biology of Aedes japonicus japonicus (Diptera: Culicidae). Annu. Rev. Entomol. 2014, 59, 31. [CrossRef]

127. Dussault, C.; Nelder, M.P.; Russell, C.; Johnson, S.; Vrbova, L. Evaluating the impact of Aedes japonicus invasion on the mosquito community in the Greater Golden Horseshoe region (Ontario, Canada). PLoS ONE 2018, 13, e0208911. [CrossRef] 
128. Oliveira, A.R.; Strathe, E.; Etcheverry, L.; Cohnstaedt, L.W.; McVey, D.S.; Piaggio, J.; Cernicchiaro, N. Assessment of data on vector and host competence for Japanese encephalitis virus: A systematic review of the literature. Prev. Vet. Med. 2018, 154, 71-89. [CrossRef] [PubMed]

129. Peach, D.A.H.; Almond, M.; Pol, J.C. Modeled distributions of Aedes japonicus japonicus and Aedes togoi (Diptera: Culicidae) in the United States, Canada, and northern Latin America. J. Vector Ecol. 2019, 44, 119-129. [CrossRef]

130. Invasive Species Compendium. Available online: https://www.cabi.org/isc/ (accessed on 21 December 2021).

131. European Centre for Disease Prevention and Control and European Food Safety Authority. Aedes japonicus-Current Known Distribution: March 2021. 2021. Available online: https:/ / www.ecdc.europa.eu/en/publications-data/aedes-japonicus-currentknown-distribution-march-2021 (accessed on 4 June 2021).

132. Hoffmann, J.A. Immune responsiveness in vector insects. Proc. Natl. Acad. Sci. USA 1997, 94, 11152-11153. [CrossRef] [PubMed]

133. Baxter, R.H.G.; Contet, A.; Krueger, K. Arthropod innate immune systems and vector-borne diseases. Biochemistry 2017, 56, 907-918. [CrossRef] [PubMed]

134. Kumar, A.; Srivastava, P.; Sirisena, P.; Dubey, S.K.; Kumar, R.; Shrinet, J.; Sunil, S. Mosquito innate immunity. Insects 2018, 9 , 95. [CrossRef] [PubMed]

135. Gabrieli, P.; Caccia, S.; Varotto-Boccazzi, I.; Arnoldi, I.; Barbieri, G.; Comandatore, F.; Epis, S. Mosquito trilogy: Microbiota, immunity and pathogens, and their implications for the control of disease transmission. Front. Microbiol. 2021, $12,630438$. [CrossRef]

136. Cheng, G.; Liu, Y.; Wang, P.; Xiao, X. Mosquito defense strategies against viral infection. Trends Parasitol. 2016, 32, 177-186. [CrossRef]

137. Lee, W.S.; Webster, J.A.; Madzokere, E.T.; Stephenson, E.B.; Herrero, L.J. Mosquito antiviral defense mechanisms: A delicate balance between innate immunity and persistent viral infection. Parasites Vectors 2019, 12, 165. [CrossRef]

138. Ali, M.K.M.; Han, Y.S.; Jo, Y.H. An overview of insect innate immunity. Entomol. Res. 2020, 50, 282-291. [CrossRef]

139. Flemming, A. Mechanism of adaptive immunity found in the fruitfly. Nat. Rev. Immunol. 2017, 17, 279. [CrossRef] [PubMed]

140. Mongelli, V.; Saleh, M.C. Bugs are not to be silenced: Small RNA pathways and antiviral responses in insects. Annu. Rev. Virol. 2016, 3, 573-589. [CrossRef]

141. Hardy, J.L.; Houk, E.J.; Kramer, L.D.; Reeves, W.C. Intrinsic factors affecting vector competence of mosquitoes for arboviruses. Annu. Rev. Entomol. 1983, 28, 229-262. [CrossRef]

142. Franz, A.W.E.; Kantor, A.M.; Passarelli, A.L.; Clem, R.J. Tissue barriers to arbovirus infection in mosquitoes. Viruses 2015, 7, 3741-3767. [CrossRef]

143. Romoser, W.S.; Turell, M.J.; Lerdthusnee, K.; Neira, M.; Dohm, D.; Ludwig, G.; Wasieloski, L. Pathogenesis of Rift Valley fever virus in mosquitoes: Tracheal conduits \& the basal lamina as an extra-cellular barrier. Infect. Dis. Nat. Mech. Viral Emerg. Persistence 2005, 19, 89-100. [CrossRef]

144. Takahashi, M. Differential transmission efficiency for Japanese encephalitis virus among colonized strains of Culex tritaeniorhynchus. Jpn. J. Sanit. Zool. 1982, 33, 325-333. [CrossRef]

145. Sanchez-Vargas, I.; Olson, K.; Black, W. The genetic basis for salivary gland barriers to arboviral transmission. Insects 2021, 12, 73. [CrossRef] [PubMed]

146. Sasaki, T.; Kuwata, R.; Hoshino, K.; Isawa, H.; Sawabe, K.; Kobayashi, M. Argonaute 2 suppresses Japanese encephalitis virus infection in Aedes aegypti. Jpn. J. Infect. Dis. 2017, 70, 38-44. [CrossRef]

147. Terradas, G.; Joubert, D.A.; McGraw, E.A. The RNAi pathway plays a small part in Wolbachia-mediated blocking of dengue virus in mosquito cells. Sci. Rep. 2017, 7, 43847. [CrossRef]

148. Carthew, R.W.; Sontheimer, E.J. Origins and mechanisms of miRNAs and siRNAs. Cell 2009, 136, 642-655. [CrossRef]

149. Ha, M.; Kim, V.N. Regulation of microRNA biogenesis. Nat. Rev. Mol. Cell Biol. 2014, 15, 509-524. [CrossRef]

150. Théron, E.; Dennis, C.; Brasset, E.; Vaury, C. Distinct features of the piRNA pathway in somatic and germ cells: From piRNA cluster transcription to piRNA processing and amplification. Mob. DNA 2014, 5, 28. [CrossRef]

151. Lin, C.-C.; Chou, C.-M.; Hsu, Y.-L.; Lien, J.-C.; Wang, Y.-M.; Chen, S.-T.; Tsai, S.-C.; Hsiao, P.-W.; Huang, C.-J. Characterization of two mosquito STATs, AaSTAT and CtSTAT. J. Biol. Chem. 2004, 279, 3308-3317. [CrossRef] [PubMed]

152. Yin, C.; Sun, P.; Yu, X.; Wang, P.; Cheng, G. Roles of Symbiotic Microorganisms in Arboviral Infection of Arthropod Vectors; Elsevier: Amsterdam, The Netherlands, 2020; Volume 36. [CrossRef]

153. Zhag, R.; Zhu, Y.; Pang, X.; Xiao, X.; Zhang, R.; Cheng, G. Regulation of antimicrobial peptides in Aedes aegypti Aag2 cells. Front. Cell. Infect. Microbiol. 2017, 7, 22. [CrossRef]

154. Schmid-Hempel, P. Evolutionary ecology of insect immune defenses. Annu. Rev. Entomol. 2005, 50, 529-551. [CrossRef]

155. Liu, K.; Xiao, C.; Xi, S.; Hameed, M.; Wahaaab, A.; Shao, D.; Li, Z.; Li, B.; Wei, J.; Qiu, Y.; et al. Mosquito defensins enhance Japanese encephalitis virus infection by facilitating virus adsorption and entry within the mosquito. J. Virol. 2020, 94, e01164-20. [CrossRef] [PubMed]

156. Magalhaes, T.; Oliveira, I.F.; Melo-Santos, M.A.V.; Oliveira, C.M.F.; Lima, C.A.; Ayres, C.F.J. Expression of defensin, cecropin, and transferrin in Aedes aegypti (Diptera: Culicidae) infected with Wuchereria bancrofti (Spirurida: Onchocercidae), and the abnormal development of nematodes in the mosquito. Exp. Parasitol. 2008, 120, 364-371. [CrossRef] 
157. Liu, K.; Hou, F.; Wahaab, A.; Kang, L.; Xie, F.; Ma, X.; Xia, Q.; Xiao, C.; Shao, D.; Li, B.; et al. Mosquito defensin facilitates Japanese encephalitis virus infection by downregulating the C6/36 cell-surface antiviral protein HSC70B. Vet. Microbiol. $2021,253,108971$. [CrossRef] [PubMed]

158. Jupatanakul, N.; Sim, S.; Dimopoulos, G. The insect microbiome modulates vector competence for arboviruses. Viruses 2014, 6, 4294-4313. [CrossRef]

159. Dennison, N.J.; Jupatanakul, N.; Dimopoulos, G. The mosquito microbiota influences vector competence for human pathogens. Curr. Opin. Insect. Sci. 2014, 3, 6-13. [CrossRef] [PubMed]

160. Rodgers, F.H.; Gendrin, M.; Wyer, C.A.S.; Christophides, G.K. Microbiota-induced peritrophic matrix regulates midgut homeostasis and prevents systemic infection of malaria vector mosquitoes. PLoS Pathog. 2017, 13, e1006391. [CrossRef]

161. Rancès, E.; Ye, Y.H.; Woolfit, M.; McGraw, E.A.; O'Neill, S.L. The relative importance of innate immune priming in Wolbachiamediated dengue interference. PLoS Pathog. 2012, 8, e1002548. [CrossRef] [PubMed]

162. Tsai, K.-H.; Huang, C.-G.; Wu, W.-J.; Chuang, C.-K.; Lin, C.-C.; Chen, W.-J. Parallel infection of Japanese encephalitis virus and Wolbachia within cells of mosquito salivary glands. J. Med. Entomol. 2006, 43, 752-756. [CrossRef]

163. Mourya, D.T.; Soman, R.S. Effect of gregarine parasite, Ascogregarina culicis \& tetracycline on the susceptibility of Culex bitaeniorhynchus to JE virus. Indian J. Med. Res. 1985, 81, 247-250. [PubMed]

164. Walker, T.; Johnson, P.H.; Moreira, L.A.; Iturbe-Ormaetxe, I.; Frentiu, F.; McMeniman, C.; Leong, Y.S.; Dong, Y.; Axford, J.; Kriesner, P.; et al . The wMel Wolbachia strain blocks dengue and invades caged Aedes aegypti populations. Nature 2011, 476, 450-455. [CrossRef] [PubMed]

165. Johnson, K.N. The impact of Wolbachia on virus infection in mosquitoes. Viruses 2015, 7, 5705-5717. [CrossRef]

166. Van den Hurk, A.F.; Hall-Mendelin, S.; Pyke, A.T.; Frentiu, F.D.; McElroy, K.; Day, A.; Higgs, S.; O'Neill, S.L. Impact of Wolbachia on infection with Chikungunya and Yellow Fever viruses in the mosquito vector Aedes aegypti. PLoS Negl. Trop. Dis. 2012, 6, e1892. [CrossRef]

167. Pan, X.; Zhou, G.; Wu, J.; Bian, G.; Lu, P.; Raikhel, A.S.; Xi, Z. Wolbachia induces reactive oxygen species (ROS)-dependent activation of the Toll pathway to control dengue virus in the mosquito Aedes aegypti. Proc. Natl. Acad. Sci. USA 2012, 109, E23. [CrossRef]

168. Moreira, L.A.; Iturbe-Ormaetxe, I.; Jeffery, J.A.; Lu, G.; Pyke, A.T.; Hedges, L.M.; Rocha, B.C.; Hall-Mendelin, S.; Day, A.; Riegler, M.; et al. A Wolbachia symbiont in Aedes aegypti limits infection with Dengue, Chikungunya, and Plasmodium. Cell 2009, 139, 1268-1278. [CrossRef] [PubMed] 